Portland State University

PDXScholar

Fall 10-31-2019

\title{
Noncompliance with Land Acquisition in Vietnam: a Policy Tools Approach
}

Dang Van Nguyen

Portland State University

Follow this and additional works at: https://pdxscholar.library.pdx.edu/open_access_etds

Part of the Asian Studies Commons, and the Public Policy Commons Let us know how access to this document benefits you.

\section{Recommended Citation}

Nguyen, Dang Van, "Noncompliance with Land Acquisition in Vietnam: a Policy Tools Approach" (2019). Dissertations and Theses. Paper 5330.

https://doi.org/10.15760/etd.7203

This Dissertation is brought to you for free and open access. It has been accepted for inclusion in Dissertations and Theses by an authorized administrator of PDXScholar. Please contact us if we can make this document more accessible: pdxscholar@pdx.edu. 
Noncompliance with Land Acquisition in Vietnam:

A Policy Tools Approach

by

Dang Van Nguyen

A dissertation submitted in partial fulfillment of the requirements for the degree of

\author{
Doctor of Philosophy \\ in \\ Public Affairs and Policy
}

\author{
Dissertation Committee: \\ Bruce Gilley, Chair \\ Marcus Ingle \\ Joshua Eastin \\ John Gallup
}

Portland State University

2019 
(C) 2019 Dang Van Nguyen 


\section{Abstract}

The Doi Moi policy (economic reform) launched in 1986 has resulted in economic boom for Vietnam. The nation with a population of around 95 million people recently joined the middle-income nation group and became a "major development success story”. In the land sector, while the land ownership is controlled by the State, the privatization process of land rights has brought Vietnamese people five fundamental rights over land. To meet increasing demands of economic development and urban expansion, the central government of Vietnam (CGV) has implemented land-taking policy from early 1990s. The land acquisition policy, on the one hand, has attracted numerous investors with cheap land access that fueled Vietnam's rapid economic development. On the other hand, the policy has also unleashed resistance among affected landholders. As manifestations of policy noncompliance, disputes and conflicts over land acquisition across country have become a highly complex and dynamic challenge for CPV - the only ruling political party in Vietnam. Over the last three decades, land acquisition policy literature in Vietnam has been dominated by economic, institutional, and good governance approaches. These theories offer alternative explanations and a range of policy recommendations for noncompliance with land acquisition. However, these approaches tend to largely ignore process/action aspects of policy implementation that importantly contribute to policy success or failure. Many recommendations for policy reform are not realistic in Vietnam's current context. This research, thus, contributes to land-taking policy literature by focusing on policy tools used by local implementers to change target groups’ behaviors. 
This dissertation study applied a multiple case study design to explore linkages between policy tools and noncompliance with land acquisition. The researcher selected three land-taking incidents in Bac Ninh province and Hanoi capital city in the North, and Ho Chi Minh City in the South for a cross-case analysis. To get real experiences with land-taking policy implementation, the researcher conducted fieldwork in Bac Ninh and Vinh Phuc provinces. Research participants included land officials and managers, government leaders, and affected landholders. Qualitative interviews, focus groups, and web-search were three major methods used for collecting data. To analyze qualitative data, the researcher adopted techniques of coding, thematic analysis, and document analysis. Common themes emerged across three cases were used to construct a cross-case analysis of three land-taking incidents.

Research results suggested a linkage between implementation tools and landholders' noncompliance with land acquisition. Vietnamese implementers were required to employ direct government organizations, authoritative tools, and informationbased tools while giving less importance to the role of financial tools in executing landtaking projects. The researcher also found inappropriate tool choice and combinations that encouraged implementers' abuse of public authority. Types of preferred tools and patterns of tool choice and use defined coercive interactions and relationship between implementers and affected landholders who had no choice but giving up their land. This qualitative study revealed that tool mixes preferred by implementers might ensure policy effectiveness and efficiency but reduce policy responsiveness and legitimacy. Study results supported research prepositions that economic, institutional, and good governance factors are insufficient to explain noncompliance with land acquisition in Vietnam. This 
tool focused study showed that landholders' resistance was related to characteristics, strengths and weaknesses of each tool and how tools were combined in tools mixes used in policy implementation.

This case study offers tool-based policy implications for reducing noncompliance with land acquisition. First, at the central level of government, Vietnamese policy makers should consider indirect government mechanism of policy implementation. Non-State actors should be allowed to take part in land acquisition serving economic development purposes. Market institutions need to be recognized in order to balance land related interests among three key actors, including: the government, landholders, and land developers (investors). Second, for land-takings serving public purposes at local level, the use of direct government organizations should be limited; BCGCs need to include more non-state actors in order to operate as an advisory unit. The government should replace land price regulations by a land valuation formula that implementers can flexibly use in land-taking projects. Authority of district governments in issuing executive orders for executing land acquisition needs to be controlled. To minimize disputes over landtakings, instead of relying on propaganda and moral suasion, the government should provide landholders with clear information through group meetings that consist of affected landholders who share the same land claims. 


\section{Acknowledgements}

Many people have helped me with the PAP program. In the first place, I wish to thank members of the project management board at Ho Chi Minh National Academy of Politics and Mark O. Hatfield School of Government for offering me an opportunity to undertake the PhD program at Portland State University. Among those, Dr. Marcus Ingle played a special role to me. I would like to say a big thank you to Dr. Ingle who, in 2009, welcomed me to the project of public leadership for sustainable development. Without Dr. Ingle's consistent support, I was not able to access the invaluable opportunity to pursue a PhD program in the US.

This dissertation was not completed without great support and assistance of the advisory committee members. I wish to thank Dr. Gilley for his key role in coordinating advices and guidelines of all committee members. To me, Dr. Bruce Gilley was a perfect advisor and committee chair. I was very lucky to have chance working with him who was first impressed me by academic publications. I owed his constructive instructions and comments on my drafts. In the last two years of the PAP program, I faced with lots of difficulties that slowed down my dissertation progress. Dr. Gilley’s firm attitude and supportive advices inspired me to overcome challenges and complete the dissertation. I am also thankful to Dr. Marcus Ingle and Dr. Joshua Eastin for helpful comments, suggestions, and encouragement during the final stage of the PAP program. Both professors provided me with insightful ideas for revising dissertation drafts. Thanks to Dr. Ingle, the quality of my academic writings was improved significantly. I also wish to thank Dr. John Gallup for realistic comments and questions that suggested further study 
on the dissertation topic. Last but not least, I want to send thankfulness to local leaders and policy implementers in Bac Ninh and Vinh Phuc provinces. Their assistance with data collection played a critical role for completing my dissertation.

Finally, I appreciate the help of Ms. Sarah Orizaga at the Mark O. Hatfield School of Government and Mr. Joshua Davis at the Office of International Students and Scholars. Both Mr. Davis and Ms. Orizaga have supported me in many ways: while Ms. Orizaga helped me with administrative procedures at the Hatfield School, Mr Joshua Davis was a wonderful adviser for international students. I owed Mr. Davis’s perfect support for program extensions and immigration requirements. 
Acknowledgements.......................................................................................................iv

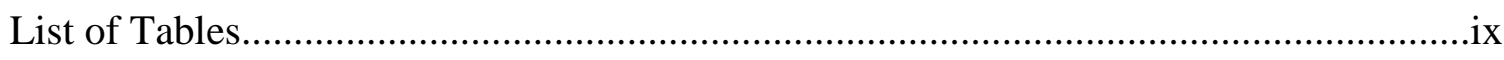

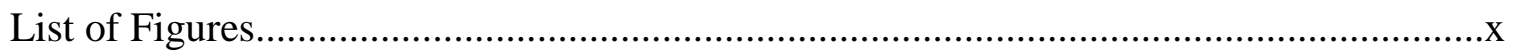

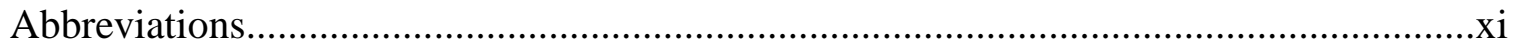

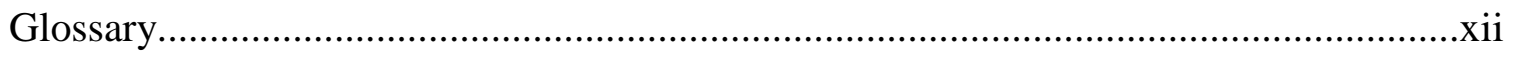

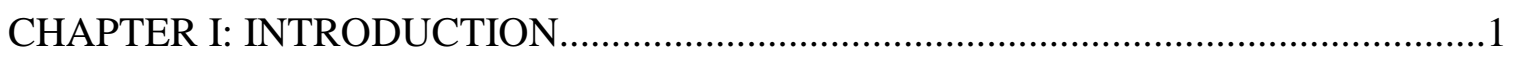

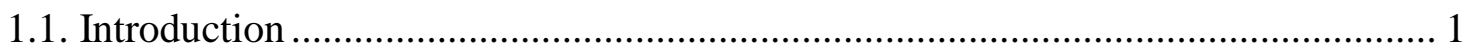

1.2. Research Background................................................................................... 2

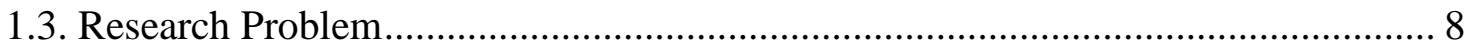

1.4. Research Purposes ............................................................................................... 13

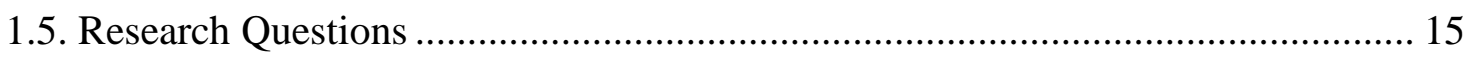

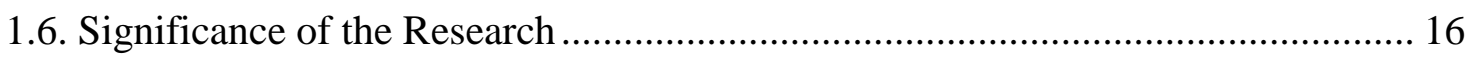

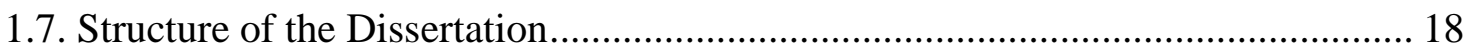

1.8. Summary of the Chapter ........................................................................................ 23

CHAPTER II: LITERATURE REVIEW AND THEORETICAL FRAMEWORK..........25

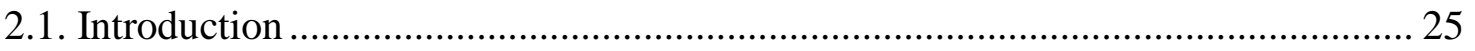

2.2. Noncompliance with Land Acquisition in Vietnam.............................................. 26

2.2.1. Policy noncompliance............................................................................. 26

2.2.2. Noncompliant manifestations with land acquisition ......................................... 28

2.3. Theoretical Explanations of Noncompliance with Land Acquisition .................... 30

2.3.1. Institutional approach ................................................................................... 30

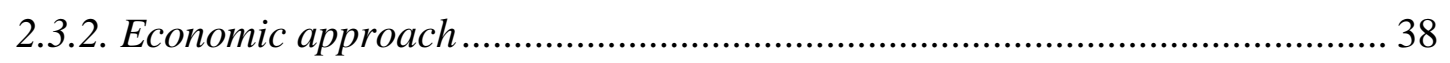

2.3.3. Good governance approach ........................................................................ 45

2.4. Research Gap Analysis .............................................................................. 51

2.4.1. Critiques of existing theoretical explanations ................................................... 51

2.4.2. Research opportunity ................................................................................ 54

2.5. Tool Approach to Policy Noncompliance: A Theoretical Framework ................... 56

2.5.1. Three regimes of public policy implementation ............................................... 57

2.5.2. The evolution of tool approach in policy implementation .................................. 62 


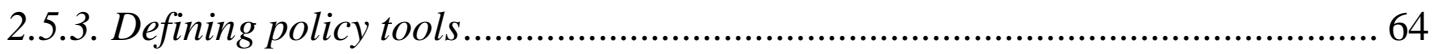

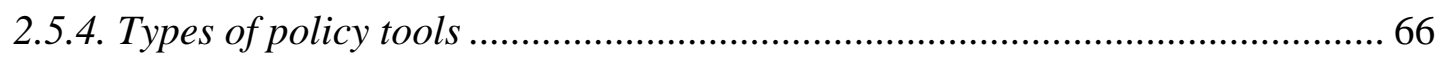

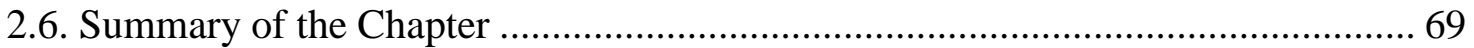

CHAPTER III: RESEARCH DESIGN AND METHODS..............................................74

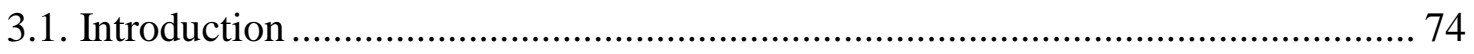

3.2. Justifications for the Selected Research Design............................................... 75

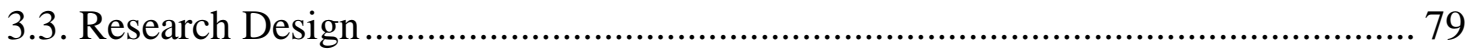

3.3.1. The unit of analysis and case selection .......................................................... 79

3.3.2. Procedures of selecting three land-taking incidents ....................................... 84

3.3.3. Site access and participant recruitment ......................................................... 87

3.3.4. The role of the researcher …………………….......................................... 88

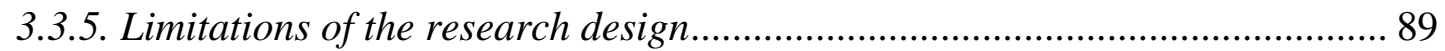

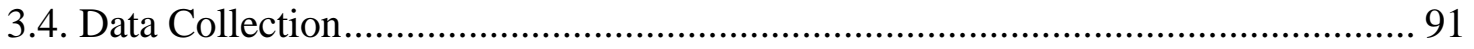

3.4.1. Key questions guiding data collection ............................................................ 91

3.4.2. Stages of data collection ............................................................................... 92

3.4.3. Data sources and data forms...................................................................... 94

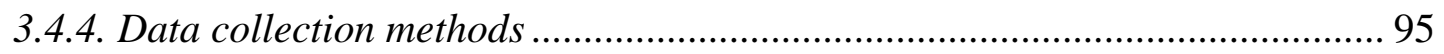

3.4.5. Recording and data management ................................................................. 99

3.5. Data Analysis and Representation..................................................................... 99

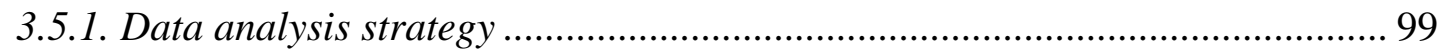

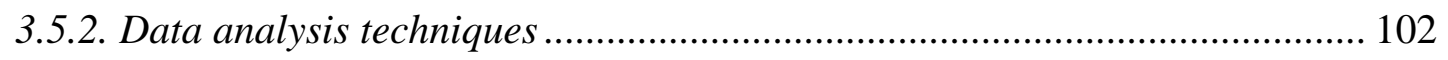

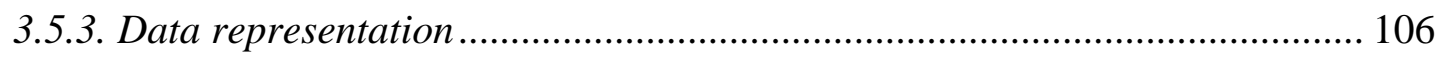

3.6. Summary of the Chapter .................................................................................... 107

CHAPTER IV: DESCRIPTION OF THE CASES.......................................................109

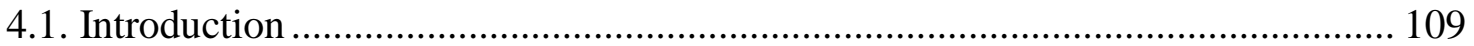

4.2. The case of Tu Son -Land Acquisition for Infrastructure in BT design............... 110

4.3. The case of Thu Thiem - Land Acquisition for Economic Development ............ 115

4.4. The case of Dong Tam - Land Acquisition for Defense Purpose......................... 118

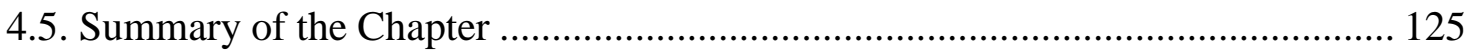

CHAPTER V: NONCOMPLIANCE WITH LAND ACQUISITION - A POLICY TOOL

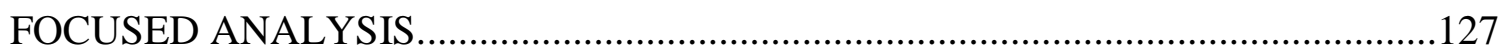

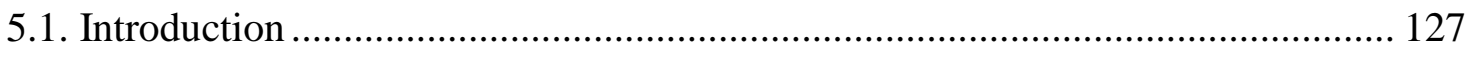


5.2. Implementation Tool Mixes ........................................................................ 130

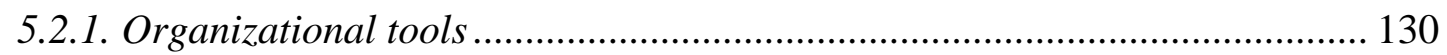

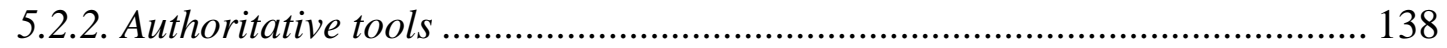

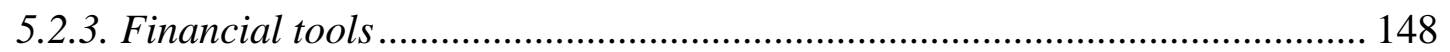

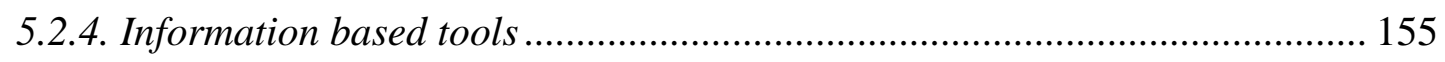

5.3. Tool based Responses to Noncompliance .......................................................... 163

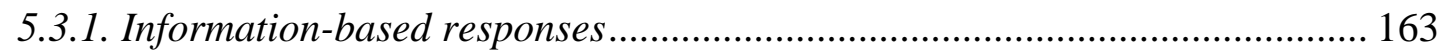

5.3.2. Authority-based responses............................................................................. 169

5.4. Summary of the Chapter .................................................................................. 172

CHAPTER VI: CONCLUSIONS AND IMPLICATIONS............................................176

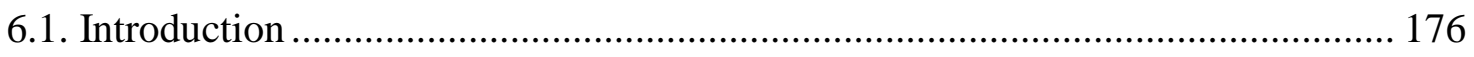

6.2. Discussions of Research Findings .................................................................. 177

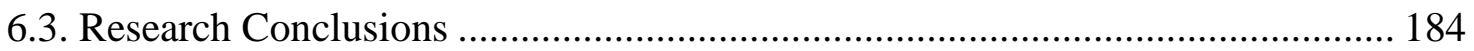

6.4. Policy Implications............................................................................................ 185

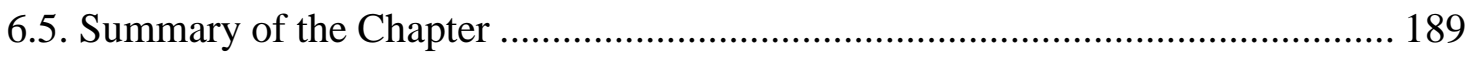

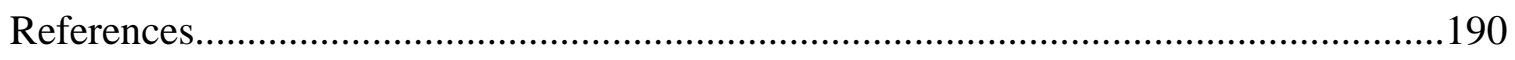

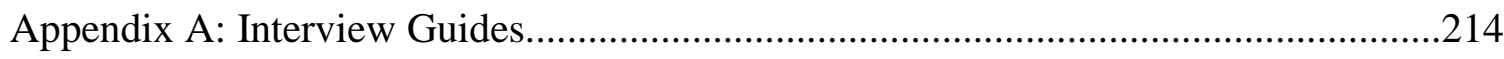

Appendix B: Questions guiding............................................................................216

Appendix C: 2013 Law on Land - Selected Articles......................................................217 


\section{List of Tables}

\begin{tabular}{|l|l|}
\hline Tables & Pages \\
\hline Table 1. Evolution of land policy in Vietnam & 6 \\
\hline Table 2. Matrix of policy mechanisms and tools & 72 \\
\hline Table 3. Coding in data analysis & 103 \\
\hline Table 4. Facts about three land-taking incidents & 126 \\
\hline Table. 5. Members of BCGC - Tu Son incident & 131 \\
\hline Table 6. Working principles of BCGC & 134 \\
\hline Table 7. Land valuation and land price framework & 139 \\
\hline Table 8. Rules of compensation, support, and resettlement & 141 \\
\hline Table 9. Failure of new apartments used for land acquisition & 152 \\
\hline Table 10. Commitments by HCMC & 168 \\
\hline
\end{tabular}




\section{List of Figures}

\begin{tabular}{|l|l|}
\hline Figures & Pages \\
\hline Figure 1. Land disputes are one of Vietnam's wicked problems at present & 9 \\
\hline Figure 2. Intensity-based typology of noncompliant manifestations & 29 \\
\hline Figure 3. Noncompliance with land acquisition in Vietnam & 73 \\
\hline Figure 4. The Socialist Republic of Vietnam & 109 \\
\hline Figure 5. Provincial Road TL 277 in Tu Son district & 111 \\
\hline Figure 6. Compulsory land acquisition in Dong Ky ward & 112 \\
\hline $\begin{array}{l}\text { Figure 7. Dialogue with noncompliant land users in Dong Ky ward on } \\
\text { September 5, 2018. }\end{array}$ & 113 \\
\hline Figure 8. New Urban Area of Thu Thiem & 116 \\
\hline Figure 9. Apartments and Office Buildings under construction in Thu Thiem & 117 \\
\hline Figure 10. A dialogue between land holders and the HCM city government & 118 \\
\hline Figure 11. Noncompliant land holders at the disputed field & 119 \\
\hline Figure 12. Police hostages in village’s cultural house & 120 \\
\hline Figure 13. Villagers' preparations to deal with government’s potential attack & 121 \\
\hline Figure 14. Dong Tam villagers met with Hanoi city's mayor & 123 \\
\hline Figure 15. Hostages were freed on April 22nd, 2017 & 124 \\
\hline Figure 16. Tools framework used to analyze land-taking incidents & 129 \\
\hline Figure 17. New apartments in Thu Thiem & 151 \\
\hline Figure 18. A public dialogue in Thu Thiem on May 9, 2018 & 161 \\
\hline Figure 19. Handwritten commitments by Hanoi’s governor & 167 \\
\hline Figure 20. Dialogue between the HCM city's mayor and Thu Thiem resident \\
\hline
\end{tabular}




\author{
Abbreviations \\ BCGC: Board of Compensation and Ground Clearance \\ CPV: The Communist Party of Vietnam \\ CGV: The Central Government of Vietnam \\ DPC: District People’s Committee \\ FAO: Food and Agriculture Organization of the United Nations \\ GDP: Gross Domestic Product \\ HCMC: Ho Chi Minh City’s Government \\ ICB: Investment and Construction Board of New Urban Complex of Thu Thiem \\ LAS: Land Administration System \\ LOL: Law on Land \\ LPD: Institute for Research on Policy, Law, and Development \\ MNRE: Ministry of Natural Resources and Environment \\ MPI: Ministry of Planning and Investment of Vietnam \\ NPM: New Public Management \\ NPG: New Public Governance \\ DONRE: District Office of Natural Resources and Environment \\ PDNRE: Provincial Department of Natural Resources and Environment \\ PPC: Provincial People’s Committee \\ PPCU: Provincial People’s Council \\ SRVN: The Socialist Republic of Vietnam \\ UN: United Nations \\ VND: Viet Nam Dong (Vietnam's currency unit) \\ WB: World Bank
}




\section{Glossary}

Agenda-Setting: the recognition of public problems that require further government consideration, attention, and actions.

Bottom - Up Approach: A way of studying policy design and implementation that considers the abilities and motivations of the lowest level implementers, and tracks policy design from that level to the highest levels of government (Birkland, 2016: 337).

Circular: The term refers to administrative instructions issued by the central government to manage policy implementation.

City/Provincial Governor: public officials with authority to govern the executive branch of city/provincial government, ranking under the premier of the central government.

Decree: The term refers to administrative instructions issued by the central government to specify the enforcement of regulations stated in laws.

District Mayor: public officials with authority to govern the executive branch of district government, ranking under provincial/city governor.

Directive: The term refers to administrative instructions issued by the central government to manage law enforcement process.

Executive Order: The term refers to administrative rules issued by the head of administrative authorities such as Premier, Provincial/City Governors, Mayors of DPC.

Governance: The rules of collective decision-making in settings where there are a plurality of actors or organizations and where no formal control system can dictate the terms of the relationship between these actors and organizations. The concept of governance can be understood in terms of structure and process. As a structure, 
governance refers to formal institutional arrangements, including laws, rules, regulations, and organizations such as state, government and non-government agencies. As a process, the nature of governance is understood as the ability to steer society or coordinate sectors of the economy/industry, and how various actors control economic activities and produce desired outcomes (Pierre and Peters., 2000; Chotray and Stoker., 2009; Bevir., 2009).

Institutional design of public policy: the term refers to formal institutions such as law, rules, regulations, and organizational structure used by the government to put a policy into effect.

Land Governance: The rules, processes, and structures through which decisions are made about access to land and its use, the manners in which the decisions are implemented and enforced and the way that competing interests in land are managed. A land governance system often consists of land policies, processes, and structures - an emphasis on both land governing processes and institutions (Palmer et al, 2009: 9).

Land Regime: The term refers to two forms of land ownership: public ownership and privateownership (Ellickson, 1993; Reale and Handmer, 2011).

Land Tenure System: "The terms and conditions on which land is held, used and transacted, within a particular system of rights and institutions that govern access to and use of land” (Ellickson, 1993; Reale and Handmer, 2011).

Land Administration System: The set of government agencies responsible for state management in the land sector.

Land Acquisition: Plans and actions of the government to acquire a specific piece of land assigned to landholders. The term can be used interchangeably with some other terms such as land-taking, land appropriation, land recovery, and land conversion. 
Land Acquisition Policy: A policy adopted by the Vietnamese government to acquire land use rights assigned to landholders for defence or security purposes, economic development, and infrastructure. In order to obtain land use rights over a piece of land, the government has to compensate land users.

Land Acquisition Project: A plan (e.g. goals, rules, procedures, and schedule) issued by the government to acquire a specific area of land.

Land Conflict: Any controversies between land actors when they pursue incompatible land related goals, whether by peaceful means or by the use of force.

Land Price System: A price system issued by provincial governments in Vietnam to be used in valuing a specific piece of land for compensation.

Land-Taking Compensation: Various forms of benefits (cash, business properties, or an alternative piece of land) offered by local governments to land users in exchange of giving up their land to the government.

Matching Capital: Resources such as land and business privileges offered by the government for investors in exchange of public constructions such as road, bridges....

Official Policy Actor: "A participant in the policy process whose involvement is motivated or mandated by his or her official position in a government agency or office" (Birkland, 2016: 108).

Public Policy: “A statement by government - at whatever level, in whatever form - of what it intends to do about a public problem” (Birkland, 2016: 9).

Policy Noncompliance: Non-collaborative responses from policy target groups over the implementation of public policy. In this dissertation, the term "policy noncompliance" is used interchangeably with "policy resistance", "policy disobedience”. 
Policy Process: A system that translates policy ideas into actual policies that are implemented and have positive effects. A classic model of policy process includes six stages: Issue Emergence, Agenda Setting, Alternative Selection, Enactment, Implementation, and Evaluation (Birkland, 2016: 27-28).

Policy Design: "The process by which policies are designed, both through technical analysis and the political process, to achieve a particular goal” (Birkland, 2016: 300). Policy Formulation: The process of generating options on what to do about a public problem.

Policy Implementation: The process by which policies enacted by government are put into effect by the relevant agencies (Birkland, 2016: 332).

Policy Tools: A tool/instrument is an identifiable method (technique) through which collective action is structured to address a public problem (Salomon, 2002: 19).

Policy Mechanism: The term refers to how or ways to put a policy into effect in practice. A policy mechanism will determine how policy tools work. Direct government, Indirect Government, Authority, Financial Incentives, and Information are common policy mechanisms used by governments across countries.

Policy Effectiveness: The achievement of the valued outcomes of a policy. Policy effectiveness is often measured in terms of units of products/service or monetary values.

Policy Efficiency: The relationship between costs and benefits throughout the policy process. A policy choice that generates more total benefits per total cost is the most efficient policy option.

State: The State is a political association that establish sovereign jurisdiction within defined territorial borders, and exercises authority through a set of permanent institutions 
(Heywood, 2007: 91). The State in Vietnam comprises the CPV, Administrative System with its Political Executives, Formal Representative Institutions, Armed Forces, Police, Security Agencies, and Social Mass Organizations controlled by the State.

Top-Down Approach: A way of studying policy design and implementation that considers the goals of the highest-level policy designers and traces the design and implementation of the policy through the lowest level implementers (Birkland, 2016: 334).

Target Group/Policy Target: "The entities - people or organizations - whose behavior the policy seeks to alter” (Birkland, 2016: 325).

Unofficial Policy Actor: "A participant in the process who does not have constitutionally or legally created incentives or mandates to be a part of the process, such as experts, researchers, and reporters, all of whom are important to the policy process” (Birkland, 2016: 109).

Wicked Problem: Challenges that have no clearly identifiable solution and that are embedded in a highly fluid and interconnected set of causal influences (Morgan, Ingle, and Shinn, 2019: 215). 


\section{CHAPTER I: INTRODUCTION}

"Public policy is fundamentally conceived as pragmatic-that is, as a political and technical approach to solving problems via instruments; that it views such instruments as natural; they are viewed as being "at our disposal", and the only questions they raise relate to whether they are the best possible ones for meeting the objective set; and that the central set of issues is around the effectiveness of instruments (Lascoimes and Le Gales, 2007)

\subsection{Introduction}

Although Vietnam is currently recognized as a "major development success story", the country's rapid industrialization and urbanization process comes with costs. Among emerging challenges, long-lasting tensions and severe conflicts between land users and government resulting from large-scale conversion of rural farmland to urban and industrial uses are "highly visible hot spots" (Brown, 2012\&2013; CECODES, VFFCRT, RTA \& UNDP, 2018). As manifestations of policy noncompliance, disputes and conflicts between land users and government over land-takings have become one of the most critical threats to the Vietnam's sustainable development (The Economist, 2017).

This introductory chapter aims to provide a general background of the dissertation research on land-taking policy noncompliance. The chapter first starts with an overview of Vietnam's context and the land policy, describes land-taking policy challenges, and 
clarifies the research problem. It then justifies the need to examine government's actions in policy implementation stage as the research opportunity, set out research purposes and questions, followed by a statement of the research significance. Chapter 1concludes with the dissertation structure and individual chapters' brief summaries.

\subsection{Research Background}

Located in Southeast Asia, Vietnam is a developing nation with a population of around 95 million (World Bank and MPI, 2016). The country's governance system is characterized by a "State centered model" in which the governing power is centralized in the "State" - a political association with sovereign power that includes but is not limited to the government institutions; and democratic centralism is claimed as the fundamental principle of public governance (Heywood, 2007: 36-43; Huang, 2009: 43).As the sole ruling political party, the Communist Party of Vietnam (CPV) serves as the core institution of the State's power system. The unity of State powers is emphasized, and there also is no clear separation between the public sphere and civil society. The central government not only controls local governments but also administrates all domestic and international affairs. In such a unitary system, social organizations are incorporated into the State system; State institutions are encouraged to support each other and collaborate for shared purposes. To ensure the guidance role of the State, the Vietnamese government can intervene in the market for development purposes. Allowing the State's intervention in the market sphere, Vietnam does not aim to develop a pure capitalist market, but a guided market economy consistent with socialist values. As a State centered model of governance, the State in which the CPV is a core institution plays a dominant role in organizing and managing Vietnam’s economy and society (Huang, 2009; London, 2014). 
In the late 1970s and early 1980s, Vietnam was one of the poorest countries in the world (Phong, 2009; WB and MPI, 2016). Agriculture dominated the economy with around 90 percent of the population living in rural areas and a relatively small proportion of the labor force working in the industrial sector owned by the State. The economy of Vietnam in the 1980s was heavily dependent on foreign aid; annual inflation rate was more than 400 percent, food was in short supply, and a majority of Vietnamese population were living in poverty. In 1986, the Vietnamese government launched economic reform (referred to as Doi Moi Policy in Vietnamese) - a transitioning process from a centrally planned to a more market-oriented economy.Shifting to a market economy has become a driving force for Vietnam's development in the last decades: the nation's GDP growth has been among the fastest in the world, accompanied by major gains in human development. Rapid industrialization and urban expansion also offered rural laborers with new job opportunities and higher incomes. The number of people living below poverty line declined dramatically: poverty rate was reduced from $58 \%$ in 1993 to $14.5 \%$ in 2008. Urban population doubly increased from 14 million in 1991 to 30 million in 2014 and more than half of the nation's GDP came from urban areas (WellDang, 2013; WB and MPI, 2016).

In modern time of Vietnam, land access is not only a driving force for political movements but also a central concern of the government. According to Toan and Quang (2014: 280-285), until mid-nineteenth century, before colonial occupation of French, Vietnam was an underdeveloped nation with an agriculture-based economy. Land was owned by the emperor who granted land to villages for State purposes. Village authorities then allocated land to households living within the village. From late nineteenth century, 
colonial French introduced a Torrens title registration system that recognized individualized, private property rights (Wiegersma, 1988). However, only a small number of elites (large landlords) connected to the French bureaucratic structure benefited from the Western right-based land tenure system. Most Vietnamese people remained outside the modern statutory rights-based land regime. Socio-political conflicts over land issues were not only because of unequal access to land but also were related to differences between modern land administration and traditional perceptions regarding land ownership (Toan and Quang, 2014: 281). From its early days of establishment in the 1930s, therefore, "land to the tillers" was a key political slogan used by CPV to attract political support from the Vietnamese people. After 1945, the revolutionary government in the North of Vietnam removed the colonial land titles and village household ownership and adopted a social class-based system of access to land. The agrarian reform in early 1950s coercively took land from landlords and directly transferred the land to tenants. Between 1954 and 1975, the Democratic Republic Government in the North nationalized most types of land and put land under the State's absolute control through agricultural cooperatives. In the South, the Republic Government of Vietnam still employed the French rights-based system that respected and protected private property rights. After the nation's re-unification in 1975, the 1980 Constitution formally abolished private land ownership in Vietnam. Since then, under the ruling of the CPV, Vietnam's Constitution and Land Laws in 1987, 1992, 2003, and 2013 consistently asserted the public ownership based land regime: land is a public property owned by the Vietnamese people and the “State” is the representative of the people's ownership over land (alternatively referred as the public ownership or State ownership in daily language). Individual citizens, 
households, and organizations are land users only with land use rights assigned by the State (Hare, 2008; Pincus, 2012).

Reforms of the land tenure system that was characterized by "de-collectivization” and "privatization of land rights" began with the CPV's Resolutions 100 in 1981 and Resolution 10 in 1988. The two resolutions respectively returned land to individuals and organizations with limited land use rights. In 1987, the security of land use rights was ensured with the issuance of the first Land Law. The revised Laws on Land in 1993, 2003, and 2013 further improved the land use right security by addressing a wide range of issues such as threats from administrative reallocation, lack of transferability, and short duration of use rights (Lodhi, 2004; Deininger and Jin, 2005; Ho and McPheson, 2010; Wells-Dang, 2013;Toan and Quang, 2014). According toArticles 5, 6, and 7 of the 2013 Law on land, land use rights in Vietnam currently are divided into three categories: ownership rights that belong to the entire Vietnamese people; control rights remains with the "State"; and land use rights are allocated to individuals, households, and organizations for a certain period of time depending on types of land. Vietnamese people, households, and organizations have five fundamental land use rights, including: inheritance, exchange, transfer, lease, and mortgage of land use rights. In such a land regime, "land-takings" (alternatively, land appropriation, land conversion, land recovery or acquisition) refer to a policy adopted by the Vietnamese government to acquire land from landholders for economic and infrastructure development purposes. In order to take back land use rights over a piece of land, the government has to compensate land users for their land use rights. 
Table 1: Evolution of Land Policy in Vietnam

\begin{tabular}{|c|c|c|}
\hline Policy Documents & Year & Key Contents \\
\hline - $1^{\text {st }}$ Constitution & 1946 & $\begin{array}{l}\text { Private ownership right on properties of Vietnamese } \\
\text { people is secured. }\end{array}$ \\
\hline $\begin{array}{l}\text { - Agrarian Reform } \\
\text { Law }\end{array}$ & 1953 & $\begin{array}{l}\text { Land Ownership was removed from landlords and } \\
\text { passed directly to tenants. }\end{array}$ \\
\hline - $2^{\text {nd }}$ Constitution & 1959 & $\begin{array}{l}\text { Article } 11 \text { recognized State Ownership, Collective } \\
\text { Ownership, Individual Ownership, and National } \\
\text { Capitalist Ownership on main materials for production, } \\
\text { including land. Cooperatives were encouraged. }\end{array}$ \\
\hline - $3^{\text {rd }}$ Constitution & 1980 & $\begin{array}{l}\text { State ownership was established as the only form of the } \\
\text { land ownership. Land was managed by the State; the } \\
\text { State had right to allocate and recover land. }\end{array}$ \\
\hline - Land Law & 1987 & $\begin{array}{l}\text { Households and Individuals were issued land use rights. } \\
\text { The State controlled all land transactions; land had no } \\
\text { values; land market was not recognized. }\end{array}$ \\
\hline - Constitution & 1992 & $\begin{array}{l}\text { State ownership over land. The State manage land and } \\
\text { allocates land to individuals, organizations, and } \\
\text { households. }\end{array}$ \\
\hline - Land Law & 1993 & $\begin{array}{l}\text { State ownership overland; land price was defined by the } \\
\text { State. Households had rights to transfer, exchange, } \\
\text { inherit, lease, and mortgage land. The only land-taking } \\
\text { form was compulsory land acquisition. Economic } \\
\text { organizations could lease land from the State. }\end{array}$ \\
\hline $\begin{array}{l}-\quad \text { Land Law } \\
\text { Amendments and } \\
\text { Supplementations }\end{array}$ & $\begin{array}{l}1998- \\
2001\end{array}$ & $\begin{array}{l}\text { Domestic economic organizations could access land for } \\
\text { housing and infrastructure developments. Households, } \\
\text { individuals could transfer, lease, or contribute land as } \\
\text { capital to economic projects. }\end{array}$ \\
\hline - Land Law & 2003 & $\begin{array}{l}\text { State ownership over land; further clarifications of } \\
\text { authorities and responsibilities of land management } \\
\text { agencies as well as rights and responsibilities of land } \\
\text { users. Market land price was recognized; domestic } \\
\text { economic organizations could lease land or be allocated } \\
\text { land from the State. Limits to compulsory land } \\
\text { conversion were set; voluntary land conversion allowed. }\end{array}$ \\
\hline - Decree 84 & 2007 & $\begin{array}{l}\text { Foreign investors could access land for commercial } \\
\text { housing developments. Improvements of transparency } \\
\text { and dissemination of compulsory land conversion } \\
\text { procedures. }\end{array}$ \\
\hline $\begin{array}{l}\text { - Constitution } \\
\text { - Land Law }\end{array}$ & 2013 & $\begin{array}{l}\text { State ownership overland; two forms of land acquisition: } \\
\text { compulsory and voluntary. Land could be acquired for } \\
\text { economic development purposes. }\end{array}$ \\
\hline
\end{tabular}


Though land acquisitions had been occasionally conducted before the launch of DoiMoi policy in 1986, the Vietnamese government widely enacted the land-taking policy to meet demands of rapid industrialization and urban expansion process across the country from the early 1990s (Buttle, 2009; Pincus, 2012). With the Law on Land of 1993, the Vietnamese government can collect land use right if the land is not being used for intended purposes. The land appropriation (land-takings) can also take place when the "State" needs land for public purposes such as national defense \& security, national interests, public interests, or economic development. More specifically, the 1993 Land Law allowed compulsory land use right acquisition as the only form of land-takings. However, the implementation of a land-taking project was very complicated because only the State had right to conduct land acquisition; investors had to negotiate compensation with land users, and with governments at every level, including commune, district, and provincial governments. The implementation of land-taking policy became more flexible after a revised Law on Land was passed in 2003. The new Land Law for the first time allowed land developers directly negotiate with land users in order to obtain a land area. In addition to compulsory land acquisition, the revised Land Law of 2003 also recognized voluntary land conversion in which investors and land users can discuss and develop mutual agreements regarding land transfer, land lease, or land contribution as capital. These two forms of compulsory and voluntary land use right-takings remained in the latest Land Law of 2013. Accordingly, compulsory land appropriation is carried out for public purposes in which land users have to accept the State's administrative decisions while voluntary land use right acquisition in which investors and land developers can negotiate compensations with land users in exchange of land. Though all Land Laws 
require local governments to carry out compulsory land-takings for public purposes only, there has been a trend that involuntary land acquisitions are also widely applied with economic development projects(Mc Pheson, 2011; World Bank, 2011a \& 2012; World Bank and MPI, 2016). In the last three decades, therefore, the implementation of such a land-taking policy played an important role in Vietnam’s rapid economic development. On the one hand, open and easy access to land and cheap land rent attracted investment projects from non-State and foreign investors. The policy, on the other hand, also generated negative consequences such as the increase of disputes and conflicts between land users and government.

\subsection{Research Problem}

Land globally is not only a means of production but also a form of valuable property (Wehrmann, 2008). In addition to economic importance, the critical role of land also derives from its spiritual attachments and emotional connections to the people (Ho and McPheson, 2010; Hall, 2013). In Vietnam, as a fundamental production material of around $70 \%$ of the Vietnamese population, land currently still is a strategic natural resource strictly controlled by the Vietnamese State (World Bank and MPI, 2016). As a sole political party leading the nation, the CPV adopts the Marxist economic perspective, arguing that the State's control in fundamental economic sectors such as the land sector is necessary to protect the people's interests and maintain the socialist characteristic of the nation’s socio-economic system. Being influenced by Marxist political economy, the ruling CPV has followed a governance perspective that views people's interests in terms of social classes rather than individuals. In such a governance system, to harmonize interests of different social classes (ex. Workers, Farmers, Soldiers, Businessmen, Public 
Officials), the State controls key economic sectors through public ownership and the State's active intervention in the economy (Huang, 2009; London, 2014).

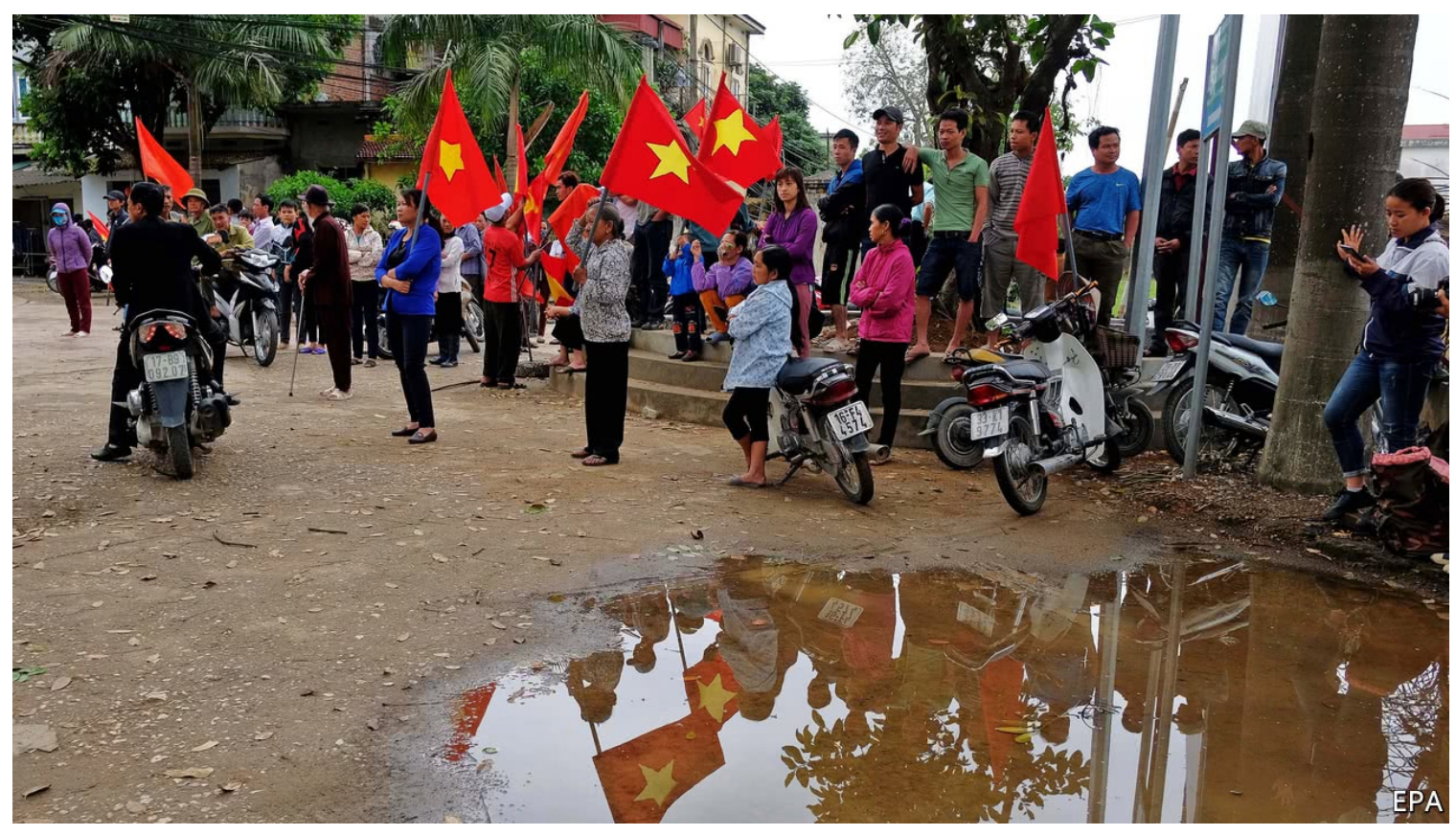

Figure 1: Land disputes are one of Vietnam's problems at present

(Source: economist.com)

The implementation of land-taking policy in practice, however, has resulted in numerous disputes and conflicts between land users and local governments. According to Lodhi (2004), from 1988 to mid-1990s, some 200,000 land related villagers sent complaints to the government at district, provincial, and central levels. In the early 2000s, land related confrontations became the most severe problem across the country. Around $50 \%$ of all complaints sent to the government in 2005 were about land conversion and compensation (World Bank, 2011a: 17). The Office to Receive Citizens’ Complaints of the Central Party Committee and the State received more than 30,000 land petitions in 2006 in which only $20 \%$ concerned boundary disputes or claims while about $70 \%$ 
involved compensation for site clearance (Gillespie, 2011). A study conducted by the Institute for Research on Policy, Law, and Development in 2009 reported that the number of land-taking incidents in recent years increased by $80 \%$. In the first ten months of 2012, over the $97 \%$ of 3,193 petitions and complaints to the government werere lated to land issues (LocNga, 2012; cited in Wells-Dang, 2013).

Noticeably, violent clashes over land-takings between government officials and land users have significantly increased in recent years. On April 15 ${ }^{\text {th }}$, 2017, a first of its kind of land-taking conflicts occurred in Dong Tam commune (Hanoi City) where local villagers held 38 local government official hostage to request a dialogue with the city Chairman. The confrontation between the land users and local government officials reached its peak when villagers stated that they were ready to die for their land if the government used force to free the hostages (Ives, 2017).The Dong Tam event was preceded by a similar incident in January 2012 in Tien Lang district (Hai Phong city Northern Vietnam) when a fish farmer family used a homemade land mine and improvised shotguns to resist local government's land-taking actions (Brown, 2012). The Vietnamese public was also aware of serious land tensions in Van Giang (Hung Yen Province, near Hanoi) from 2006 to 2012. Long lasting disputes in Van Giang district led to a severe violent clash between about 2000 police officers and approximately 3000 land users in April 2012 (Labbe, 2015). Those high-profile events in Dong Tam, Van Giang, and Tien Lang, as well as the statistics described above show that land-taking disputes and conflicts are not only an economic problem but also a socio-political threat to Vietnam's social cohesion, economic development, and political stability (Brown, 2012; The Economist, 2017). 
From a public policy perspective, the widespread incidence of long-lasting disputes and violent conflicts is an indicator of policy noncompliance and raises the question of policy effectiveness (e.g. policy acceptance and the achievement of valued policy outcomes). Land-taking policy noncompliance is defined as land users' unwilling to accept local governments' decisions over issues such as land price, compensation, or acquired land area. The policy noncompliance is manifested in specific forms of disputes and conflicts between affected land users and local governments. In theory, a policy always aims to alter the behavior of target populations (Gofen, 2015; Birkland,2016). Disputes and conflicts over land-takings show land users' disagreements with the government's policy decisions. Evidently, the land-taking policy is not welcomed by the target group in some particular situations, and there is no indication that this phenomenon will end in the coming years. The fact that the land-taking policy is unable to change land users’ behaviors (e.g. they do not act as expected by policy makers and implementers) shows a policy failure (Birkland, 2016: 345). In this case, the land-taking policy does not fail in achieving its goals of land collection; it fails because of unintended consequences such as long-lasting land users-government confrontations and tensions.

According to policy researchers, noncompliance among target groups is often described as a problem of policy implementation and enforcement (Mazmanian and Sabatier, 1989; Gofen, 2015). Policy implementation is what develops between the government's intention and the ultimate impact in the world of action - the process by which policies enacted by government are put into effect by relevant agencies (O’Toole, 2000; Birkland, 2016: 332). When a policy gets implemented, a variety of interests and desires are clearly manifested. Interest conflicts that have not been solved during the 
stages of policy formulation, design, and adoption might emerge again. As a complex political process, policy implementation involves various actors and stakeholders. A world of multi-institutional actors - more than one government, agency, or sector requires cooperation and coordination for implementation success” (O’Toole, 2000; Hill and Hupe, 2002). Even a "good policy design', therefore, does not ensure a policy target's compliance. The ways local governments execute and enforce public polices in practice also play a critical role. In other words, the success of a policy not only requires "good policy design” but also "good policy implementation”. Conversely, implementers might still obtain expected outcomes with a poorly formulated policy if they carefully and rightfully manage policy implementation (Pressman \& Wildavsky, 1973; Brinkerhoff and Crosby, 2002; Salomon, 2002; Anderson, 2015; Sandfort and Moulton, 2015).

Land-taking policy practices and literature suggest a research problem: why don't land users comply with land-taking policy? And how do local governments respond to policy noncompliance to minimize public risks? In order to explore the research problem, this dissertation is interested in potential linkage between policy tools and noncompliance over land-takings. The researcher starts with a theoretical assumption: public policy failures might relate to types, uses, advantages, problems, and trade-offs among the range of policy tools. Policy effectiveness not only depends on the way policy tools are combined in a policy mix but also is affected by how those tools are applied in particular situation. Even if right tools are chosen, they can be as problematic as using them in wrong ways (Cooper, 2018: vii). Therefore, this study proposes that actions of local governments, including tools choice and use, in the "land-taking policy implementation stage” might contribute to land users’ noncompliant attitudes and behaviors. This major 
research proposition directs the researcher's attentions to policy tools used by local government officials to interact with affected land users as policy target group.

\subsection{Research Purposes}

The general purpose of this study is to explore potential linkage between landtaking policy implementation tools and land users' noncompliance. Specifically, to achieve the main purpose above, this study will conduct three main tasks:

- Examining land-taking policy implementation: In order to deal with policy failure, argued by policy experts, it is necessary to consider issues related to the entire policy process: policy formulation, design, and policy implementation (Hill and Hupe, 2002 \& 2009). This means that manifestations of policy failure such as policy noncompliance can relate to various elements of policy-making or policy implementation, or both stages. Policy professionals, therefore, also share a consensus that learning from policy failure occurring in the implementation stage is one of the strategies to secure policy success (May, 1992; Birkland, 2016). As pointed out by May (1992), policy learning can take place in three forms: instrumental learning, social learning, and political learning. The viability of policy interventions and implementation design can be improved through instrumental learning - a learning form that focuses on implementation tools and techniques. This dissertation research, thus, is motivated by concerns about government's actions, relationships, and dynamic interactions between government agencies and target groups during the policy implementation process. It is particularly interested in how local governments interact with non-state actors to implement land-taking projects. The focus on the stage of policy implementation allows 
the researcher to examine coordinating mechanisms, methods, devices, or tools used by government to achieve policy goals.

axploring the role of policy tools: This dissertation secondly will explore if implementation tools used by local government officials relate to land users' noncompliance. Empirical studies show that policy noncompliance often arises as a result of long-lasting and unsolved disagreements between parties. To ensure effective implementation, policy implementers are required to accommodate views and preferences of different participants and harmonize conflicting interests (Mint, 2012: 287). This requirement not only places policy implementers in front of economic-political concerns but also challenge them in terms of technical issues of tool choice and use. This is because, theoretically, government tools are defined as devices for interactions between policy implementers and policy targets. Policy tools can “cause agents or target groups to do something they would not do otherwise or with the intention of modifying behavior to solve public problems or attain policy goals” (Schneider and Ingram, 1997: 93). Tool selection and use, thus, not only significantly affect relationships between the two parties but also the effectiveness of policy implementation. Policy success (e.g. high level of policy compliance), demands collaborative actions by multiple actors and stakeholders, both within and outside the government sectors. An investigation of tool use in the landtaking policy implementation stage, thus, might provide additional insights regarding a wicked-problem of noncompliance with land-taking policy.

- Exploring alternative tool mixes: This study will also consider alternative tools to secure land users’ compliance. Policy noncompliance not only challenges the viability of policy goals but also reveals problems in interactions between government and target 
groups. This is because different actors evolving in policy implementation often have their own values, beliefs, incentives, and perspectives that influence outcomes of policy implementation. Since policy tools define a set of actors, their roles, and relationships among them, the tool approach offers a novel approach to explain land-taking policy noncompliance. It is important to know if land-taking problems relate to tools and if local governments in Vietnam can reduce land-taking policy noncompliance by shifting their tool choice and use. These concerns require an in-depth exploration of tool mix used by government officials in their local contexts.

\subsection{Research Questions}

Research question: When and how do the policy tools used in the implementation of land-taking policy in Vietnam help to explain noncompliance?

Research tasks: In order to address the research question above, the researcher will carry out following research tasks:

(i) Describe background history and progress of three land-taking incidents.

(ii) Examine tool mixes used by implementers to execute land-taking projects

(iii) Explore implementers' tool preferences and patterns of tool use

(iv) Describe contextual factors affecting implementers' tool choice and use

(v) Identify linkage between implementation tools and landholders' noncompliance over land acquisition.

(vi) Explore if implementers change tools in order to deal with noncompliance, and if tool changes can increase policy effectiveness (ex. reduce land users' resistance and reach a settlement). 

(vii) Make tool-based recommendations to minimize landholders' noncompliance in land-taking policy implementation.

\subsection{Significance of the Research}

Since land still plays a role in livelihoods of around $70 \%$ of the Vietnamese population, socio-political tensions resulting from land-taking policy noncompliance are critical challenges for CPV as the sole ruling party (Brown, 2013; Yves, 2017; The Economist, 2017). The study of land users' noncompliance regarding land-taking policy implementation, thus, is especially significant to both the CPV and the Vietnamese government. The tool approach adopted in this study will offer an additional explanation of land users' policy resistance manifested in land-taking disputes and conflicts. Research findings will, therefore, increase CPV leaders' understanding about land-taking problems, suggest new initiatives, and enable them to make more informed policy decisions within the current context of Vietnam. The tool approach will also bring policy makers and implementers at the central level new insights about land-taking policy noncompliance, suggest alternatives in re-designing rules and procedures for more effective policy implementation. Increased compliance among land-taking policy target groups will not only improve the effectiveness of government administration but also strengthen the legitimacy of CPV as the nation's leading party.

This study is also critical to local policy implementers who are directly responsible for land-taking policy implementation at the provincial, district, and commune levels. A tool-based study of policy noncompliance will provide an additional in-depth description of government's failure in changing land users' behaviors. Recommendations generated from this study will be helpful to local governments in 
managing the policy implementation process and improving policy effectiveness. Specifically, research results might be helpful in enhancing implementers' awareness of stakeholder network and their roles, and how to discover new ways of tool use for more effective collaboration between the government's agencies and non-state actors. Local policy implementers will also be guided how to properly use policy tools to legitimate their actions and convince land users in land-taking policy enforcement. Local government agencies in the land sector will also gain information about what needs to be improved regarding tool choice and applications; land officials will learn how to better mix implementation tools in order to minimize policy noncompliance. Overall, the toolbased research approach might be helpful to local policy implementers by providing an in-depth description of strengths and weaknesses of available implementation tools, the relationships between tool choice, tool use, and policy compliance/noncompliance; and how to effectively mix and apply tools in order to reduce policy noncompliance within the local context.

This dissertation research is helpful for Vietnamese policy professionals and academic researchers who are interested in wicked problems such as land-taking policy noncompliance. Instead of looking at land-taking problems from traditional lens (ex. institutional, economic, or democratic governance), policy researchers can learn a new research pathway - the new public governance perspective as a new research philosophy, and the tool-based theoretical framework within it that is still new to Vietnamese academic community. As a valued centered perspective, the NPG can motivate researchers to develop new theories on the role of policy tools and seek new ways of tool 
use relevant with Vietnam's local contexts in order to enhance policy legitimacy and facilitate collaborative responses from policy target groups and other non-state actors.

\subsection{Structure of the Dissertation}

This dissertation is structured into six chapters as follows:

Chapter I. Introduction: Dealing with land-taking policy problems, in addition to advocacy for a reduction in the State's control over the land sector, there has been a support for a bigger role of market forces and improvements of land legislation (Pincus, 2012; World Bank, 2009 \&2012; Bell, 2014). Academic literature, however, suggests that government's capacity in governance and policy implementation do matter. Policy compliance cannot be achieved if action aspects of policy implementation are ignored (Mc Pheson, 2011; Pincus, 2012; World Bank, 2011a \& 2012; World Bank and MPI, 2016). Chapter I, therefore, provides a background of this dissertation study: the chapter first overviews Vietnam’s current context, reviews the evolution of land policy in general and land-taking policy in particular, and clarifies the research problem of land-taking policy noncompliance. These sections are followed by the presentation of research questions, research purposes, and research tasks that will be targeted within this study. Chapter I also justifies the need of this study by discussing how CPV, government leaders and officials at every level, professionals and academic researchers in Vietnam can benefit from research results. This introductory chapter, finally, is completed with a brief overview of the dissertation structure.

Chapter II. Literature Review and Theoretical Framework: The main purpose of chapter 2 is to critically review land-taking policy literature, analyze research gaps, and develop a theoretical framework used to explore potential relationship between 
policy tools and land users' policy noncompliance. In the first section, the author conceptualizes the key term of "policy noncompliance" and develops a typology of landtaking noncompliant manifestations relevant to Vietnam's context. This is followed by a critical review of three influential theoretical approaches in explaining noncompliance over land-takings: institutional, economic, and good governance explanations. Policy noncompliance (ex. low level of policy acceptance) might relate to a variety of factors and, thus, can be explored using different theoretical lens. With a focus on government in actions, the third section clarifies the research gap that this dissertation fills in: whether tool choice and application in the policy implementation stage affects land users' noncompliance. Next, the author develops a tool based theoretical framework used in this dissertation study. This section provides a definition of policy tools and categories of tools as means or methods to realize policy goals. It argues that noncompliance in landtaking policy implementation in Vietnam is conventionally studied using a top-down approach that pays too much attention to institutions, rules, procedures and the capacity of local governments. Similarly, the good governance perspective that requires participatory institutions is not really realistic if we consider current context of Vietnam. As an alternative approach to noncompliance with land acquisition - the tools approach focuses on the role of local governments intaking actions and interactions with nongovernment actors rather than the quality of policy design or the capacity of local government.

Chapter III. Research Design and Methods: The fact that qualitative research design is rarely used in part explains a limited understanding of land-taking policy noncompliance. Chapter III, thus, first aims to justify the use of "qualitative case study" 
as this dissertation's research strategy and design. The chapter then is organized into three main parts: (i) Research Design; (ii) Data Collection; and (iii) Data Analysis and Representation. Unit of analysis and case selection are the most fundamental elements of a qualitative research design. In this study, land-taking instances were chosen as the "unit of analysis”. The research population, therefore, consisted of all on-going land-taking projects. However, since this study focused on policy noncompliance, the researcher excluded land-taking instance without resistance. This means that only land-taking incidents in which land users did not comply with local governments' policy decisions were considered for case selection. Research participants included local leaders, land officials, and land users who were directly involved in land-taking policy implementation. Regarding data collection, the author mainly relied on online sources such as government and non-government organizations' websites, online newspapers...for gathering secondary data. Primary data collection was carried out in rapidly urbanizing provinces in the North of Vietnam (VinhPhuc and BacNinh) where large areas of farmland were converted for industrial development and urban expansion. This dissertation's data are in forms of documentation, video clip, field notes, and transcripts. The main methods of data collection included focus group, in-depth interview, field observation, web-search, and document analysis. Qualitative data were analyzed using techniques such as coding, content and thematic analysis. Research results were organized and presented in themes associated with the research questions.

Chapter IV: Description of the Cases. Chapter iv presents a description of the selected land-taking projects that local government had to deal with noncompliance. Three land-taking incidents took place in Thu Thiem in the HCMC area; in Tu Son 
district (Bac Ninh province); and in Dong Tam commune (Hanoi capital city). Governments in HCMC and Bac Ninh acquired land for economic development and public infrastructure. Land acquisition in Dong Tam, whereas, was for defense purpose. The key details related to each of the incident include the location and local context, starting time and time length, acquired land area, land-taking purposes, number of affected people, number of noncompliant landholders, the evolution and intensity of noncompliance, the government's responses to noncompliance and the consequences. Facts provided in this background chapter not only help to draw a picture about the specific noncompliance but also further clarify why economic, institutional, and good governance factors are insufficient to explain the selected incidents. A detailed description of incidents also helps to reveal the research opportunity for the policy tool approach that is expected to generate new insights about landholders’ noncompliance.

\section{Chapter V: Noncompliance with Land Acquisition: A Tool focused Analysis.} Chapter v presents a cross case analysis of three land acquisition incidents. Data used for analysis includes two types: (i) primary data collected by the researcher in Bac Ninh (and Vinh Phuc) provinces and (ii) secondary data published by other authors and agencies. Instead of analyzing single land-taking project, the researcher conducted a theme-based analysis that covered similarities and variations emerged from three cases. Qualitative research results revealed similar tool mixes used by local implementers in Hanoi, HCMC, and Bac Ninh to acquire land. The tool mix included a direct government organization (BCGC), authoritative tools (most importantly, executive order and land price regulations), information-based tools (e.g. proclamation, public poster, moral suasion, public dialogue, information portal) and three financial or financial equivalent tools of 
cash, land, and resettlement apartment. A shared feature across three incidents was that authoritative tools and information-based tools played a decisive role in land acquisition. The role of three financial or financial-equivalent tools in land-takings was limited. Authority-intensive tool mixes enabled implementation effectiveness and efficiency but limited responsiveness and legitimacy. Dealing with policy noncompliance, "executive order”, "propaganda”, and "moral suasion” were the three tools commonly used by implementers. Another shared pattern of three incidents is that after information-based tools failed in persuading landholders, the government was willing to coercively take land using executive orders and government agencies.

Chapter VI: Conclusions and Implications. In this chapter, the researcher clarifies linkages between implementation tools and noncompliance with land acquisition. Research findings are discussed in relation with available literature. The researcher argues that tools do contribute to landholders' noncompliance. This is because available tools used in acquiring land allow coercive land acquisition once implementers face resistance. Tool preferences over direct government organizations, authoritative tools, and information-based tools define a one-way relationship between policy implementers and affected landholders who have no choice except receiving compensation and giving up their land. Coercion, instrumentality, and routinization are three prominent features of Vietnamese implementers' tool choice and use. These characteristics ensure implementation effectiveness and efficiency but are not necessarily associated with responsiveness and legitimacy of government's actions. This, from a tool perspective, explains why and how government's actions contribute to noncompliance with land acquisition in Vietnam. Based on research results, the researcher suggests 
implications and recommendations for policy makers, policy implementers, professionals and academic researchers who are interested in tools approach to public policy problems.

\subsection{Summary of the Chapter}

As a developing country, land is not only a valued commodity but also is a special asset and an important means of production. Historical evolutions of Vietnam in the 20th century shows that any change in the land policy sector might have profound effects on the nation's economy and society. After the Vietnam War, land policy reforms starting in early 1980s resulted in the privatization of land use rights. Vietnamese people currently have five land use rights while the land ownership is controlled by the State. Over the last two decades, land-taking policy have been widely implemented across the country to meet demands of economic development and urban expansion. Easy access to land use, on the one hand, attract numerous investors who play vital role for economic growth. On the other hand, Vietnam's economic development and socio-political stability are also challenged by unexpected outcomes of the land-taking policy implementation: policy target's noncompliance manifested in the increase of disputes and conflicts between land users and the government. This reality raises the research problem: why land users do not comply with land-takings?

Although land-taking problems have attracted attentions from public officials, professionals, and academic researchers, most up to date studies on the topic were conducted from social science perspectives such as sociology, economics, and legal studies. Studies based on a public policy approach are still very limited. This reality motivates an exploratory dissertation research adopting policy tool lens. The main research question is if policy tools relate to land users' noncompliant behaviors? 
Accordingly, land-taking disputes and conflicts are viewed as manifestations of policy noncompliance that often takes place between land users and local governments in policy implementation stage. The policy tool approach places an emphasis on interactions and relationships between policy implementers and policy target groups. Based on a qualitative case study, the researcher will explore tool choice and use in local contexts, and how policy tools might relate to land users' noncompliant behaviors. While research results will first serve as a start for future studies, policy makers at the central level of government might benefit from policy implications, and local policy implementers might be guided to effectively reform policy implementation. 


\title{
CHAPTER II: LITERATURE REVIEW AND THEORETICAL FRAMEWORK
}

\author{
"A key attraction of the tools approach is that it can simplify \\ this complex concept (public policy), making more tangible the \\ abstract idea of policy....It encapsulates the idea that there are \\ choices to be made, and that the selection of instruments can \\ make policy-making better, or more efficient, or socially optimal \\ in some way” (Margetts and Hood, 2016: 133)
}

\subsection{Introduction}

The rise of long-lasting disputes and violent conflicts between land users and local governments over land-takings in Vietnam reveals unexpected policy outcomes. As manifestations of policy noncompliance, land-taking disputes and conflicts vary in terms of scope and intensity and might be closely associated with local particular conditions. What causes noncompliance with land-taking policy and how to increase policy acceptance among land users have become the two main general questions attracting public concern and the interest of policy makers, implementers, professionals, and academic researchers in Vietnam. The purpose of this literature review chapter is to provide an overview of what has been studied, what is still unclear, and what is studied in this dissertation. 
This chapter consists of three main parts: (i) reviewing land-taking policy literature, (ii) analyzing the research gap, and (iii) elaborating a theoretical framework to guide the research. Specifically, the main task of the first section is to define the concept of policy noncompliance and develop a typology of land-taking noncompliant manifestations relevant with Vietnam's context. It will then conduct a critical review of institutional, economic, and democratic governance explanations as the most three influential theoretical approaches to explaining land-taking policy problems in Vietnam. The next section of chapter II will argue that recommended reforms of land legislation and economic interests are insufficient to deal with land-taking policy problems while reform initiatives towards a democratic governance are impractical in Vietnam's current institutional context. Seeking an additional theory of land-taking policy problems, the final section describes a theoretical framework of policy tools that will be used to explore how implementation tools might affect land users' noncompliant attitudes and behaviors.

\subsection{Noncompliance with Land Acquisition in Vietnam}

\subsubsection{Policy noncompliance}

When a government responds in a preferred way to a public problem, we refer to that response as a public policy. A public policy, theoretically, is defined as "a purposive course of action or inaction followed by an actor or a set of actors in dealing with a problem or matter of concern" (Anderson, 2011: 7). The government issues what it intends to do (public policy) in forms of laws, regulations, statutes or a constitution to alter target groups' behaviors and promote a consistency of actions in response to specific conditions (Mintz, 2012; Birkland, 2016). Policy target groups are populations whose behavior is expected or intended to be changed by government action (Howlett, Ramesh, 
and Perl, 2009: 163). Target groups of policy might be domestic or international (Doods, 2013); individuals such as public officials, bureaucrats, and citizens; or organizations such as private firms and public agencies, and even countries or states (Fen, 20014). The success of a public policy, therefore, requires compliance with the policy intent among target groups. A high level of compliance indicates the target's acceptance of the goals and objectives of the policy and they respond as intended by policy makers. In other words, policy compliance shows that the government's policy has effectively changed the target group's behavior.

In contrast, noncompliance by the target population raises the question of public policy effectiveness (e.g. the government's failure to alter a particular the target groups' behavior). According to Fen (2014), policy noncompliance refers to target behavior that is inconsistent with a given policy's goals and objectives. Noncompliance might be direct (e.g. breaking the law), indirect (e.g. not to follow recommendations), active (e.g. doing something different than what is expected by a policy), or passive (e.g. refusing universal services). Noncompliant responses indicate that policy targets are willing to act in opposition to policy expectations. Noncompliance, thus, not only reflects target groups' disagreements with the government but also reveals an inconsistency between policy objectives and target group behavior (Cialdini and Goldstain, 2004).

Based on the conceptualization above, land-taking policy noncompliance in Vietnam broadly refers to non-collaborative responses from land users who are the policy targets affected by the implementation of land-taking projects. Noncompliance with landtaking policy, more specifically, is defined as situational tensions and confrontations between local governments and land users in which land users act in opposition to policy 
implementers' intent and expectations. Disputes and conflicts between the two parties can take place prior and during, or even after a land-taking project. Controversies might be related to various issues such as acquired land areas, land prices, land valuation methods, compensation offers, or all of those matters in combination. Because of unsolved disagreements, land users do not accept land-taking policy decisions; government thus cannot acquire a piece of land as scheduled. This results in tensions and delays in the implementation of land-taking projects. Manifestations of land users' noncompliance vary, depending on the intensity of confrontations, and can range from resistant attitudes to peaceful demonstrations and violent acts. An intensity based-typology of land-taking policy noncompliance in the following section will present common types of noncompliant manifestations with land-taking policy in Vietnam's context.

\subsubsection{Noncompliant manifestations with land acquisition}

Since land related problems are a complex phenomenon in the developing world, no single typology can capture common manifestations or forms/patterns of controversies (Warner, 1999; Boone, 2013). In actuality, problems over land policy can be classified on the basis of various dimensions such as causal factors or parties involved, at either macro or micro levels (Wehrman, 2008); land regime, social level and dimensions, or land control forms (Boone, 2013; Hall, 2013).Available typologies of land problems, however, do not cover the unique characteristics, scope, and intensity of controversies that mainly occur between a public institution (government) and land users (policy target group) regarding land-takings in Vietnam. This dissertation, therefore, develops an intensitybased typology of policy noncompliance to identify and classify different manifestations relevant to Vietnam's context. Accordingly, in addition to various forms of everyday 
resistance, manifestations of land-taking policy noncompliance are classified into three main groups: at the lowest level are administrative land claims and petitions, followed by peaceful land protests, demonstrations, and occupations. Violent conflicts over landtakings are the most severe form of policy noncompliance.

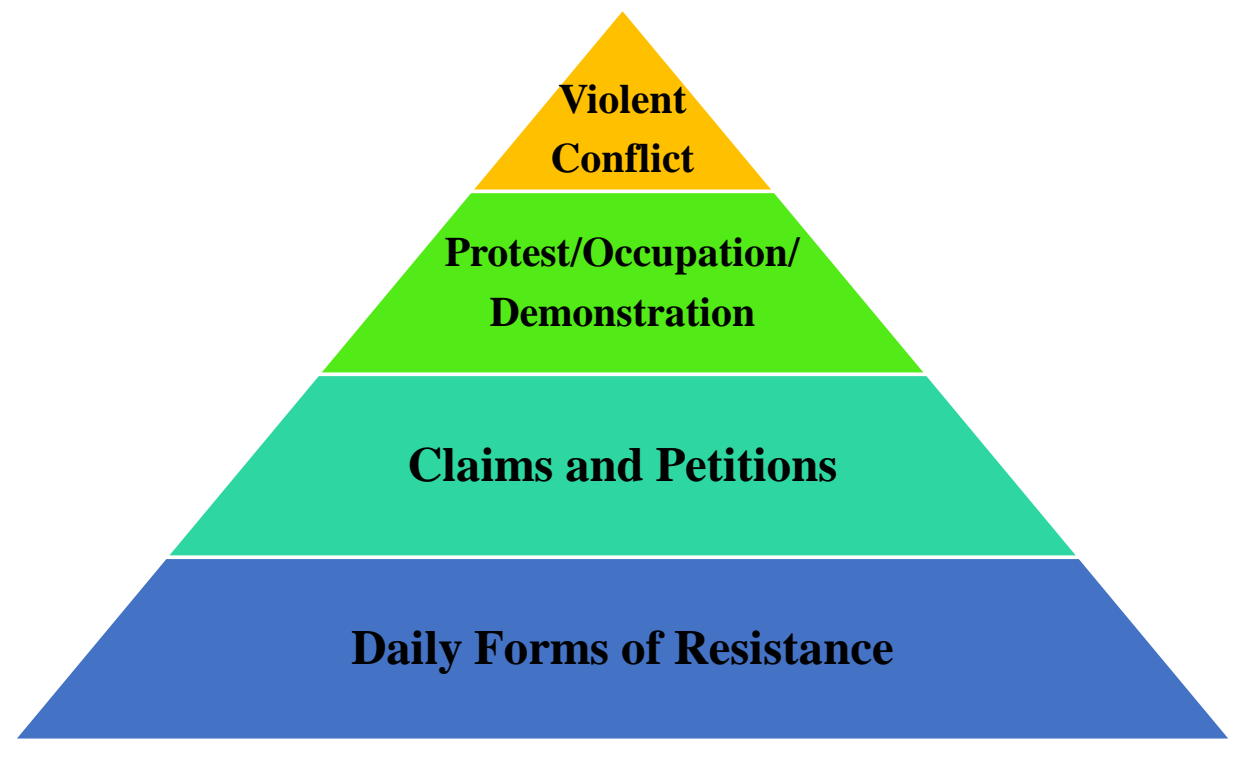

Figure 2: Intensity Based Typology of Noncompliant Manifestations

(i) Everyday forms of resistance: this form of noncompliance refers to any (intended or situational) actions enacted by individual land users aiming to individual government officials who get involved in land-taking projects (ex. Window breaking, individual threatening, and individual grievance).

(ii) Land-taking claims and petitions: land claims and petitions occur when land holders disagree with local governments' intents and decisions regarding particular landtaking projects. They, thus, send requests to State agencies such as courts or local governments for reconsideration of goals, rules, or procedures. If tensions last long and 
affect the progress of land-taking project implementation, a trial is required in which the dispute is resolved by courts.

(iii) Land-taking protests/occupations/demonstrations: when land holders still disagree with decisions made by local governments or courts over land-takings, they can collectively organize peaceful demonstrations/protests or land occupations. These manifestations of policy noncompliance often attract many people in a collective action, last long, but still manifest a peaceful attitude.

(iv) Violent conflicts over land-takings: this is the most serious/negative form of land-taking policy noncompliance. Involved parties rely on physical force and violent acts to show the intensity of their disagreement with a policy in attempt. A violent landtaking clash occurs when land users violently resist the government's coercive actions to protect their land related interests.

\subsection{Theoretical Explanations of Noncompliance with Land Acquisition}

Acritical review of available land-taking policy literature reveals the dominance of institutional and economic explanations while governance and public policy implementation approaches plays a less influential role. This not only explains researchers’ preferences of analysis of land legislation and large-n quantitative surveys but also shows that process aspects of policy implementation and their potential linkages to noncompliance over land-takings have largely been neglected.

\subsubsection{Institutional approach}

Institutional theory always is one of the most influential theoretical approaches in studying policy problems (Ostrom, 2007; Anderson, 2014). According to Ostrom (2007: 37), institutions are shared concepts and they are manifested in both written and 
unwritten forms. Those shared concepts are "used by humans in repetitive situations organized by rules, norms, and strategies”. Some scholars such as Ho (2005: 2) use the term "institution" with a narrower meaning, referring to "institutional arrangements embodied in promulgated policies, formal laws, and customary rules, and the state administration”. Scott (2014: 58-59) points out three vital elements of institutions, including regulative systems, normative systems, and cultural-cognitive systems. The role of institutions is not only to distinguish between acceptable and unacceptable behaviours but also to support and empower activities and actors.

Institutional settings of the land sector refer to a wide array of issues such as the role of the State, the market, and the private sector, but "the way in which property rights and land use arrangements are structured and managed are widely accepted as being of the utmost importance” (Markussen, Tarp, and Van De Broeck, 2011). To explain land policy problems, institutional analysts are primarily concerned with the role of a nation's land regime and land tenure system (Ho, 2005; Lipton, 2009; Ingram and Hong, 2009). While "land regime" is used to describe two types of land ownership (e.g. public and private), the concept of "land tenure system" is more complicated, referring to "the terms and conditions on which land is held, used and transacted, within a particular system of rights and institutions that govern access to and use of land" (Ellickson, 1993; Reale and Handmer, 2011). A land tenure system defines legal or customary relationships among people, either individuals or groups, with respect to land: "who can use what resources for how long and under what condition” (FAO-UN, 2012: 7). Overall, the primary concerns of the institutional approach to land-taking challenges in Vietnam are 
problematic aspects of written norms such as law, rules, legislations, and the organizational structure responsible for land administration.

As in other developing nations, institutional ambiguities and inconsistencies of land legislation (e.g. laws, rules, and regulations) are among the most prominent contributors toland-taking problems in Vietnam (Vo, 2011, Ho and Mc Pherson, 2010, Mc Pheson, 2011; World Bank, 2009, 2011a\&2012, Wells-Dang, 2013). The collective ownership over land was stated consistently in the Vietnam's Constitutions of 1980, 1992, and 2013: all land belongs to the State. Based on a review of legal documents, the World Bank (2011a) pointed out that the State's absolute power over land is reasserted in key legislation such as the Constitution and the Laws on Land. Article 53 of the Constitution 1992 that is clarified by Article 4 of the Law on Land 2003, stated that the State is the representative of the people's ownership over land and the State manages land on behalf of the people who have land use rights only. As the sole representative of land ownership, the Vietnamese State has rights to determine land use purposes, land use limit and period, land allocation to land users (individuals, households, or organizations), and land conversion for development purposes. The term "people’s ownership", however, does not define specifically who is a "real owner" over a particular area of land. No guidance in the Constitution and land legislations specifies how land is managed. No specific State agency is assigned to manage land ownership. One is also unable to find instructions on who (and under what conditions) can have access to land. In addition, land legislation also does not clarify the State as a representative of the people's ownership and the State as an institution having control rights over land. As commented by Mac Pheson (2011), there is no "explicit guidance over who has to do what, when, 
where, with whom, for whom, how, and over what period to allocate and use land efficiently, equitably, and sustainably”.

Consequently, as pointed out by Lodhi (2004), Ho and McPherson (2010), and Wells-Dang (2013), while the State is the most powerful actor determining every land issue, flaws in land legislation provide various opportunities for government officials to interpret legal requirements and determine land planning in the ways they want. Land officials can determine what legal requirements mean and how they are applied. Land management is largely subject to interpretations and regular amendments under particular conditions. The unclear definition of the land regime (people's ownership) makes land access in Vietnam a highly politicized process that government officials can take advantages for economic gain and political influence. Although land acquisition is supposed to follow land use planning, what happens in practice is that both central and local authorities are able to take land whenever they need it. No clear legislation can monitor or prosecute State agencies when disputes and conflicts occur. This reality made argument for a clarification of the role of the State in land administration a main topic in policy debates before mid-2013 in Vietnam (when the revisions of Land Law were approved by the National Assembly). Public debates at that time focused on two key topics: (i) the scope of a land users' right to exploit a piece of land, and (ii) how and when the State might take the land for other purposes (Brown, 2013).

Another institutional dimension of the trend in the rise of noncompliance relates to land pricing mechanisms and land valuation methods (Suu, 2009; World Bank, 2009\&2011a). Under the CPV's rule, for most of the second half of the $20^{\text {th }}$ century, pursuing a centralized and planned economy, the Vietnamese government did not 
recognize land as a valuable good; landholders were not allowed to trade land. They instead were just able to trade assets on land. After nearly three decades of the transition towards a market economy, private ownership over land is still not recognized. Vietnam's Land Laws currently still use the terms: land users (not land owners), price for land use rights (not price for land). Though the Law on Land of 1993 recognized land price, the price system annually issued by the State does not reflect land value on the land use rights market. Although the Law on Land of 1993 also recognized land use right certificates, Vietnamese people cannot freely trade those rights in an official market. This is because there is no private ownership over land, and an official free land market also does not exist (Butler, 2009; World Bank, 2011a). In such a land regime system, methods and principles of land pricing and valuation are solely determined by the State: local governments are allowed to develop their own land price and valuation system based on a general land price framework issued every five years by the central government. Provincial People's Councils then issue specific land price systems used for compensation in each province. Land prices are calculated on the basis of profitability in cases of agricultural land or by comparing the practical land transfer price for nonagricultural land (Land Law 2013). All these characteristics lead to a perception of unfairness in land value and pricing calculations. This is because the existing land pricing and valuation methods result in a big gap between land prices offered by local governments and the real value of land on the land use right market. Studies conducted by Ho and McPherson (2010); World Bank (2009; 2011a; 2012); De Wit et al(2012) show that, even though the 1992 Constitution and the Laws on Land of 1998 and 2003 required local governments to develop land prices in line with market prices, land prices 
offered by local governments were always around $20-40 \%$ of market prices. According to the World Bank (2009 \& 2011a), the main cause of long-lasting disputes and conflicts over land-takings is that Vietnam's current land legislation, lacks proper measures to value and determine land price. As a consequence, both local governments and affected people cannot find any concrete guidance or objective standards for land valuation and pricing. Furthermore, despite its legality, there are no specific regulations on mandatory land valuation services. Land pricing and valuation, therefore, are totally determined by government agencies in charge of the implementation of land-takings, compensation, support, and resettlement.

In terms of organizational structure, Vietnam's land administration system has been criticized for its lack of capacity that results in poor policy implementation. The Ministry of Natural Resources and Environment currently is the sole government agency responsible for land administration in Vietnam. The land administration system consists of four levels associated with four levels of government: central, provincial, district, and commune. According to Land Law of 1993 that started the decentralization process in the land sector, the central government manages land for large investment projects using more than 1 ha. Most decisions on land management belong to provincial and district levels. The Land Law of 2003 further decentralized the land administration system: government at the provincial level can issue land use right certificates for organizations, religious bodies, and foreign investors while the district level of government has authority to issue these for individuals, households, and communities. Ho and Mc Pheson (2010) and World Bank (2012), however, argue that such a single department of land administration does not have enough capacity (ex. staff, budget, and authority) and 
influence to work effectively with varieties of actors in the land sector. In reality, land use planning is largely an internal government exercise characterized by unclear relationships between sectoral agencies. There is limited integration and coordination across governmental bodies. Structural problems of the land administration system not only make the efficient, equitable, and sustainable management of land resources impossible but also result in conflicts among different land use plans. The limited capacity of the land administration system is more evident inthe fragmentation of the land information management, inconsistency in records, and the insufficient capacity of district governments in policy implementation. Such a fragmented institutional system of land administration is not efficient in the current context as the development of information and communication technologies offers more useful tools for land management. While having much power in land management, the insufficient capacity of the district level leads to poor policy implementation that is closely linked to land user grievances and noncompliant attitudes.

In addition to problems associated with the land administration system, the organizational model of land-taking board also matters (World Bank, 2009; De Witt, 2012\&2013). Under provisions of the Land Law 2003, there are two types of Units for Land Compensation and Clearance. If the Land Development Organization (LDO) is a permanent organization established by the Provincial People's Committee, the Board of Compensation, Support, and Resettlement (BCSR) is temporarily established by the District People's Committee. As a public agency, activities of LDO do not confront landtaking noncompliance because LDO does not convert land for any approved investment project. Instead, it only transfers contents of land use planning to the market based on 
principles of benefit sharing between land users, investors, and the State. In contrast, land-takings conducted by BCSR confront a high possibility of policy noncompliance because BCSR's activities follow administrative regulations that do not fully respect the market mechanism. BCSR is always headed by a district government leader and consists of officials from several district departments, representatives of investors, residential community, and affected land users. Converting land for approved investment projects, BCSRs are responsible for the entire land acquisition process, from land valuation and compensation to support and resettlement. In actuality, as assessed by the World Bank (2009), such an organizational model cannot ensure the objectivity and the fairness of land valuation and compensation. This was evident in the World Bank's 2011a report that, although land valuation services provided by independent organizations are recognized by the Decree No. 17/2006/ND-CP, local governments are not required to use land price frameworks developed independently by those organizations.

As commented by Buttler (2009), Vietnam's institutional conditions in the land sector permits the State agencies to exercise absolute power over land issues while undermining the role of the market and non-State actors. Such an institutional context creates openings for the abuse of compulsory land conversion. As representatives of the State, local governments can rely on administrative decisions to appropriate land for socio-economic development projects. In other words, the general purpose of local economic development can be used as a reason to justify for non-voluntary land recovery plans. This results in an increasing trend in which compulsory land-takings are applied for commercial projects often with unclear public benefits while investors and businessgovernment alliances are groups that are most benefited from coercive land acquisitions. 
This reality explains why nearly all cases of land-taking dispute and conflict between government and land users are related to investment projects generating commercial benefits while non-commercial cases are negligible (World Bank, 2011a: 46-48).

\subsubsection{Economic approach}

The economic perspective in general views individuals as interest-maximizers whose behavior is motivated by "material self-interests"; their decisions are determined by economic rationality (Arrow, 1958; Sabatier, 2014). According to the economic approach, all policy actors and stakeholders are economically rational because they are people who are “egoistic, rational, utility maximizers” (Mueller, 1976: 395). In particular situations, both official and unofficial policy actors often weigh the costs and benefits among different options as well as their likely outcomes. In order to make a decision, economic rational actors will establish an order of preferences and select the option (s)that maximize interests (Ostrom, 2007: 30). Therefore, seen from an economic lens, profit maximization is the key motivation for land users’ noncompliance with land-taking policy decisions. Adversaries involved in land-taking disputes and conflicts pursue and protect their economic interests. Accordingly, manifestations of policy noncompliance such as disputes and conflicts over land-takings are land users' rational responses. As an economic rational actor, land users resist government's land-taking decisions because they are not satisfied with economic benefits offered by the government. Wehrmann (2008: 21) added that the economic motivation for land actors is further facilitated by shortcomings of the land market and the deficit of land institutions. This is because, even in a perfect land market, market forces alone cannot lead to socially and ecologically 
optimal land use patterns. This is evident in the case of Vietnam's land price institutions and market.

One unique characteristic of Vietnam's land governance is the co-existence of the "official" land price system issued by the State's and the "unofficial" land price system used by landholders on the free market. According to Lodhi (2004); Butler (2009); Mac Pheson(2011), Toan and Quang (2014), historically, the dual characteristic of the land market began in Vietnam in the colonial period. During the colonial time, despite the statutory rights-based property rights and title regime adopted by the French, Vietnamese self-regulating communities still heavily relied on customary land rights mode that recognized the land ownership based on occupation and community knowledge. Land holders, thus, often relied on written documents for land transactions. These mutual relationship and community pressure-based documents were then approved by local authorities. To validate claims over land, Vietnamese people were traditionally familiar with the use of personal connections within communities rather than legal entitlements. This tradition was strengthened under the Communist regime in the North from 1954 and in the South from 1975. From the early 1960s, the State became the sole actor having authority to allocate and transfer land and housing. Although private sales and transactions were not recognized, a self-regulatory land and housing market still existed. In recent years, the percentage of land transactions taking place outside the State's land tenure system is still high: around 75\% (VNCI, 2007; cited in Gillespie, 2011). Community norms and precepts are still preferred by urban residents to deal with land transactions; land laws play a marginal role in the lives of those people. This unique characteristic of land price systems makes competition for land more complex: a large 
number of land-taking noncompliance is caused by the large difference between the received compensation based on the State's land price and the real value of land that can be sold on the market.

From an economic perspective, acquiring land in a compulsory manner for economic development often cause unfairness in benefit sharing between beneficiaries (e.g. investors and local governments) and the affected people (land users). Who loses and who wins in terms of economic gains is a key cause of land-taking policy problems (Suu, 2009, World Bank, 2012, Bell, 2014). In developing countries like Vietnam, a large population relies on agriculture and land related economic activities for their livelihoods. The rapid increase in population and high demand of economic and infrastructure development make land more valuable. Vietnam's current land legislation allows both compulsory and voluntary land acquisition. As stated in the Land Laws of 2003 and 2013, compulsory land acquisition is not only applied for public purposes of national defence and security, or public interests, but is also used for economic development. Land users have to give up all or part of their land to the government once the government decides to carry out a land-taking project. Affected land users are primarily concerned with how to restore and improve their livelihoods after their land is acquired. Benefit sharing, of which economic compensation is just one form, is critical for land users' livelihood rehabilitation. A majority of scholars, therefore, view competition for landed economic interests as the most critical cause of land-taking policy noncompliance (Ho and Mc Pheson, 2010;World Bank, 2011\&2012; Kim, 2011; De Wit et al, 2012). Political aspect of land-taking problems in Vietnam is the power inequality between the two key actors: local governments and land users. Landholders are at a disadvantages 
side in struggles over land with a powerful actor - the State represented by local governments. Politically, the aim of the State in taking control of land is to advance public interests but land policy practices show that landholders always are losers in the 'competition for land” (Butler, 2009: 166). In such an unequal power structure, landtaking problems arise due to disagreements about benefit sharing.

A large literature specifically criticizes unrealistic land valuation method and low compensation as the main cause of land users' grievances and resistances. Suu (2009) and World Bank (2009), for example, provided intensive reports showing that, over the last two decades, thousands of hectares have been appropriated for purposes of urban expansion and industrial development in Vietnam. Decisions about land valuation and compensation, however, ignore market principles. Land users often received very low compensation calculated by land officials based on an unrealistic land price system issued by local governments. In addition, considering different types of land, while favouring non-agricultural land users and public and private investors (enterprises and individuals), Vietnam's existing land acquisition legislation is economically unfair to farmers. Though the value of land converted to commercial, industrial, or residential uses often increases hundreds of times, farmers often get paid at an unbelievably low compensation (World Bank, 2009\&2011a). Butler (2009) commented that the current land pricing system discriminates against poor land users and transfers wealth to wealthier investors and more powerful actors. The reason is that by keeping land price low, local governments can attract investment and prevent windfalls to land users. However, windfalls in practice can occur in many places and current policy actually transfers windfalls that can be used as additional compensation for land users, to investors. Such an unequal distribution of 
economic benefits induces more protests and refusals to land adjustments, relocations, and acquisitions. In fact, unfair land prices and unrealistic compensations are often the first reason mentioned by land users when they explain why they do not comply with local governments' land-taking decisions (Ho and Mc Pheson, 2010; Kim, 2011).

Landholders are typically offered two kinds of compensations: in-kind provision of housing and cash. Both forms of compensation, however, do not meet land users' demands: the new resettlement areas are located far from employment which make land users unwilling to move. Further, the public sector is unable to provide enough housing before the transition. As resettlement programs fail, compensation in cash increases. This kind of compensation creates more disagreements between land users and government because private investors supported by local governments often offer very low compensation. Between 1993 and 1998, the State's price of land was equal to 10-30\% of the land price on free market (World Bank, 2009). It recently was estimated that land prices in urban areas still were 40 to $70 \%$ lower than the market value (TN News, 2012). Land prices offered by the government of Hanoi Capital City are much higher than land prices adopted in other provinces. But even in Hanoi, it is equivalent to only $50-70 \%$ of the land value on the market (World Bank, 2009: 36). Only 10\% of land users responded that their compensation is close to market value (CECODES et al, 2012; cited in WellsDang, 2013). A survey of 600 land users conducted by the World Bank in Vietnam found that more than $80 \%$ of affected people are dissatisfied with land-taking compensation. Among surveyed participants, up to 38\% said they cannot use the compensation to buy other parcels of land, 28.5\% reported their reduction or loss of income, and $16.3 \%$ lost jobs (World Bank, 2011a). 
As pointed out by TriaKerkvliet (2006) and Kim (2011), while land users' rights are limited, the agrarian reform and de-collectivisation process from the late 1980s allowed local governments in Vietnam the authority to approve land transfers through which they collected fees and contributions for local services. In the view of peasants, however, the fee collection and expenditures were not transparent because they did not know how the fees were collected and how local governments spent them for public services. Also, due to the lack of public finance to deal with the high rate of rural-urban migration or infrastructure development, local governments were allowed to establish new forms of economic relationships with private entrepreneurial firms. Accordingly, local governments in exchange for public financing of public infrastructure approved private land development projects. By this arrangement, both local governments and private real estate investors benefited from current land-taking policy while the economic losers were landholders (Kim, 2011). Though compensation offered by investors was significantly higher than annual farming incomes, receivedpayments did not offset land users 'lifetime economic loses. In addition, the one-time delivery of compensation and support in cash did not fully consider non-monetary and long-time benefits (World Bank, 2009\&2011a). Another reason as described by the World Bank (2009) and Toan and Quang (2014) is that the alliances between local governments and investors was often biased to protect investors' interests. The enforcement of land-taking projects was often conducted in separate stages: land allocation for investors was not associated with compensation, support, and resettlement. Both investors and local governments believed that their responsibilities ended after they completed compensation, support, and resettlement. Affected people had no option but accepted what was determined by 
government agencies (returning land at cheap price) while investors easily obtained land with low compensation and cheap rent but then many of them left the land for unused for several years.

Loss of income, redundancy among rural labour force, and unemployment put economic pressures on land users (Van, 2006; Suu, 2009; De Wit, 2013). In the last three decades, peri-urban areas in Vietnam experienced a high rate of agricultural land change for other purposes. Some researchers such as De Wit (2013) felt that the inter-provincial competition seemingly resulted in too many industrial parks in Vietnam. While many of those parks were still empty or were not fully used, land dispossessions in large areas put a high demand on non-agricultural jobs. Therefore, according to the Vietnamese government's Decree 17/2006/ND-CP, investors and entrepreneurs who use converted land were required to employ some former land users. The situation in reality, however, is far from the government's regulations. For example, a company in Hai Duong province employed only 48 workers while they promised to recruit 11, 000 labourers. In 2004 alone, land appropriations for the government's programs made 63,760 farmers in Northern Vietnam jobless (Xuan Quang, 2004; cited in Suu, 2009). Many land users became landless people because of the government's uncontrolled land-taking projects (Tran Duc Vien, 2005; cited in Suu, 2009). For land plots left between industrial parks or infrastructure developments, land users are often unable to continue farming due to the lack of irrigation systems, pollution, or small areas. Farmers lose stable jobs, lose incomes, and face insecure livelihoods. Overall, as pointed by the World Bank (2006\& 2009), the land-taking process largely creates opportunities that benefit middle- and upper-income groups while poor land users become economic losers due to their low 
competitiveness in new living communities. Only a few groups of people have a better standard of living or become richer.

\subsubsection{Good governance approach}

From late 1990s and early 2000s, Vietnam based international organizations such as the World Bank, the Asia Development Bank (ADB), and the United Nation Development Program (UNDP) have advocated for “a good governance system” as a fundamental perquisite for dealing with socio-economic problems in developing countries. Overall, good governance is not only about the quality of government institutions but also governments' interactions with business and social organizations (Enemark et al, 2009; Deininger, Selod, and Burns, 2012). Though a good governance system is not necessarily associated with a democracy, good governance literature suggest that a developing nation cannot meet standards of good governance without some kinds of participatory institutions (Kjaer, 2004; FAO-UN, 2007; Chotray and Stoker, 2009; Enemark, McLaren, and Molen, 2009; World Bank, 2011b; Deininger, Selod, and Burns, 2012; De Wit. et al, 2012; De Wit, 2013). According to the World Bank, for example, four fundamental elements of good governance, including: civil service reform and privatization initiatives, rule of law, accountability, and transparency, are considered as fundamental indicators and policy conditions for development. For the Pacific Asia region, the ADB (1995) recommended four key values of good governance: accountability, transparency, participation, and predictability. In order to highly score with these indicators, a nation is required to develop participatory conditions. The good governance approach, thus, especially supports the transformation towards a democratic land management system in developing nations. In the land sector, several 'Land 
Governance Frameworks” developed by World Bank, FAO, and UNDP have been used as policy guidelines. Studies regarding land-taking policy problems in Vietnam, therefore, often focus on key principles of good land governance such as accountability, transparency, control of corruption, and public participation...etc. Based on quality indicators of good governance, Vietnam's current land governance system is described by researchers and international observers as a "bad system" - a system that is corrupt and willing to abuse public authority to seize land from landholders (FAO, 2007; World Bank, 2011b; Brown, 2013).

In order to improve the quality of land governance, transparency in land managementis among the first issues of concern for both domestic and international researchers. A transparent governance system characterized by the availability of information to the public and clarity about government rules, regulations, and decisions. Transparency in government decision-making and policy implementation and information disclosure can inhibit corruption among public officials and increase the effectiveness of land management (ADB, 1995). According to a research conducted by the World Bank (2012), however, provision of land related information in Vietnam still falls short of legal requirements. There have been lots of barriers preventing land users from full access to information over land issues. In another intensive study on transparency in the land sector, the World Bank (2014) examined four sources of land related information: on provincial websites, and at land offices of three levels of government (provincial, district, and commune). Research results showed that though the Vietnamese government made impressive progress in information disclosure, access to land information was largely dependent on the availability and the willingness of local 
governments' officials and leaders. The implementation of transparency rules was limited in practice. Citizens and firms reported difficulties in finding information they need. This study confirms land users' common belief that local officials' hesitation and unwillingness to provide land related information not only causes poor transparency but also reduces citizens' trust in government's land management actions (World Bank, 2009; World Bank and MIP, 2017).

Holding public institutions in the land sector accountable for their actions is another big challenge. Vietnam's governing system is featured by hierarchies and power centralization (London, 2014). Such a system is based on a scientific rationality that the central authority acts as the supreme source of power and delegates functions and tasks to subordinates. Each level in this structure performs differentiated functional tasks, people and sub-organizations in the lower tiers are accountable to those above them (Huang, 2009). In reality, however, State institutions in Vietnam are characterized by fragmentation - "the lack of clear hierarchy and assignment of roles and responsibilities both within the central government and between the central government and provinces...Horizontal and vertical fragmentation of power has resulted in overlapping mandates with conflicting rules and decisions (World Bank and MPI, 2017: 31). Because of the overlapping of responsibilities among Vietnam's land authorities, land users sometimes do not know exactly which government agencies are responsible for their land concerns. As a result, land users' claims and petitions may go around local governments' administrative agencies. Even if land petitions are transferred to local courts, private parties such as land users cannot expect very much from courts because in such a situation, decisions often are pushed back to government officials. Local government 
directives will be used by courts to make final decisions that can be justified as a protection of the State benefits (Gillespie, 2014; World Bank, 2011a). In other words, because of hierarchical accountability and unclear functions among land management agencies, it is very often that land users are unable to find evidence and explanations for land authorities' decisions. There are no checks and pressures to compel the transparency, fairness, and accountability of decisions over land. This reality accounts for a fact that most of complaints concerned land-takings sent to government agencies remain unsolved (Toan and Quang, 2014).

Numerous studies conducted by both Vietnamese and international researchers and organizations such as Denmark Embassy et al; World Bank; NEU and UNDP also reported land related corruption as a pervasive problem. From late 1980s, according to Wells-Dang (2013), a noticeable characteristic of land conflicts between land users and local governments was that those conflicts were viewed as peasants' response to corruption in the land sector. In the eyes of research participants, corruption in land management was "the biggest and most frustrating issue in our society". An analysis of articles between 1999 and 2006 on the "Youth Newspaper", conducted by Kim (2011), found that the majority of articles about land issues portraying local government officials as "greedy and corrupt individuals who took advantage of their position and did not follow the official regulations". While most local people were still living in economic hardship, land corruption was believed as the only mean by which government officials can have a much higher living standard. According to Embassy of Denmark et al (2011), World Bank (2011a, b, \& 2012), corruption mainly happened with the issuance of land use right certificates and in land acquisition/allocation. This is because current land 
administration rules and procedures allow local land officials to intentionally create difficulties or delay administrative procedures. Land users, therefore, often have to pay bribes in order to get their land claims solved quickly. Lodhi (2004) went further as arguing that the main cause of local unrests and uprisings is the abuse of authority and land related corruption among local officials. Since compensation was based on the value of economic production, local authorities were encouraged to assist land developers to get a low price. The formation of local government-investors alliances was confirmed by Mr. Dang Hung Vo (2011) - a high-ranking land official, that the existing land conversion policy created endless chance for corruption, benefits local governments and private investors while underestimated land users' interests. Since land officials have a decisive role over land issues, corruption can take place in all land management activities and land transactions (Denmark Embassy et al, 2011). This reality is confirmed by the World Bank and GIV (2012) that police officers and land officials were the most corrupt groups in the Vietnam's government system.

Despite some progress in creating conditions for citizen participation in governance, previous studies suggest that limited public participation in land administration plays a significant role in exacerbating land-taking policy noncompliance (World Bank, 2009\&2011a, b \&2012; Kim, 2011; Wells-Dang, 2013). According to good governance perspective, public participation is critical to land administration because it allows land users and stakeholders to exercise their rights and contribute to effective land management. However, as pointed out by De Wit et al (2012), despite the adoption of the Grassroots Democracy Resolution in 1998, the Vietnamese people have limited formal means for voicing dissent or participating in the policy process. There is a lack of power 
for non-government actors to participate in decision-making, even at local level of governance. This is in part because non-government grassroots groups and social protests are not allowed in nations ruled by a One Political Party System (Huang, 2009). Specifically, though the Law on Land of 2003 required that land use planning must be disclosed to the public, no specific guidance can be used to determine who should be consulted or how land disputes should be resolved (Adams, 2012; cited in Wells-Dang, 2013). Current legislations allow community members to participate in land use planning at the commune level only. At higher local levels, land use planning requires the participation only of the People's Council. Policy noncompliance, thus, is an inevitable consequence of a reality that: "if the project fitted the master plan and had been approved, the ward, district, and city government bodies generally help the developers to attain the land use right at low price from the current users” (World Bank, 2009: 44; Kim, 2011).

Despite having representatives in Board of Compensation, Support, and Resettlement (BCSRs), voices of local communities, social associations, and affected people play only a marginal role in land-taking policy implementation (World Bank, 2009: 44). In actuality, local people can discuss land issues at commune-level meetings but very few decisions can be made at those meetings. A survey of public participation found that only $22 \%$ of respondents have an opportunity to make comments about local land plans, and only two out of five reported that their responses had been taken into consideration (Oxfarm, 2012d; cited in Wells-Dang, 2013). Based on a case study in VungAng Economic Zone (Ha Tinh Province), De Wit et al (2012) commented that despite the ruling Party's Grassroots Democracy Resolutions that allow the people to inspect and supervise the operation of socio-economic development projects, citizen 
participation in the policy process is very poor. Community members were not directly represented in Committees such as Committee of Land Valuation, Compensation, and Resettlement; Harmony Committee; Propaganda Committee; and Citizen Monitoring Committee. Kim (2011) and Wit et al (2012), asserted that Mass Organizations in Vietnam such as Peasant Union, Youth Union, Women Union, and the People’s Council "ultimately side with the State, rather than the people”. Mass organizations are not truly institutions of "civil society" which can critically interact with the State. They are instead dependent on the Vietnamese State and operate as advocacy agencies to encourage the people's acceptance of the State's policy decisions.

\subsection{Research Gap Analysis}

\subsubsection{Critiques of existing theoretical explanations}

Despite having widespread influence, the institutional approach is unable to explain why within the same commune and adopting the same procedures, local governments achieve different levels of implementation effectiveness. In other words, variations in target group's noncompliance indicate that land-taking policy noncompliance is not only related to institutional conditions. Policy literature suggests that, on the one hand, while institutional conditions always play a prominent role, reforms of land institutions alone are not enough for government to effectively deal with land policy problems, including policy noncompliance. Based on a wide survey of land problems in the developing world, for example, Wehrmann (2008) argued that conflicts over land can take place anywhere regardless of a nation's institutional setting. This argument is supported by Gillespie, Hualing, and Nghia (2014): their examination of land acquisition policy literature from Vietnam's neighboring countries such as China and 
Cambodia showed that legal and administrative reforms are insufficient to solve landtaking problems. This is because, globally, land institutions are not the only factors affecting policy compliance or noncompliance. On the other hand, considering Vietnam's current politics and policy context that is featured by "a single party system" (the Vietnamese Communist Party as the sole ruling political party), reforms of the policy's institutional design will be limited by the Communist party's ideological values and beliefs. That is, the public ownership and the State's control over the land sector is a core economic - political principle. Such a political and policy context not only limits institutional changes of the land-taking policy but also makes improvements of policy implementation and governance a more realistic strategy in short term period in order to increase land users’ policy acceptance.

The economic approach of land-taking policy noncompliance is correct when pointing out that rational actor will select the best option (s) among their alternatives to maximize economic interests. Conflicts between land users and government over landtakings are first and foremost because of unfair land prices that result in too low compensation. However, while the key assumption above is applicable to market situations, it could be challenged in non-market contexts. As argued by Simon (1955), Williamson (1979), Mintz (2005), and Denhardt (2011), the economic rational explanations do not take into account the influence of non-economic constraints such as psychological factors to policy target groups when they have to make decisions in nonmarket situations. The concepts of cost and benefit are not only limited to economic interest. It also includes time and resource devoted to establishing and maintaining relationships or an individual reputation for being reliable and trustworthy. As a result, 
non-economic factors might motivate actions that do not generate maximized interests. In short, an important shortcoming of the economic explanation to land-taking problems is that it almost ignores non-economic contributors. Therefore, dealing with target groups' noncompliance in land-taking policy implementation is not simply a matter of offering them the best economic benefits. Also, as argued by Brinkerhoff and Crosby (2002: 6) and Stone (1997), policy-making and implementation are conducted in political communities (e.g. country or state/province). Each community has its own standards to set goals, define problems, and justify policy solutions. As each policy is being implemented, it is affected by the unique contextual characteristics of the political community. This argument is well documented in policy literature that target groups' motivations to comply or not comply with a policy might be influenced by various factors (Meier \& Morgan, 1982; Winter and May, 2001; Brinkerhoff and Crosby, 2002; May, 2004 \& 2005; Tyler, 2006; Levi and Sacks, 2009; Jones, 2010; Im et al, 2012).

The governance approach to land-taking problems that advocates for market factors and modern democratic elements such as rule of law, public participation, accountability, and decentralization of the decision-making process, faces contextual barriers. Vietnam now is a developing nation led by CPV as the only ruling party; the governing-structure is still unitary and hierarchical in nature; and the Leninist modelbased Party-State system continues to control fundamental sectors of Vietnam's economy and society (Huang, 2009). More specifically, over the last three decades, reform process (Doi Moi policy) has mainly resulted in the deconcentrating of the Vietnam's administrative system while decision-making power remains centralized (De Wit et al, 2012). This maintains CPV and State agencies as the most powerful actors in public 
governance while non-government actors and other underdeveloped civil society forces still play a limited role. State's control over the society and government intervention in the economy, the immature of civil society, and the lack of representative and participatory institution, therefore, make recommended improvements towards a democratic governance system largely influenced by Western concepts unrealistic in Vietnam’s current context(Beresford, 2008; De Wit et al, 2012; London, 2014, World Bank and MPI, 2016; TriaKerkvliet, 2018). This argument is supported by international scholars who assert that the development of democratic elements in developing countries face distinct challenges such as the lack of democratic culture and civil society, poverty and pressure for immediate results, and the lack of institutional infrastructure (Denhardt, Terry, Delacruz, and Andonoska, 2009). In other words, level of the nation's development, governing tradition, and current policy context encourage efforts to search for a new alternative approach that is appropriate to Vietnam's socio-cultural traditions and current political-institutional conditions.

\subsubsection{Research opportunity}

As reviewed above, in searching for explanations of land-taking problems, previous studies pay too much attention on economic and institutional aspects of the policy, capacity of local governments while action aspects of policy implementation and governance is still understudied. As an unexpected policy outcome, theoretically and practically, land-taking policy noncompliance might relate to different elements of the policy process - a system that includes mechanisms and procedures to translate 'policy ideas” into actual policies (Anderson, 2011; Birkland, 2011). The creation of public policies involves two main activities: policy formulation and design (responsibility of 
political leaders), and policy implementation carried out by public bureaucrats (Mint, 2012: 285). Different roles of political decision makers and bureaucrats in the policy process might create a wide gap between policy makers' intents and preferences and policy implementers' attitudes and behaviors. In other words, policy implementers might ignore policy goals and act to maximize their own interests that affect policy outputs and policy outcomes. As a result, policy effectiveness is not only related to the quality of policy formulation and design, organizational resources, but also government officials' actions in policy implementation. Process aspects of policy implementation, therefore, need to be concerned in securing target groups' compliance (Salomon and Elliot, 2002, Howlett, 2011; De Wit et al, 2012; De Wit, 2013; World Bank, 2011, 2012, \&2014; Fu and Gillespie, 2014).

A policy cannot succeed in changing target groups' behaviors without policy legitimacy - an important element that is able to convince all actors and stakeholders that the policy is necessary, vital, and worth pursuing (Brinkerhoff and Crosby, 2002). Theoretically and practically, policy legitimacy is not only dependent on how a policy is made and for what purposes but also on ways of executing it (Birkland, 2016). This requires attention on interactions and relationships defined by policy tools between government and non-government actors in the policy process. Lascoumes and Gales (2007) convincingly argue that the effectiveness of policy implementation is largely dependent on the choice of tools; policy tools might determine policy effectiveness:

"Public policy is fundamentally conceived as pragmatic - that is, as a political and technical approach to solving problems via instruments; that it views such instruments as 'natural'; they are viewed as being 'at our disposal', and the only questions they raise 
relate to whether they are the best possible ones for meeting the objectives set; and that the central set of issues is around the effectiveness of instruments” (Lascoumes \& Gales, 2007).

Over the last two decades, the rise of new policy instruments has resulted in policy researchers' belief that our society is transitioning to a new era of public governance. As a key component of new governance perspective, the tool approach to implementation problems advocates for a shift in the "unit of analysis" from public programs/policies and public agencies to governing instruments. This dissertation, therefore, is motivated by a research opportunity: looking at tools used in land acquisition in order to generate new insights and develop an additional explanation of land users' noncompliance over land acquisitions. In the following section, the researcher presents the theoretical framework of tool approach in detail.

\subsection{Tool Approach to Policy Noncompliance: A Theoretical Framework}

Though qualitative researchers are not required to start with a theoretical framework, it is more helpful if a study is guided by a theoretical lens (Maxwell, 2013: 49). With a theory in mind, the researcher can develop right research questions and collect relevant data to address those questions. In this qualitative study, specifically, theory is not used to develop hypotheses as in quantitative designs. It instead serves as an “anchor” that makes the researcher focused on the research interest. The researcher's attention is drawn to phenomena or events, and relationships that might otherwise be neglected or unnoticed. The theoretical framework will also help the researcher put together the data that seem irrelevant or unconnected and make sense of what will be observed. 
The focus of this study is potential linkages between implementation tools and policy noncompliance. Data collection and analysis, thus, will be driven by the theory of policy tools. In following parts, the researcher will first provide an overview of three policy implementation regimes and the tool approach, then define the policy tool/instrument, and clarify what types of policy tools/instruments are available for government officials. However, defining the concept of "policy tool" and developing a typology of government's tools are not easy tasks. This is because there are many types of policies with complex features that need to be considered if we want to have a complete understanding of "government tools/instruments". The critical review below is an effort to incorporate different viewpoints into a simple picture of policy tools.

\subsubsection{Three regimes of public policy implementation}

Osborne (2010) used the term "implementation regime" to refer to overall field of design and delivery of public policy and public services. Accordingly, the public sector has passed through three implementation regimes associated with unique implementation mechanism and tools. Three implementation regimes include: (i) Public Administration, emerged in late $19^{\text {th }}$ century and lasted until late 1970s; (i) New Public Management that appeared from the yearly 1980s to late 1990s; and (iii)New Public Governance, arose from the start of the $21^{\text {st }}$ century onwards.

Under the traditional public administration regime, public officials and agencies play decisive roles in the success of policy implementation (Pressman, Wildavsky, and Aaron, 1973; Sabatier, 1986; Shafritz, Russell, and Borick, 2012). Aiming at efficiency as a key criterion, the administrative tradition places administrative procedures and the bureaucratic system at the center of public governance. As a result, "top-down" and 
"bottom-up" approaches to policy implementation are the two most influential approaches within the public administration regime (Hill and Hupe, 2009; Sandfort and Moulton, 2015). Top downers argue that policy success largely depends on the quality of policy design. Based on a causal theory of change that links "initial conditions" with “predicted consequences”, top-downers assert that if a policy outcome is not realized, it is because of an infeasible link or wrong theory of change that results in a mismatch between means and ends. Policy implementation fails because the policy lacks clarity or guidance for implementers. Policy success is largely determined by policy formulation and design. In contrast, bottom-uppers emphasize the role of various implementation actors such as street-level bureaucrats who interact at the local level on problems. Policy outcomes are mainly dependent on the capacity of "street-level bureaucrats" who carry out the policy. In order to create conditions that facilitate expected policy outcomes, the experiences and insights of local implementers need to be included in the policy design process.

Despite its domination in public sector in a long time, the public administration perspective has increasingly been challenged by modern governance practices. A key weakness of both "top-down" and "bottom-up" approaches, for example, is the unrealistic assumption that policy implementers are provided by decision-makers with clear goals and directions (Howlett et al, 2009: 165). In reality, policy implementation is not a simple stage. Implementers might have to deal with variety of unexpected factors that can determine policy success or failure (Hill \& Hupe, 2002\&2009). Another prominent shortcoming of the public administration regime over policy implementation is the over-confidence in administrative procedures to ensure equality of public treatment 
(Osborne, 2010). In actuality, public resources are never sufficient to meet public demands. Government intentions are influenced by many factors that might define policy implementation success or failure. In other words, public policy success is hardly achieved without the involvement of actors and the accumulation of resources outside the government system. Limitations of public administration regime motivated the emergence of new public management and new public governance perspectives.

From late 1970s andearly1980s, the governments were not the only actor providing public goods. Instead, varieties of non-governmental organizations (private actors) involved in policymaking and policy implementation. Inter-organizational and inter-sectoral activities, networks, coalitions, contractual relationships, collaboration between formal and informal actors... became main features of public management. Emerged from that time, the term "governance" in the public administration and policy disciplines referred to "the rules of collective decision-making in settings where there are a plurality of actors or organizations and where no formal control system can dictate the terms of the relationship between these actors and organizations (Chotray and Stoker, 2009; Bivir, 2011). This perspective led to the rise of the new public management (NPM) that took the market model as the standard for measuring government success (Hood, 1995; Osborne, 2006 \& 2010). New public management regime, therefore, supports an expanded role of private and nonprofit sectors in public policy implementation and service provisions. Proponents of NPM regime believe that citizens' needs are better met by the dynamic involvement of non-government actors in public policy process. Privatesector-management techniques should be applied to public service delivery and policy 
implementation. Efficiency, effectiveness, and responsiveness, therefore, are among the most prominent emphases of the new public management.

However, the new public management perspective has been criticized for its interorganizational focus in an increasingly plural world and for its emphasis on the role of management techniques learnt from the private sector. Since management tasks in the public sector are not simple as in the private sector, those techniques have been becoming out of date (Osborne, 2006). NPM has also been challenged for its limitations in building political trust and legitimacy among citizens (Morgan and Shinn, 2014). Economic factors such as profit, market share, or return on investment cannot be used as common denominators to enhance citizens' trust in political institutions. Also, efficiency, effectiveness, and responsiveness are not enough to determine the legitimacy of political institutions and processes. The sustainable development of a political community requires the incorporation of elusive values such as equity, protection of right, and transparency into public governance. These political elements that are undermined in NPM show weaknesses of NPM and leads to the movement of new public governance.

From 1990s, a movement of new public governance (NPG) placed political values at the center of governance debate (Osborne, 2010; Morgan and Shinn, 2014). Proponents of new public governance perspective argue that building legitimacy and trust among citizens in their political institutions should be the ultimate purpose of public governance. Political values such as political trust play a fundamental role in determining the legitimacy of political institutions, processes, and outcomes. The goal of government, thus, is not just improved efficiency, responsiveness, or effectiveness in policy implementation and provisions of public services. Government, in addition, should aim to 
promote the larger common good that can strengthen citizens' trust in government and the legitimacy of government's actions. The new public governance perspective, thus, emphasizes the creation of government processes in order to produce implementable agreements among various stakeholders whose legitimate values might be very different but need to be preserved and integrated into the larger public good. Instead of focusing on official actors, formal rules and procedures, and political factors, the value based new public governance regime views public policies as "dynamic combinations of purposes, rules, actions, resources, incentives, and behaviors leading to outcomes that can only imperfectly be predicted or controlled” (Brinkerhoff and Crosby, 2002: 5). Policy implementation, therefore, is a multi-level and multi-actor system in which nongovernment players and varieties of other factors interact in a decentralized structure that influence policy outcomes. This complex process of policy implementation requires collaboration among public, private, and nonprofit actors in order to deal with complex public problems.

New public governance, thus, advocates a collaborative approach to the provision of public services, working with partners within and across public, private, and nonprofit sectors. This perspective results in a shift in focus from agencies and programs to policy tools to sustain network agreements (Salomon, 1981\&2002; Osborn, 2006\&2010; Morgan and Shinn, 2014). Accordingly, the main function of policy tools is to coordinate various actors in a multi-level system of policy implementation and governance. As argued by Salamon (2002) and Gales (2011), the important role of policy instruments/tools is that they can define the relationship between the government and the governed, and greatly affect policy outcomes. Policy makers and implementers, therefore, 
need to develop policy mixes that can incorporate socio-political-institutional factors into technical policy options. Rather than selecting policy priori among different alternatives, policy makers should consider the guiding role of tools in policy development and implementation.

\subsubsection{The evolution of tool approach in policy implementation}

Policy tools as a theoretical approach was initiated by researchers such as Anderson (1971) and Salamon (1981). The theoretical framework originally first and foremost was concerned with "what government uses rather than what happens inside government system or what government does” (Hood, 1983). Linder and Peter (1989) put concerns with policy instruments into a broader context of policy design. One of the main research interests on policy instruments at that time was: how governments attempt to perform their tasks? By what means do they rely on to reach policy goals? In the 1990s and early 2000s, the tool argument became more powerful due to the proliferation of public actions used to address public problems (Salamon, 2002: 1-3). In contemporary world, as described by Salamon, public services or goods are not only directly provided by government bureaucrats. A wide range of third parties such as commercial banks, private universities, private corporations and firms also gets involved in public actions. A variety of new government tools emerge and increasingly play an important role in public good delivery. In his classic book on government tools, Salamon (2002: 4-6) wrote: "What is distinctive about many of the newer tools of public actions is that they involve the sharing with third parties actors of a far more basic governmental function: the exercise of discretion over the use of public authority and the spending of public funds....The proliferation of these new tools of public action has created new 
opportunities to tailor public action to the nature of public problems”. This new trend makes "indirectness" becomes a common feature of governing tools in modern era. Since government agencies increasingly operate in complex and interdependent relationships with third party partners, public officials are required to develop collaborative relationships and share public authority with non-government actors in order to implement public policies and programs. As an alternative approach to deal with public problems, the policy tool approach emphasizes the "how" question (Brinkerhoff and Crosby, 2002; Salamon, 2002; Agranoff and McGuire, 2003; Gales, 2011; Sandfort and Moulton, 2015; Cooper, 2018).

From the 1990s, therefore, the tool approach was labeled as "the third generation of policy implementation research" that moved beyond both the top-down and bottom-up approaches (Howlett et al, 2009: 164). Tool supporters argue that policy studies in the $21^{\text {st }}$ century should start by defining a policy in terms of tools rather than in terms of areas or fields. Instead of focusing on an individual program or even a collection of programs and government agencies, policy researchers should concentrate on the tools of governments, on techniques of social intervention. Instead of looking at what happens inside government and what government does that may lead us to an endless list of problems, as ever argued by Hood in 1983, the tool-based approach helps researchers, policy makers and implementers reduce the complexity of modern government's operations and focus on some basic elements that link government's wishes and fulfillment. Under the tool lens, the public policy process becomes simpler and easier to understand. Like a dentist who can fix a dental problem or a carpenter who can address problems around the house with a tool box, complex policy problems can also be 
effectively fixed if we consider the role of tool choice and use (Lascoumes and Gales, 2007; Gales, 2011; Margetts and Hood, 2016).

The evolution of theories of public governance, regimes of policy implementation, and recent developments of the tool approach suggest a shift to focus on policy tools that might offer new insights regarding land-taking problems in Vietnam.

\subsubsection{Defining policy tools}

A variety of policy tool definitions can be found in the public policy literature (Dodds, 2013: 23; Margetts and Hood, 2016). In one of very first publications on government tools, Salamon and Lund (1989) defined tools as "a method through which government seeks a policy objective”. Bemelmans-Videc,Ray\&Vedung (1998: 3) conceptualized policy instruments as "the set of techniques by which governmental authorities wield their power in attempting to ensure support and effect or prevent social change”. Howlett, Ramesh, and Perl (2009) and Mint (2012) viewed actual means or devices used by governments to address problems and implement solutions as policy tools. From a sociological perspective, Lascoumes and Le Gales (2007) provided an indepth analysis of policy instruments and the instrumentation. In addition to distinguishing between "instrument”, “tool”, and "device”, the authors placed a strong emphasis on the relationship between State and society in their definition. Accordingly, the "instrument' is a type of social institution while the "technique" is a concrete device that operationalizes the instrument, and the "tool' is viewed as a micro device within a technique: "Policy instrument constitutes a device that is both technical and social, that organizes specific social relations between the state and those it is addressed to, according to the representations and meanings it carries. It is a particular type of 
institution, a technical device with the generic purpose of carrying a concrete concept of the politics/society relationship and sustained by a concept of regulation" (Lascoumes and Le Gales, 2007).

Beside short and simple definitions, some policy scholars such as Salomon, Howlett, and Cooper help readers to be aware of important differences between policy mechanisms and policy tools. In his influential book on government's tools, for example, Salamon (2002: 19) presents a definition that is more about policy mechanism: "policy instrument is an identifiable method (technique or means) through which collective action is structured to address a public problem”. Salamon's general definition is further clarified by Cooper (2018) when he argues that policy mechanism answers the question of "how to put a policy into practice" while policy instruments address the question: by what methods/techniques or means? In other words, policy mechanisms such as coercive regulations, direct and indirect government will determine how or ways policy tools work and policy instruments such as executive orders, rules, or contracts refer to what legal devices will be used to put those mechanisms into operation (Cooper, 2018: 4).

In this study, in addition to a differentiation between policy mechanisms and policy tools, the two terms of policy instruments and tools are used interchangeably. Both refer to specific devices of interventions such as government organizations, law, tax, regulations...that governments can use to change a given set of social interactions. This study also adopts a sociological perspective to policy tools. Accordingly, "public policy instruments are a form of power. Instruments are not neutral: they structure public policies and their outcomes; they have impacts on their own, independent from the policy goals; and they structure the mode of governance” (Le Gales, 2011). 


\subsubsection{Types of policy tools}

Constructing typologies of policy tools was an early interest of numerous scholars such as Cushman (1941), Dahl and Lindblom (1953), Lasswell (1958), Lowi (1966), and Anderson (1971). However, classifying tools and instruments or developing a typology of policy tools is no simple task. This is because, as argued by Linder and Peter (1989), academic scholars and public policy makers might greatly vary in their understandings and conceptualizations of government tools. Additionally, Salamon (2002: 21) comments that "tools have multiple features and can be defined at any of a number of levels of abstraction”. The multidimensionality of policy tools, thus, makes the task of describing and sorting them complicated. Unlike tools in physical world, "tools of public actions rarely appear in pure form...Rather, they come bundled in particular programs, many of which combine more than one tool” (Salamon, 2002: 21). This results in difficulties in identifying "which features are truly the defining features, and which are the design features that can vary with particular manifestations” (Salamon, 2002: 21).The complex nature of public actions and complicated tool dimensions suggest that any single facetbasedtypology of tools would be very disputable.

The challenge of policy tool classification is evident in policy literature where various features, aspects, or dimensions are used by researchers to identify and categorize tools. Those defining feature might be the degree to which they affect actors inside or outside government; the extent to which they involve government expenditure; intended outputs, or coerciveness and directness of instruments (Dodds, 2013: 23-32).In one of very first book on "policy tools”, for example, Hood (1983) split government’s tool-kit into two simple groups: (i) Detectors - instruments that government uses to collect 
information; and (ii) Effectors - tools that government relies on to make an impact on its citizens. Hood then introduced eight basic tools based on four types of resources, including: (i) Nodality - the use of information; (ii) Treasure - the use of money; (iii) Authority - the use of legal powers; and (iv) Organization - the use of formal organizations. Considering strategies of intervention, McDonell and Elmore (1987) divided government tools into four types: (i) Mandates - rules constraining behaviors, (ii) Inducements - funds to incentivize certain behaviors, (iii) Capacity Building - funds enabling agencies to act; and (iv) System Changing - organizational changes to agencies in order to implement policies. In 1990, Schneider and Ingram presented an output-based tool categorization aiming at behaviors that government programs seek to modify. This categorization consists of five tool types: (i) Authority Tools, (ii) Incentive Tools, (iii) Capacity Tools, (iv) Symbolic Tools, and (v) Learning Tools. More simply, introduced by Bemelmans-Videc,Ray\&Vedung (1998), policy instruments can be classified into three categories: (i) Economic Means, (ii) Regulations, and (iii) Information (they called: carrots, sticks, and sermons, respectively). Howlett, Ramesh, and Perl (2009) went further when they offered two models for identifying government devices used to address public problems:(i) “Economic Models” and (ii) "Political Models”. Both models view the coerciveness as a fundamental criterion for differentiating tools. Though the two models favor non-coercive tools, they differ in how to avoid using the most coercive policy instruments.

A disputable characteristic of tool typologies as described above is that researchers often rely on a single criterion to define and differentiate policy tools. In his intensive book on tools of government, therefore, Lester Salamon (2002: 24) presents an 
alternative approach for tool classification. He argues that, due to the complexity of tool features, instead of focusing on a single dimension that can work for all purposes, we need to consider a range of aspects that can be used to compare different tools. Based on common criteria of policy assessment such as efficiency, effectiveness, and equity, Salamon suggests four tool dimensions to "clarify the full matrix of choices that policy makers face and the significant tradeoffs that exist among them”. Those four key dimensions include: (i) Degree of Coerciveness; (ii) Degree of Directness; (iii) Degree of Automaticity; and (iv) Degree of Visibility. Each dimension can be used to group policy tools and assess them in terms of effectiveness, efficiency, equity, manageability, and legitimacy.

In this study, the researcher uses a tool typology as summarized in table 2below to conduct the case analysis. The tool matrix is adapted from key books and book chapters on "Policy Tools and Policy Design” written by Hood (1983), Salamon (2002), Howlett (2011), Dodds (2013), and Cooper (2018). Each policy mechanism consists of various tools or devices used by the government to transfer policy ideas into actions in practice.

- "Direct/Indirect Government" refers to the involvement of the government in the provision and delivery of public goods/services. If direct government is defined by the provision and delivery of public goods/services based on public agencies, employees, and budget, the indirect government mechanism allows non-state actors, in exchange for money, to deliver certain public goods/services on the government's behalf (Salamon, 2002: 282; Howlett, 2011: 64). Direct government-based tools include organizations such as line departments or State-owned enterprises that rely upon the use of government institutions, personnel, and budget to achieve policy goals. 
- "Authority" as a policy mechanism refers to the use of the real or perceived threat of sanctions enforced by the government in order to guide policy targets undertake activities in directions preferred by the government. A unique characteristic of the authority-based mechanism is that it allows the government to rely on coercive power of the State to achieve policy goals (Howlett, 2011: 83). Coerciveness, therefore, is the most important feature of authority-based instruments such as laws, regulations, executive orders, or administrative rules.

- Financial and financial-equivalent incentives as a policy mechanism refers to the use of finance-based resources in order to affect targets' behaviors. The government might offer financial/treasure incentives for desired activities while the imposition of financial costs aims to control discouraged activities (Howlett, 2011: 101). Grants, vouchers, cash transfer, subsidies, land are examples of finance-based tools.

- Information as a policy mechanism refers to ways policy makers and implementers "inform an audience of target actors about a policy issue or pattern of behavior to influence what people think, know, or believe when they engage in target behavior" (Salamon, 2002: 218). In other words, by information mechanism, the government intendedly communicate knowledge and information to target groups in order to change their behaviors. Common information tools include proclamation, public hearings, information campaigns, public posters, propaganda...etc (Howlett, 2011: 115).

\subsection{Summary of the Chapter}

Over the last three decades, land-taking disputes and conflicts have become a wicked challenge in Vietnam. The increase of land-taking incidents indicates a policy noncompliance in which landholders resist government's land acquisition plans. 
Implementers increasingly confront with disobedience among affected landholders. To some extent, the policy fails in changing target groups' behaviors.

As manifestations of policy noncompliance, land-taking disputes and conflicts have attracted numerous researchers that can be grouped into three influential approaches: (i) institutional approach; (ii) economic approach; and (iii) good governance approach. To explain noncompliance with land acquisition, institutional approach focuses on the institutional design of land-taking policy. Land legislation, in the eyes of institutional theorists, play the most important role. In order to reduce noncompliance with land acquisition, institutional approach supports reforms of land legislation and the administration system in the land sector. From an economic approach, researchers point out problems of benefits sharing resulted from the implementation of land-taking policy. Accordingly, because of unfair land prices and unrealistic compensation, affected landholders become losers. They resist land acquisition because they do not benefit from the policy. To minimize policy noncompliance, economic approach argues that the State should reform methods of land valuation, so that landholders can have fairer compensation. Economic perspective also advocates for a market mechanism-based policy implementation in which landholders can protect their land related interests by trading land with investors. As the third influential explanation, good governance approach centers on the quality of Vietnam's land governance system. Poor scores on key indicators of the good governance framework such as transparency, accountability, corruption prevention, and public participation are considered as significant contributors to noncompliance with land acquisition. Reform of governing system in the land sector, 
thus, is required to improve the quality of land governance, and minimize land-taking policy noncompliance.

Three influential approaches above, however, tend to largely ignore process/action aspects of policy implementation that importantly contributes to policy acceptance or noncompliance. The research argue that institutional and economic factors are insufficient to understand land-taking noncompliance. Many reform recommendations suggested by the good governance approach are not appropriate, considering current context of Vietnam. This study, thus, proposes to contribute to landtaking policy literature by focusing on policy tools used by implementers to change target groups' behaviors. The researcher controls the role of economic, institutional, and governance factors, and argue that implementation tools that define interactions and relationships between implementers and target groups might play a role in noncompliance with land acquisition. The government can reduce policy noncompliance by changing tool choice and use.

Policy tools are devices used by implementers to transfer policy ideas into actions in practice. Policy success or failure not only depends on policy formulation and design but also subject to the quality of policy implementation - actions of implementers in real context. An action focused study of noncompliance with land acquisition, therefore, requires a discovery of policy tools. Adopting a tool approach, this study aims to explore implementers' tool mixes, discover strengths and weaknesses of each tool, examine how tools are combined in tools mixes, its consequences, and potential linkages between implementation tools and landholders' noncompliance over land acquisition. 
Table 2: Matrix of Policy Mechanisms and Tools

Sources: Salamon (2002); Howlett (2011); Dodds (2013); and Cooper (2018)

\begin{tabular}{|c|c|c|}
\hline \multirow{2}{*}{$\begin{array}{c}\text { Categories } \\
\text { of Policy } \\
\text { Mechanisms }\end{array}$} & Policy Mechanisms & Policy Tools \\
\hline & How to put the policy into practice? & $\begin{array}{c}\text { By what } \\
\text { methods/means? }\end{array}$ \\
\hline $\begin{array}{l}\text { Direct } \\
\text { Government }\end{array}$ & $\begin{array}{l}\text { The delivery or withholding of a good or } \\
\text { service by government employees. } \\
\text { Government plays a direct role in } \\
\text { providing goods or services for the } \\
\text { necessities of life and the pursuit of } \\
\text { happiness. }\end{array}$ & $\begin{array}{l}\text { e.g. Government } \\
\text { Agencies; Government } \\
\text { Loan; Government } \\
\text { Corporation; } \\
\text { Government Insurance }\end{array}$ \\
\hline $\begin{array}{l}\text { Indirect } \\
\text { Government }\end{array}$ & $\begin{array}{l}\text { A business arrangement between a } \\
\text { government agency and a private entity in } \\
\text { which the private entity promises, in } \\
\text { exchange for money, to deliver certain } \\
\text { products or services to the government } \\
\text { agency or to others on the government's } \\
\text { behalf. }\end{array}$ & $\begin{array}{l}\text { e.g. Government } \\
\text { Insurance; Contract; } \\
\text { Grant; Loan Guarantee; } \\
\text { Public-Private } \\
\text { Partnership (PPP). }\end{array}$ \\
\hline Authority & $\begin{array}{l}\text { Rules that identify permissible and } \\
\text { impermissible activity on the part of } \\
\text { individuals, firms, or government } \\
\text { agencies, along with accompanying } \\
\text { sanctions or rewards, or both }\end{array}$ & $\begin{array}{l}\text { e.g. Statutes; } \\
\text { Legislations; Voluntary } \\
\text { Regulations; Treaty, } \\
\text { Executive Orders, } \\
\text { Decrees, Circulars... }\end{array}$ \\
\hline $\begin{array}{l}\text { Treasure/ } \\
\text { Financial } \\
\text { Incentive }\end{array}$ & $\begin{array}{l}\text { Policy makers use prices or other market } \\
\text { mechanisms to create treasure/financial } \\
\text { incentives for individuals to change their } \\
\text { behavior in ways that reduce social harms } \\
\text { or secure benefits for society at large. }\end{array}$ & $\begin{array}{l}\text { e.g. Vouchers; Grants; } \\
\text { Subsidies; User Fees; } \\
\text { Tax Expenditures. }\end{array}$ \\
\hline $\begin{array}{l}\text { Public } \\
\text { Information }\end{array}$ & $\begin{array}{l}\text { Policy makers inform an audience of } \\
\text { target groups about a policy issue or } \\
\text { pattern of behavior to influence what } \\
\text { people think, know, or believe when they } \\
\text { engage in target behavior. People change } \\
\text { what they do because public policy has } \\
\text { changed what they think or has changed } \\
\text { what they think about, without necessarily } \\
\text { changing anything else about the situation }\end{array}$ & $\begin{array}{l}\text { e.g. Public Meetings; } \\
\text { Hearings; Information } \\
\text { Campaign; Public } \\
\text { Posters, Press } \\
\text { Conferences... }\end{array}$ \\
\hline
\end{tabular}


Figure 3: NONCOMPLIANCE WITH LAND ACQUISITION IN VIETNAM

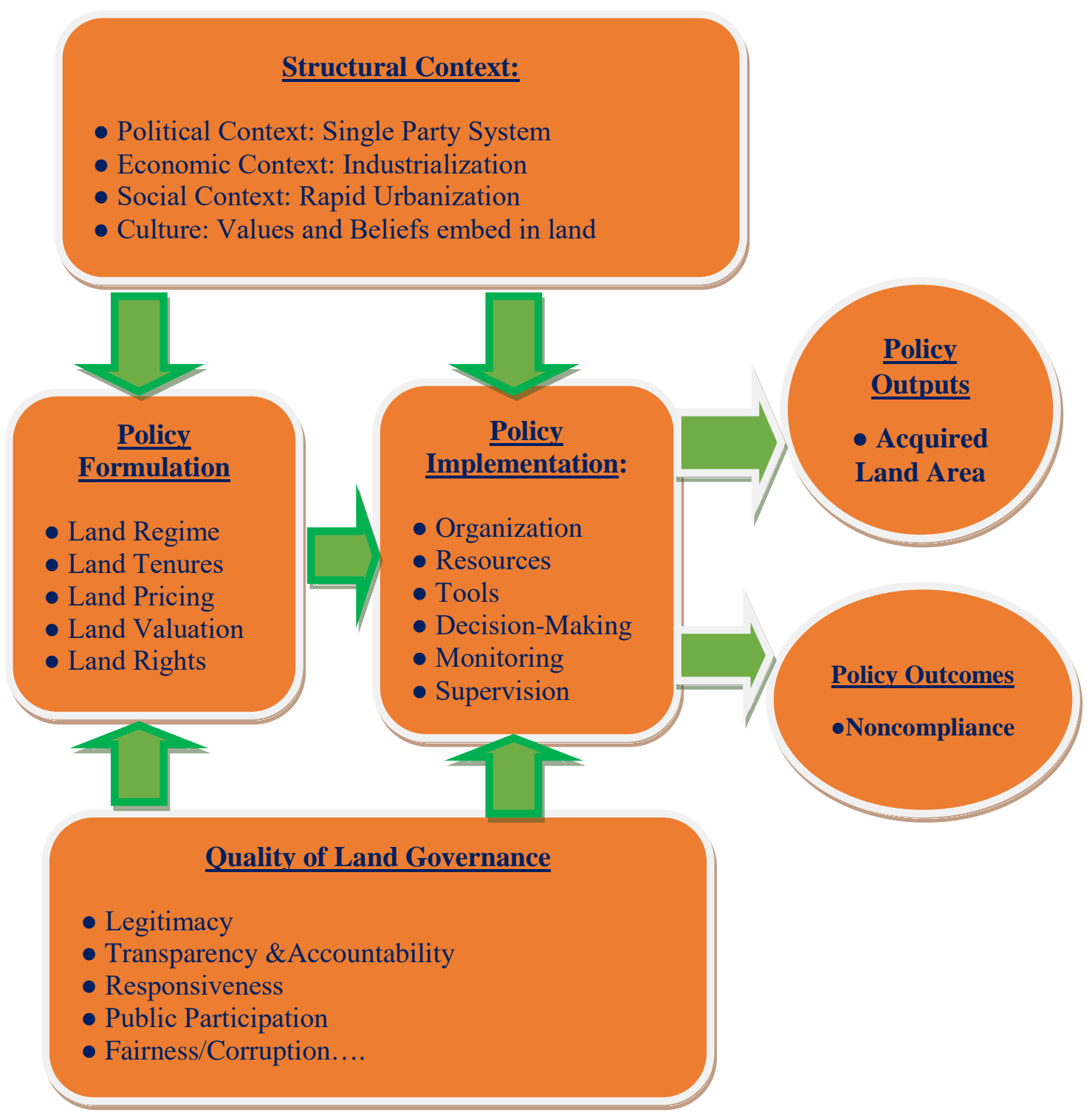




\section{CHAPTER III: RESEARCH DESIGN AND METHODS}

\subsection{Introduction}

If "research strategy” refers to "qualitative” or "quantitative” approach, the research design is an overall plan or a protocol regarding a particular scientific study (Singleton and Straits, 2010; Bryman, 2012; Yin, 2013; Maxwell, 2014). Researchers starting with "how" and "why" questions that primarily stress exploratory and explanatory purposes are more likely to favor small-n qualitative studies while "what", "who", and "where" questions aiming to description and prediction are more preferred large-n quantitative investigation. Overall, a good research strategy and design needs to provide clear information about entities to be studied (e.g. individuals, groups, organizations, events, or people); aspects of entities that are of researchers' interest; relationships or issues being investigated or explored within a research project, and types of data that will be collected (Singleton and Straits, 2010: 79).Considering this dissertation's research problem an research questions, the qualitative case study is employed to explore potential linkages between policy tools and land users' policy noncompliance.

This chapter contents methodological issues. The researcher will describe fundamental elements of a qualitative research such as the research design and strategy, methods of data collection and analysis, and the presentation of research results. The 
chapter is organized as follow: the first section will justify the choice of an "instrumental case study" as the dissertation's research design. Attention will then be turned to key elements and steps in conducting a multiple-case study, including: the unit of analysis and case selection process, research site access and participant recruitment, description of the researcher's role, and data collection and analysis techniques. The final section will discuss how data and research findings are presented in following chapters.

\subsection{Justifications for the Selected Research Design}

While quantitative researchers are interested in the "quantity of things", qualitative approaches are more focusing on their "qualities or non-quantifiable things" (Bazelley, 2013: 3). Qualitative research can be defined as a process beginning with "assumptions, a worldview, the possible use of a theoretical lens, and the study of research problems inquiring into the meaning individuals or groups ascribe to a social or human problem” (Creswell, 2007: 37). In order to study social or human problem, qualitative researchers often focus on some entities, collect data in natural settings, and qualitatively analyzes data to establish patterns or themes. The emphasis on quality of things indicates that if a large number of samples is required by quantitative research designs, qualitative researchers only work with a limited number of research entities or cases. The main interest of qualitative researchers is to observe, describe, interpret, and analyze the ways that people think about themselves, act on, or experience the world around them. Because of this fundamental nature, researchers inspired by qualitative approaches are often centered on a separate and single entity or multiple instances of the phenomenon under study (Creswell, 2013; Yin, 2014). While a qualitative study can adopt varieties of methodological approaches such as ethnography, grounded theory, 
phenomenology, narrative analysis, or discourse analysis, this dissertation employs "Case Study" as the research design.

According to Yin (2014: 16-17), a case study is defined with two components: (i) the scope of a case study inquiry, and (ii) its features. For the first component, case study is "an empirical inquiry that investigates a contemporary phenomenon within its real-life context, especially when boundaries between phenomenon and context may not be clearly evident” (Yin, 2014: 16). While the first component emphasizes the important role of contextual conditions in understanding the topic or the case under study, the second component of case study definition refers to some other methodological features. Accordingly, a case study inquiry will cope with the technically distinctive situation and rely on various sources of evidence. The data collection and analysis in case studies are guided by prior developments of theoretical propositions. Specifically, the case study design is selected as the research design for this dissertation because of its following advantages (Singleton and Straits, 2010: 356; Creswell, 2013; Yin, 2014):

First, "case study" is a powerful tool when researchers want to explore a new phenomenon (Stake, 2005; Creswell, 2013; Yin, 2014). In situations of little available knowledge about the research topic, researchers will find qualitative case study helpful because the openness and flexibility of qualitative strategy allow researchers explore all possibilities. Focusing on single unit or a limited number of units, case study is more relevant in investigating dynamic situations in natural settings of things and phenomenon. Based on real experiences in research sites, researchers can hear silenced voices from research participants or deal with dimensions/factors that are not easily measured. They also can develop detailed descriptions and understandings of the research topic. Since 
noncompliance with land-taking policy is a wicked problem, case study is a right design to develop an in-depth understanding of the complex phenomenon under study.

Second, "case study" also can be used when available theories need to be further developed. According to Yin (2014: 6-7), the use of case study design is not limited to exploration of a single unit or phenomenon. In reality, numerous explanatory and descriptive case studies can be found in scientific disciplines such as political science and sociology. This reality indicates that the design of case study never simply serves as a preliminary method used for exploratory purposes only. The case study design instead can also be used to describe, explain, or even test theoretical propositions. Research literature of land-taking policy in Vietnam suggests that influential theories such as institutional, economic, and participatory governance face contextual limitations of a centralized Party-State governing system. This motivates a scientific exploration driven by policy tool theory that can offer new insights about land-taking problems. If tool choice and use can affect implementation effectiveness and policy success, how do tools relate to noncompliance over land-takings? A "tool centered case study", thus, is an appropriate design to investigate if there are linkages between policy tools and land users’ noncompliance in land-taking policy implementation.

Third, this dissertation's research questions are in form of "how" that favor the design of qualitative case study. This is because "such questions deal with operational links needing to be traced over time, rather than mere frequencies or incidences” (Yin, 2014: 10). Giving no previous study has been done on the role of tools in land-taking policy noncompliance in Vietnam, this dissertation research first and foremost aims to exploratory and explanatory purposes. Based on an in-depth examination and analysis of 
local governments' tool choice and use, this dissertation explores action/process aspects of the land-taking policy and how those aspects contribute to land users' noncompliant behaviors. This action centered research interest draws all attentions to devices (mechanisms and tools) used by local government officials to interact with land users during the policy implementation process. Understanding of the potential linkage between policy tools and noncompliant behavior might not only explain why the target groups (land users) resist land-taking policy decisions but also suggest further research opportunities in future.

Fourth, qualitative strategy and case study design also ensures that the qualitative explorer can get an insiders' view of reality by directly interacting with research subjects, including land users and government officials, in a small sample study. The researcher is able to play a role of active learner who can tell the story from participants' views as well as making judgments as an expert. With qualitative approach, the researcher is not only interested in events and participants' behavior but also concerned with "how the participants in study make sense of these and how their understanding influences their behaviors" (Maxwell, 2013: 22). This helps the qualitative researcher to understand the research topic from local people's views of points. Unlike quantitative studies that examine and compare differences and relationships found in a large number of samples, exploring a limited number of cases (e.g. 03 land-taking incidents) allows an in-depth investigation of how local context influences government's actions and how individual circumstances of land users shape their individual behaviors.

Finally, the sensitiveness of the research topic in Vietnam's context encourages the choice of an instrumental case study design. As a wicked problem, it is not easy for 
the researcher to access land-taking projects and collect data on a large number of affected land users and government officials. This reality suggests "the instrumentality" as a unique characteristic of this dissertation's research. The "instrumentality" means that case study is instrumental to accomplishing something else rather than understanding particular situations (Stake, 1995: 3). The instrumental case study is especially an

appropriate research approach when researchers are interested in a research puzzle, a need for general understanding, and a feeling that studying some cases in their own choice might bring them new insights into research questions. These features differentiate "instrumental case study" from "intrinsic case study" in which researchers are assigned, even being obligated to conduct study on particular cases without other choices. In other words, the "instrumentality" of the research design allows the researcher with some flexibilities and a purposeful selection of land-taking incidents as cases for analysis.

\subsection{Research Design}

\subsubsection{The unit of analysis and case selection}

\section{-Unit of analysis:}

At the starting point of study, it is important for researchers to clarify the unit of analysis - who or what will be described or analyzed. According to Singleton and Straits (2010: 81-83), the right choice of unit of analysis will not only help researchers exactly identify research population and sample (case), collect adequate data, but also avoid false assertions about research findings. This means that research conclusions are made only about the particular unit of the researcher's interest. Researchers, in other words, can eliminate logical fallacy if they choose the appropriate unit of analysis and only draw conclusions on the basis of information collected from the analysis unit. 
The "unit of analysis" refers to entities (objects or events) under study (Singleton and Straits, 2010: 81). Research entities might be organizations, individuals, events, artifacts, or even nations. The choice of analysis unit depends on researcher purposes and researchers' interests. The implementation of land-taking policy in Vietnam involves varieties of entities such as local government agencies, local leaders and officials, land users, and investors...etc. Therefore, a land-taking policy study can use either "local government", "individuals”, or "land-taking events" as the unit of analysis. Based on research purposes, land-taking instance (or project) in which government executes required legal and administrative procedures in order to acquire land use right over an area of land from land users is chosen as the unit of analysis for this dissertation study.

- Samples and Cases:

While research population is a whole class of similar objects or events, a "sample" is a case or a single unit the researcher observes (Singleton and Straits, 2010: 151). In this case study, since the unit of analysis is the land-taking instance, the research population consists of all land-taking projects implemented in Vietnam by the government in order to collect the land use right over a piece of land assigned to land users. However, considering the main research interest of policy noncompliance as suggested by pilot studiesin Bac Ninh and Vinh Phuc provinces, non-resistant landtakings offer limited opportunity to explore the linkage between policy tools and policy noncompliance. The researcher, therefore, exclude compliant projects in which most affected land users accept the government's compensation offers. Only "noncompliant instances" (alternatively, incidents) in which there is a group of at least 20\% of affected 
land users who resist local governments' land-takings were selected as the cases for observation and exploration.

Unlike traditional approaches to policy implementation that largely examines government's organizational capacity such as human and financial resource or organizational structure, this study is interested in "government in actions" - ways that the government interacts with policy target groups in the policy implementation process. This research inquiry, therefore, does not require collecting data on organizational sizes and structure, financial and human resources, or individuals' characteristics (e.g. age, gender, education level...). Instead, a government's action centered study will explore the choice and application of implementation tools that transfer policy ideas into government's land-taking actions in practice. Based on research assumptions that actions of local governments might also affect target groups' policy acceptance or nonacceptance, the selection of land-taking incidents as the cases for analysis is expected to ensure the focus on instruments used in specific land-taking situations.

\section{- Case selection technique}

Though sampling in qualitative study is not as important as in quantitative research, the researcher's theoretical understanding and practical experiences encourage a careful consideration of "case selection" based on sampling principles. This not only ensures the right choice of cases but also helps the researcher determines case featured dimensions showing the typicality that can illustrate matters of concerns. Most simply, the sampling process in quantitative study is to determine how many units will be chosen from the research population and by what method? (Singleton and Straits, 2010: 151). Since this study applies qualitative strategy to explore policy noncompliance, the 
researcher excludes land-taking projects without disputes and only focuses on a limited number of land-taking incidents. The case selection question, therefore, is: what type of land-taking incidents in which land users resist government's land-taking decisions will be chosen? How many cases will be selected? And by what techniques or methods?

The main technique for case selection employed in this research is purposeful sampling: land-taking incidents (cases), research sites, and research participants were conveniently and purposefully chosen based on subjective judgment and experiences of the researcher (Bryman, 2012: 418). Therefore, only land-taking incidents relevant to research questions and instrumental purposes were chosen. This general strategy enables the typicality (ex. level of tension and conflict) of selected land-taking cases. In addition to purposeful case selection, theoretical sampling is another technique used in combination with criteria above (typicality and instrumentality) to determine whether a case is selected or not. "Theoretical sampling" is "the process of data collection for generating theory whereby the analyst jointly collects, codes, and analyzes his data and decides what data to collect next and where to find them” (Glaser and Strauss, 1967: 45). This technique indicates that the case selection is an ongoing process rather than a distinct and single stage. The researcher can work on several interested cases, but he/she might also look for other cases while being in research sites and finally focus on the most typical cases that meet their research expectations and requirements.

The case selection process was managed as follow: first, a sampling frame was developed to identify and determine what type of incidents (case) would be selected. In order to have a good sampling frame, various land-taking projects (instances) with typical characteristics of the research population were reviewed by the researcher and local 
officials. The selection of noncompliant land-takings (incidents)then was conducted on the basis of a set of criteria such as the number of affected land users, acquired land area, level of tension, land use purpose, and locations of land-taking projects. The use of these criteria ensures typical features of land-taking incidents. In order to enhance the diversity of collected information, the cases were selected in different settings. Variations regarding local conditions enable contextual differences in policy implementation and potential effects of those differences on levels of policy noncompliance over landtakings.

The purposeful case selection technique excludes land-taking instances or projects without disputes and conflicts. This is because those effective projects often affect a very limited number of households that facilitates agreements on compensation between land users and the government/investors. More importantly, land-taking projects without affected residents' resistance often aim to serve public purposes such as constructing a school/university, roads, or bridges that greatly benefit local people, including affected land users. The purposes of serving public interest legitimate land-taking policy actions and, thus, easily convince land users returning their land to government. The land acquisition process is often executed with limited noncompliance or even without affected people's resistance. This does not push local governments into complex situations as in implementing non-complainant land-takings. Land officials are not required efforts regarding tools choice and use in order to acquire land use rights. Therefore, though adopting the same rules and procedures, land-taking instances without conflicts are not typical cases for this tool focused policy noncompliance study. 
Based on principles above, the researcher selected three land-taking incidents taking place in Hanoi city and Bac Ninh province (in the North of Vietnam) and Ho Chi Minh city in the South for a cross-case analysis.

\subsubsection{Procedures of selecting three land-taking incidents}

Research requests first were sent by the researcher to four provinces and cities in the North of Vietnam including: Ha Noi, Bac Ninh, Hung Yen, and Vinh Phuc. Informal conversations with land officials in Hanoi and Hung Yen provinces revealed that they were not ready to support the dissertation research plan. Though government officials in Hanoi and Hung Yen were able to provide some government reports, official statistics, and willing to participate in interviews, they were very hesitated to organize meetings with government agencies and land users involved in on-going land acquisition incidents of interests. The researcher, thus, canceled fieldwork plans in the two province/city.

The two provinces of Bac Ninh and Vinh Phuc where governments responded to research requests served as research sites to get real experiences about land acquisition. With supports from local officials, several profiles of on-going land-taking projects in the two provinces were reviewed during the pilot study stage. Some "qualified land-taking projects', then, were selected to apply for government's approval of the research plan. However, due to contextual complexities, access to potential cases suggested by the researcher was refused. According to local officials, tensions and complicated situations at local communities are not conducive of doing research. Intended interviews and focus groups with land users at local communities might be risky for both local governments and the researcher. Though government officials in two provinces were willing to arrange visits to effective land-taking projects (instances without land users' resistance) and 
participate in this study, they were able to set up only one land-taking incident for an indepth investigation in Dong Ky ward (Tu Son district - Bac Ninh province). The case of Dong Ky, thus, is the only one incident that the researcher gains real experiences in a local setting.

Difficulties in accessing land-taking incidents in local settings made study of high-profile land-taking events in Hanoi City and Ho Chi Minh City an alternative option. After reviewing the availability of data, the researcher chosen the two "typical incidents" that serve as "instrumental cases”. For the two cases of Dong Tam and Thu Thiem, the researcher relied on online sources of secondary data such as government websites, online newspapers, Youtube.com...etc. Numerous media publications regarding the two cases such as video clips, newspaper articles, and interviews with leaders, official documents, and stories telling by affected land users who involved in the two land-taking projects, were collected by the researcher. While the two cases might reduce the researcher's real experiences at local settings, they offer a great chance to look at complex situations and explore action aspects during the execution of land acquisition. Specifically, three land-taking incidents selected for analysis present an opportunity to discover action aspects of policy implementation process.

Unlike similar land-taking disputes, most noncompliant land users affected by the three projects did not, first and foremost, criticize local governments for financial and economic consequences. The less important role of economic factors first is evident in the large number of land users accepting compensation and moving out of their land. Second, more importantly, the key question raised by 115 disobedient landholders in Thu Thiem was: are we really affected by the Thu Thiem project? Is our land really covered 
by land-taking plans? Similarly, land holders in Dong Tam also did not dispute compensation or the application of land-taking law and rules. They instead questioned the Hanoi city government if the defense land area covers their land? Though only 14 households had to give up the land to the government as the result of the land-acquisition, unclear land boundaries determined by the city government was the root cause of villagers' collective disobedience. The case of $\mathrm{Tu}$ Son, whereas, shows a typical noncompliance over land-takings serving private and public partnership (BT) projects. The involvement of private investors in BT projects makes land-takings more complicated and disputes are more likely to occur. In views of land users, private investors greatly benefit from constructing properties such as apartments and houses on cheap land and selling at very high price on the market. These practices motivate land users' requests to directly negotiate with investors for market-based land price and higher compensation. Such a request, however, is not supported by the government. This often results in long lasting disputes and tensions between the government and affected land users. In many situations, the government has to rely on compulsory acquisition as the final action.

Three selected incidents show that, instead of common economic and institutional factors such as low compensation, unfair land price, or the ambiguity of land legislation, actions of local governments in policy implementation do matter. The three incidents, thus, provide an opportunity to explore action or process aspects that have been still underestimated in explaining land-taking problems in Vietnam. In the section below, three land-taking incidents will be analyzed from a policy tool lens that centers on 
devices/tools driving interactions and relationships between the government and policy target groups.

\subsubsection{Site access and participant recruitment}

- Research site access:

In order to gain real experience at research sites in Bac Ninh and Vinh Phuc provinces, the researcher relied on local government's websites as the first official sources for seeking background information. In order to find the most suitable research sites at district level of government, the researcher contacted with local governments through Office of Provincial People's Committee, Provincial Department of Natural Resources and Environment; and District People's Committee, asking for permission to conduct study with local residents and government agencies such as Provincial Center for Land Development, District Boards of Compensation, Support, and Resettlement. With support from local governments in the two provinces, a pilot study was conducted in March 2017 to initially examine land-taking incidents and local settings prior determining the selection of research fields and looking for cases.

- Recruitment of research participants:

To collect insights regarding tools choice and use in land-taking policy implementation, the researcher needs to access policy implementers and policy target groups in local settings. There are two groups of informants in this study: (i) government leaders and officials who are responsible and directly involved inland-taking policy implementation, and (ii) land users who are affected by particular land-taking projects. Due to the sensitiveness of the research topic, the researcher was not able to collect information from investors. In reality, as shared by local officials, investors often play a 
very minimal role in land-taking projects. Because most land-taking incidents are in compulsory form, government officials are the only people with legitimate authority to work with affected land users. This reality explains why investors were unwilling to participate in this research. Some told the researcher that they even were not allowed to respond interview requests without approval from local government.

The selection of research informants, therefore, was as follows: first, in consultation with local government leaders, only land officials who directly got involved in land-taking policy implementation were invited for in-depth interviews. The researcher also accessed local leaders (ex. district/commune mayors and party secretaries) for information at the decision-making level. Local land officials and leaders then supported the researcher in recruiting affected land users who were invited to participate in focus groups. Totally, ...interviews were conducted with.... policy implementers (government officials and leaders) and ....affected land users (this section will be properly completed after finishing case analysis).

\subsubsection{The role of the researcher}

As pointed out by Singleton and Straits (2010: 356-358) and Creswell (2013), conducting qualitative research is a challenging journey because design elements of a qualitative research are not specified and fixed before data collection. Qualitative researchers often start their research process with a broad research topic, a methodological approach, and some research propositions. The research design can be revised during field visits in order to adapt to local settings. Instead of using data collection tools developed by other researchers, qualitative explorers rely on themselves as an instrument for data collection. Researchers in qualitative studies have to visit 
research sites for multiple times and directly collect data over a long time through the use of multiple methods such as: observing behaviors, examining documents, and interviewing participants. They thus have to set research agenda, decide what questions to ask, take notes, and record. Qualitative researchers also have to review, and code collected data, organize themes across the data sources, and conduct data analysis by themselves. Only the researchers who are directly involved in data collection analyze data. During data collection process, the researcher observed policy implementation activities, talked to policy implementers, interviewed land users, and joined in community meetings to develop an in-depth description of the topic under study. In this qualitative study, therefore, the researcher plays multiple roles: an observer, a participant, a data collection instrument, and a data analyst.

\subsubsection{Limitations of the research design}

As pointed out by Creswell (2013) and Yin (2014), since the main purpose of qualitative research design is to describe in detail the topic under study, researchers often formulate their exploratory research questions with "how" and "what". Case studies, therefore, often require a large amount of time to do field observations and interviews. It also highly depends on observational and interpretive skills of researchers because individual researchers only interact with a limited number of people in limited settings. Due to the focus on some cases, researchers might face difficulties if they want to make replications and comparisons. Most importantly, small - n qualitative research design lacks the generalizability and researchers are unable to make predictions. All these are common limitations of the selected case study design. Case study results, therefore, are often served as a reference for further studies in future. 
Another shortcoming of the design of case study adopted in this dissertation relates to the difficulties in seeking and accessing "typical cases" (ex. a high level of tension and a significant number of noncompliant land users). Noncompliance regarding land-taking policy is a sensitive problem in contemporary Vietnam. Accessing "hot" land-taking incidents, therefore, is not an easy task. This unexpected situation resulted in the selection of two cases of Dong Tam and Thu Thiem as an alternative option. For these two high-profile cases, since the researcher was not able to directly interact with research participants in local settings, most collected data are secondary. Though lots of data were gathered from public sources such as articles and interviews conducted by reporters, government documents, or video clips, the dependence on secondary data reduced the researcher's ability to explore the research topic in local settings.

In addition, the researcher's inability to directly access the two incidents in Thu Thiem and Dong Tam and the dependence on secondary data might also affect the validity and reliability of research findings and interpretations. The exclusion of nonresistant land-taking projects is also a limitation of this research. Without an examination of effective land-taking instances, the researcher is not sure if there are any variations in tool choice and use; and if variations in the application of policy tools really contribute to effective policy implementation. However, due to the focus on policy noncompliance, this study does not aim to compare differences in terms of tools between effective and non-effective execution of land-taking projects. Such a comparative study can be saved for future. 


\subsection{Data Collection}

\subsubsection{Key questions guiding data collection}

Instruments used for data collection consists of interviews and focus groups in Vinh Phuc and Bac Ninh provinces and searching online sources. The researcher spent time in Vinh Phuc and Bac Ninh provinces to talk to local land officials, managers, and leaders and affected land users in order to gain real experience with land-taking policy implementation. In Tu Son district (Bac Ninh province), the researcher also had chance to attending community meetings, observed the enforcement of land-taking procedures and stakeholders' responses in practices. The collection of primary data at research sites and secondary data from public sources was directed by specific questions below:

- What are mechanisms and tools available for land-taking policy implementers?

- Do land-taking policy implementers rely more on economic incentives, coercive authority, or persuasion and capacity building? Direct or indirect mechanisms? Why?

- What are mechanisms and tools preferred by government officials? How do policy implementers justify their tool preferences?

- What are strengths and weaknesses of preferred mechanisms and tools?

-What political, economic, institutional, and socio-cultural factors affect policy implementers' tool choice and use?

- Do non-state actors such as investors and land users play any role when government officials select implementation tools? If not, why?

- How effective are tool choice and use from affected land users' perspective? 
- In response to land users' noncompliance, do local government officials change their choice and use of tools? How do they make changes and how effective are those tool related changes? If they do not change tool choice and use, why?

- Is it possible to increase policy compliance among land users by making changes in tool choice and use? Considering context of Vietnam, what are feasible tool alternatives?

\subsubsection{Stages of data collection}

The data collection of this study is a continuing process that consists ofthreestages with multiple field visits. Fieldwork activities target purposes and specific tasks associated with each stage: (i) Stage 1 - Pilot fieldwork in both provinces to select and confirm research sites and verify the research problem; (ii) Stage 2 - Field visits with a focus on policy implementation; and (iii) Stage 3 - Field visits with a focus on linkages between implementation tools and policy noncompliance. As a qualitative study, the dissertation's research design is modified during the data collection process.

- Stage 1: Pilot Fieldwork in March and April 2017

Starting with a broad research interest in manifestations of policy noncompliance (land-taking disputes and conflicts), the pilot study at potential research sites served as an opportunity to verify, clarify, and confirm the research problem. General data collection strategy and tools such as interview guides were also developed during the pilot fieldwork. Based on background information on government websites, the researcher made contacts with local governments in four potential research sites for support (four provinces in the North of Vietnam: Bac Ninh, Vinh Phuc, Hanoi, and Hung Yen). Some initial field visits with field observations and free talks with local officials served to not 
only determine if locations are suitable and convenient for study but also revise and refine the research problem and the research design. Finally, two Northern provinces of Bac Ninh and Vinh Phuc were chosen for field experience and data collection. The researcher also confirmed the research problem of policy noncompliance from a tool approach and determined case study as the dissertation’s research design.

- Stage 2: Field visits with policy implementation focus in August 2017

In addition to policy literature, the pilot study suggested that land-taking policy noncompliance in Vietnam might be related to a variety of factors associated with different stages of the public policy process. Therefore, the second field visit was to ensure if a focus on the implementation stage of the land-taking policy is a right choice. After 14 days in the two provinces of Bac Ninh and Vinh Phuc, the researcher got updated with latest rules and procedures of the land-taking policy. Some focus groups and in-depth interviews were conducted with local officials and affected land users for a deeper understanding of the land-taking policy. Finally, the researcher decided to explore policy implementation stage. Some profiles of land-taking incidents were collected for initial review and analysis. In addition to choosing potential informants and inviting them to participate in the research, data collection tools such as interview and focus group guides were further developed and revised based on field experience.

- Stage 3: Field visits with a focus on policy tools and land users’ noncompliance in March\& August 2018, and February 2019.

The researcher came back research sites with a focus on linkages between implementation tools and land users' noncompliance over land-takings. Requests to explore some selected typical cases (on-going land-taking incidents) were sent to local 
governments. However, due to the sensitiveness of the research topic, the access to a “hot” land-taking incident in Vinh Yen city (Vinh Phuc province) was refused by the city government. The city government suggested some other less serious incidents. However, since there were only some noncompliant landholders, the researcher ignored the two incidents suggested by local governments in Vinh Phuc province. In Bac Ninh province, with efforts to access on-going incidents, the researcher was able to access a land-taking incident in Dong Ky and Trang Ha wards (Tu Son district).

Due to difficulties in accessing typical on-going land-taking incidents in both selected research sites, the high-profile incidents of Thu Thiem (Ho Chi Minh city) and Dong Tam (Ha Noi city) were chosen. Both cases showed typical features and richness of available data. For example, both land-taking incidents affected the livelihoods of a large number of land users, lasted long, and attracted public concerns and debates on mass media. This forced governments in the two cities to provide official data to the public. Thousands of articles, government reports, interviews, and video clips... are available online. More importantly, the purposive sampling of cases with significant conflict is intended to provide relevant cases where mechanisms of non-compliance and responses to non-compliance can be studied. This allows the researcher to reach conclusions about the mechanisms at work in these cases. After reviewing criteria and requirements of case selection, consulting with supervisor, the researcher decided to choose the two incidents in Thu Thiem and Dong Tam, and the collection of secondary data started in April 2018.

\subsubsection{Data sources and data forms}

Field notes and observations, research participants, government's websites, international organizations' websites, online newspapers, Youtube.com, official 
documents and reports, and scholarly Journals are the main data sources of this study. Data are in the forms of official documentations and statistics, photos and video clips, technical reports, interview articles, notes, and transcripts. More specifically, there are two types of data used in this dissertation research:

(i) Primary data gathered from research participants, including government officials and land users. This type of data was collected by the researcher for this dissertation’s research purposes.

(ii) Secondary data is the data gathered by other institutions and researchers/reporters for other purposes (Bryman, 2012). For this study, the researcher collected secondary data from the government agencies, Vietnam based international organizations, other research teams, and publications of mass media agencies.

\subsubsection{Data collection methods}

In-depth interview, focus group, document review, and web-search are four techniques used for data collection. These techniques aim to gather qualitative (verbal and written) evidences in order to: "exploring, describing, and explaining a complex situation” (Rubin and Rubin, 2012: 49). The researcher relies on in-depth interviews to collect information from local governments' leaders and land officials. As key policy implementers at local levels, they are among the most helpful informants about landtaking policy problems. Individual interviews with local policy implementers are not only more convenient than focus groups but also ensure more time for in-depth discussions of the topic under study. With separate interviews, the researcher can compare policy implementers' different viewpoints on key themes of interest. 
Practically, pilot studies suggested that focus group is not really a suitable method for gathering information from government officials. In Bac Ninh province, when officials sit in groups, they often responded with general comments; all questions were transferred to land officials whom participants believed the best source of information on land acquisition issues. Therefore, the researcher conducted only three focus groups with government managers and officials. Remaining focus groups were with noncompliant land users who get involved in disputes and conflicts over land-takings. The focus groups provided land users a forum to share their own experiences with land-taking policy implementation and respond to others' views regarding to the concerns. Whereas, websearch and document review are especially helpful in gathering information on rules, regulations, and statistics about policy implementation. The use of data collection techniques is specifically conducted as follows:

- In-depth Interview:

As a key data collection tool in this qualitative research, the interviews are semistructured and responsive in nature because they are conversations between the researcher and informants based on some specific topics with prepared questions. Each responsive interview that lasts from 60 to 90 minutes is developed around three elements: main questions, follow-up questions, and probes (Rubin and Rubin, 2012: 116). The main questions cover the overall research questions and structure the interview, while further details and in-depth justifications on themes, concepts, or events are gathered by followup questions. The role of probes is to keep conversations on track and clarifying ambiguities. Alternatively, these are topical interviews in which the researcher "looks for 
specific facts, descriptions of events, or examples that will help answer a particular, focused research question” (Rubin and Rubin, 2012: 31).

Fieldwork study revealed that leaders and officials in the land sector were the most active respondents while officials working in other government agencies that involve in land-taking policy implementation were unable to provide detailed information on interested topics. These participants shared that their role is only to collaborate with land officials whose responsibility is the land-taking policy implementation. This reasons why in-depth interviews were only conducted with research participants working in the land sector. In practice, due to the sensitiveness of the research topic, the researcher was unable to schedule interviews with government leaders. They were unwilling to participate in a recorded interview. They, however, could meet with the researcher and had free conversations without recording. The researcher took this chance to ask some key questions and took notes that then were used for data analysis.

Totally, the researcher conducted 13 in-depth interviews. Interviewees included heads of DONRE of Tu Son, Yen Phong, Que Vo in Bac Ninh province; Vinh Yen and Binh Xuyen (Vinh Phuc province); deputy director of Bac Ninh’s CLD; head of Bac Ninh's land management agency, head of Tu Son's CLD; land officials in Dong Ky and Trang Ha wards, and Tu Son DONRE, and two affected landholders in Dong Ky and Trang Ha wards. In addition, the researcher also conducted numerous short conversations (in around 10 to 15 minutes) with landholders and government managers/leaders. These conversations were taking notes for later analysis.

- Focus Group: 
A limited number of participants were invited to sit together in an isolated setting. The researcher acted as a facilitator who posed some questions, moved the conversation along, and intervened if necessary, to manage the focus groups on track. Participants in focus groups were able to freely share their opinions and experiences, responded to each other's viewpoints on topics under discussion. Each focus group included about $6-8$ individuals representing affected land users and lasted from 60 to 90 minutes. In practice, as reported above, focus group was not really an appropriate data collection instrument. The researcher used focus group as a means for discovering general issues and then included in in-depth interviews.

The total number of focus groups, thus, is 06 . Focus groups were organized with government officials in Tu Son district; managers in the land sector Bac Ninh provincial government; managers in the land sector in Vinh Phuc provincial government; two focus groups with landholders in Dong Ky and Trang Ha wards (Tu Son, Bac Ninh); and one with landholders in Tich Son ward (Vinh Yen district, Vinh Phuc province). .

- Web-search and Document Review:

Web-search and document review involve examining anything in written forms (Rubin and Rubin, 2012: 27). Collected documents include government's socio-economic plans, land use planning reports, annual land acquisition reports, executive orders, decrees and directives, CPV's resolutions, meeting transcripts, video transcripts, newspapers, speeches, interviews, or internet posts...etc. Web-search was also a technique to collect data available in form of video clips. Information obtained from public sources was used to support data collected from research participants. Web-search 
and document review were the only technique used to collect data on Thu Thiem and Dong Tam incidents.

\subsubsection{Recording and data management}

At the beginning of the data collection process, the researcher intended to record all interviews and focus groups. However, while recording was accepted with land users, only some government officials allowed their interviews to be recorded. This is because all issues regarding an ongoing land-taking project are very sensitive in local contexts. Land officials were often anxious that recordings can be used against them who get involved in land-taking policy implementation. Taking notes, therefore, was an alternative technique for data collection at research fields.

Selected sections of recorded interviews and group discussions were transcribed; field notes were typed; and data in forms of media outputs such as video clips and articles accompanied by links were saved in separate folder. All collected data are stored in personal device such as USB and laptop. Each interview/focus group is numbered so that the researcher is the only person who can identify and use the research data. Only selected extracts are translated into English for data representation and analysis purposes.

\subsection{Data Analysis and Representation}

\subsubsection{Data analysis strategy}

The purpose of data analysis is to make clear and convincing answers to the research questions based on raw data (Rubin and Rubin, 2012: 190). One of the most important features of qualitative studies is that researchers seek an understanding of a particular issue or problem or phenomenon from the perspective of whom experiences it (Vaismoradi, Turunen, and Bondas, 2013). The task of qualitative data analysts, 
therefore, is to search for commonalities, contrasts, and the meanings in the collected data (Grbich, 2007). According to Creswell (2013, 181-220), the analysis of qualitative data aims to answer two questions: (i) "what does the data say?”, and (ii) what do the findings mean? A typical qualitative data analysis often follows three common steps: (i) line by line coding; (ii) categorizing; and (iii) analyzing and interpreting key contents and themes (Bryman, 2012). In this study, the researcher relies on the theoretical prepositions-based approach as the general data analysis strategy. That is, the tool focused research prepositions developed prior data collection are used to organize common themes and guide the data analysis. Basically, the analysis of qualitative data follows steps below:

- Organizing data: the collected data were saved and stored into different categories such as in-depth interviews, focus groups, government's documents, and media publications. The researcher carefully reviewed all organized data files to find if the data can be used or any mistakes/errors occurred.

- Finding and organizing key concepts and main ideas: the researcher carefully read documented data, listened and re-listened to recordings, and watched video clips to find key concepts and construct main ideas. Concepts and ideas were then grouped into categorical issues associated with research propositions; initial codes were formed. By this approach, the researcher was able to note down important concepts and ideas as they appeared and organized the data in responding to the research questions.

- Developing themes in the data: based on research prepositions, some common tool-focused themes were tentatively developed by the researcher. The researcher then relied on codes to find evidence supporting key themes developed prior the data collection or construct new themes found in the coded data. Typed transcripts and field 
notes, government documents, and media outputs were marked with codes that helped the researcher easily found and linked the data in writing up research results. Sub-themes such as "policy mechanism”, "tool mix", "tool preference”, “contextual factors”, “tool response” ...etc. were used to conduct a cross-case analysis.

- Ensuring validity: validity raises the question of integrity of research findings, interpretations, and conclusions (Bryman, 2012: 47). In this qualitative study, the researcher is concerned with two types of validity, including: internal validity and ecological validity. While internal validity is helpful to verify if there is a potential relationship between implementation tools and noncompliance over land-takings, ecological validity encourages an awareness of questioning whether research findings really happen in local natural settings. Specifically, the researcher is the first person to check the accuracy of qualitative accounts. Evidence from different sources (ex. land users vs. land officials) is corroborated to shed light on themes. In addition to field observations, corroborating evidence allows the researcher to triangulate information and provide validity to research findings. The second technique for ensuring validity of the research is seeking feedback from research participants. By this technique, research participants were invited to provide feedback on findings and interpretations. Participant feedback then was used to judge the accuracy and credibility of qualitative accounts (Maxwell, 2013: 261).

- Interpreting research findings and developing naturalistic generalizations: research findings first were summarized, interpreted, and discussed in the context of literature covered in this study. By this step, the researcher discussed the significance of the study findings in relation to both empirical and theoretical literature. In the next step, 
the researcher developed generalized lessons and initial conclusions. Finally, policy implications of research findings were assessed for the topic under study: e.g. how to make better choice of implementation tools to reduce the incidents of noncompliance.

\subsubsection{Data analysis techniques}

This study's data analysis is an on-going process that started from the beginning of data collection: the researcher regularly reviewed field notes, documents, media publications, and transcripts to develop a general overview of textual contents, video clips, and informants' responses, identified notable words (key concepts),key sentences (main ideas),and compared them to find differences and similarities that then were used to organize into themes. In addition to "coding" as a key technique, content analysis and thematic analysis were the two methods used for analyzing the collected data.

- Coding: the main purpose of coding is to mark key ideas found in the data (Braun and Clarke, 2006). The deductive coding technique employed in this study starts with pre-set themes developed by the researcher to group similar types of information into themes or categories. This process, however, is very open and flexible because the researcher can either select informants' words or his own words for coding. In either way, the key words used as codes must reflect meanings of the sentences or participants' experiences. The table 3 below presents some key codes and code categories used in this study.

Several categories of codes showing shared experiences by research participants were developed. By comparing codes, the researcher can develop some code categories covering similar responses among participants. Each category captures a theme or issue that is convenient for finding coded paragraphs, further exploring them and conducting 
analysis. Linked categories consist of participants' common experiences that help to quickly identify significant issues or topics. Instead of reviewing single codes, code categories can be used for later analysis purposes.

Table 3: Coding in data analysis

\begin{tabular}{|l|c|}
\hline \multicolumn{1}{|c|}{ Categories } & Codes \\
\hline$\bullet$ Policy Mechanism & Direct/Indirect Government, Authority, \\
& Finance, Information \\
\hline$\bullet$ Organizational Tools & Government, Non-Government \\
\hline$\bullet$ Authoritative Tools & Regulation, Rule, Executive Order \\
\hline$\bullet$ Financial or financial equivalent Tools & Cash, Land, Apartment \\
\hline$\bullet$ Information based Tools & Dialogue, Press Conference, Propaganda, \\
& Moral Suassions, Poster, Proclamation \\
\hline$\bullet$ Contextual Factors & Legislation, culture, society, economics \\
\hline
\end{tabular}

- Content Analysis: to gather information and evidence for qualitative reports, researchers can examine documented and video-typed contents to find out who says what, to whom, and with what effect - this refer to content analysis method(Bloor and Wood, 2006). The method of content analysis is defined as "an approach to the analysis of documents and texts that seeks to quantify content in terms of predetermined categories and in a systematic and replicable manner” (Bryman, 2012: 290). Researchers subjectively interpret the documented data "through the systematic classification process of coding and identifying themes or patterns” (Hsieh and Shannon, 2005). By examining 
textual data, researchers can identify and describe patterns of language and words used in documents and by informants in interviews and focus groups. They might also find frequency and relationships of trends and patterns as well as structures and discourses of communication. Based on reviewing documents and transcripts, researchers can break the texts into sub-units of contents for further exploration. Information/messages collected from content analysis can be used for hypothesis tests or theory development (Vaismoradi et al, 2013). The content analysis method can also provide a useful tool to describe what patterns are, quantify the data, and offer a more effective means to compare views of different research participants (Morgan, 1993). Most importantly, the content analysis method is more useful in a study that researchers aim to test hypotheses, modify, or extend existing theories (Hsieh and Shannon, 2005).

In this study, content analysis was used to work with government's documents and online publications such as news articles, media interviews, and journal articles. The researcher followed three steps of content analysis as outlined by Elo and Kyngas (2008):

(i) Preparation: the researcher immerses in the collected data in order to obtains the sense of the whole.

(ii) Organizing: the researcher codes, creates categories, groups codes into headings, develops a general description of the research topic.

(iii) Reporting: the researcher develops conceptual systems, conceptual maps, or categories, and a story line to present research results.

- Thematic Analysis: as this study's main qualitative data analysis method, thematic analysis is used by researchers to identify, analyze, and report patterns (themes) within data (Braun and Clarke, 2006). Data set in forms of interviews, texts, or focus 
groups will be searched by the researcher to find repeated patterns of meaning. Various aspects of the research topic, then, will be interpreted based on a constructionist epistemology. A theme is something important found in data in relation to research questions and represents patterned responses or meaning within the data set.

In order to determine what counts as a theme and how to work with the collected data, this study adopt "theoretical thematic approach" in which the researcher's theoretical interests direct the entire data analysis process. Instead of providing a rich description of the data overall, a study with theoretical thematic approach focuses on analyzing in detail some aspects of the data. This means that the researcher's analytic preconceptions will guide data coding, and the analysis is not data driven. Instead, thematic data analysis started when the researcher began to collect online data or conducted interviews/focus groups at research fields. Drafting ideas and developing a structure of the research report also were initiated during the data collection and analysis process.

Specifically, thematic data analysis in this study followed6 steps as suggested by Braun and Clarke (2006):

(i) Becoming familiar with data: the researcher reviewed all documented data, listened to recordings and transcribed the collected data, repeatedly read the data and searched for initial ideas/issues of interest.

(ii) Generating initial codes: important features found in the data such as significant actors, images, and words were coded.

(iii) Looking for patterns/searching for themes: codes were grouped into themes and gathered relevant data to each theme. 
(iv) Reviewing themes/patterns: the researcher checked if themes were workable with the coded extracts and developed a map of themes/patterns for analysis.

(v) Defining and naming themes: the researcher refined themes, clearly defined key themes, and organized the overall story told by themes.

(vi) Producing the research report: extracts, photos, video clips, or charts were used to produce the final research report.

\subsubsection{Data representation}

Without a good data representation approach, researchers are unable to make sense of the data for others (Grbich, 2007). In this qualitative study, data analysis and representation start with an overview description of land-taking cases. This section provides facts - a detailed view of aspects about three land-taking noncompliant incidents. It highlights key events, major characteristics of each incident and its local setting, roles and activities of actors and stakeholders involved in the incidents. The data are then organized into common themes emerging across three cases such as policy mechanism, tool mix, tool preferences...etc. Finally, research findings that are generalizations learned from cases in terms of themes will be discussed in the context of published literature, compared and contrasted with other studies on land-taking noncompliance.

Regarding data illustration techniques, in addition to "quotes", the researcher also relies on "graphic summaries" and "visual displays" for presenting study results. “Graphic summaries” that includes tables, charts, matrices, graphs...can provide a quick summary of some kinds of collected statistics or key patterns/themes found in the research data. This technique of data representation is useful for presenting an overall 
snapshot of themes or an overview of factors under analysis. Whereas, "quotes" in both English and Vietnamese are selected segments of transcripts used in final reports for either illustration purposes or as a starter for more detailed discussions and explanations. Finally, visual displays such as photos and video clips bring readers real feelings and impressions about things that the researcher wants to emphasize or illustrate.

\subsection{Summary of the Chapter}

Chapter 3 on research methodology presents the research design and methods for data collection and analysis adopted in this dissertation study. The relationship between policy tools and policy noncompliance is a brand-new research direction in Vietnam. The researcher, thus, aims to address the research question if tools contribute to noncompliance with land acquisition? How? Because the research question is in form of how that targets exploratory purposes, a qualitative case study is selected as the research design. Case study is a right choice of research design because it allows the researcher focusing on a limited number of cases and developing an in-depth understanding of the topic under study. The researcher will have chance to interact with research participants in local settings, discover unique story of each case, and tell stories from insiders' lens. By qualitative strategy, the researcher is not able to discover if implementation tools relate to policy noncompliance but also understand when and how tools can contribute to landholders’ noncompliance.

This study selected land-taking instances as the unit of analysis. Since the research interest was land-taking noncompliance, the researcher was interested in landtaking incidents in which local governments had to deal with landholders' resistance over land acquisition. After several filed visits, three land-taking incidents taking place in 
different locations (Hanoi, Bac Ninh, and HCMC) were selected for analysis. While the case of Tu Son allowed the researcher to get real experience of policy implementation in local context, two high profile cases of Thu Thiem and Dong Tam brought the researcher an opportunity to explore similarities and variations of land acquisition across province/city in Vietnam.

The researcher used two types of data for analysis: primary data collected by the researcher at research sites and secondary data gathered from media publications. Research participants in this study included affected land users, policy implementers, local government managers and leaders. In-depth interviews, focus groups, and websearch were three major instruments used to collect data. The researcher spent a large amount of time over the last two years in Bac Ninh and Vinh Phuc provinces. While the selected incident of Tu Son is a district in Bac Ninh, the researcher also conducted fieldwork in Vinh Phuc province to gain additional experience with land acquisition in a different setting.

Three techniques of data analysis used in this study included: coding, thematic analysis, and content analysis. The researcher listened to recordings, watched video clips, and reviewed field notes and documented texts to find out common themes across three incidents. Instead of analyzing single case, the researcher conducted a cross case analysis based on common themes emerged from three incidents. 


\section{CHAPTER IV: DESCRIPTION OF THE CASES}

\subsection{Introduction}

Three land-taking incidents selected for this study took place in Thu Thiem in the HCM city area; in Tu Son district (Bac Ninh province, North of Hanoi); and in Dong Tam commune (Hanoi capital city).Governments in Ho Chi Minh City and Bac Ninh province acquired land for urban/economic development and public infrastructure. Land acquisition in Dong Tam, whereas, was for defense purpose.

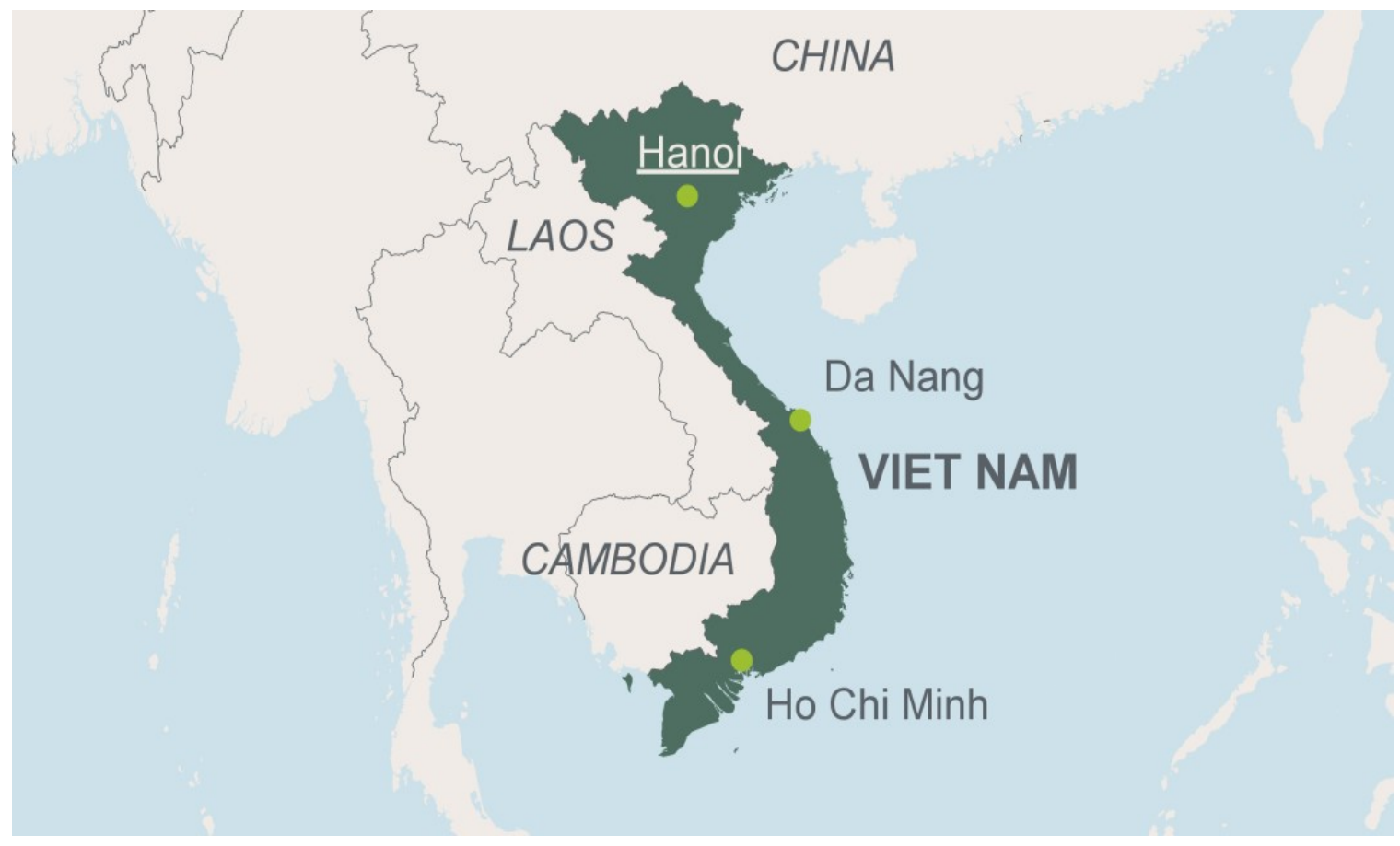

Figure 4. The Socialist Republic of Vietnam 
Chapter iv presents a description of the selected land-taking projects that local government had to deal with noncompliance. The key details related to each of the incident include the location and local context, starting time and time length, acquired land area, land-taking purposes, number of affected people, number of noncompliant landholders, the evolution and intensity of noncompliance, the government's responses to noncompliance and the consequences. Facts provided in this background chapter will not only help to draw a situational picture about the specific noncompliance but also further clarify why economic, institutional, and participatory governance factors are insufficient to explain the selected incidents. A detailed description of incidents will also help to reveal the research opportunity for the policy tool approach that is expected to generate new insights about landholders’ noncompliance in land-taking policy implementation in Vietnam.

\subsection{The case of Tu Son -Land Acquisition for Infrastructure in BT design}

The land-taking instance in Tu Son (Bac Ninh province) is in a building and transfer design (BT project) in which the government partners with private investors to construct public infrastructure or provide public services. The public-private partnership (PPP) was recognized in the Vietnam’s 2014 Law of Investment and further specified by the central government's Decree 15/2015/NĐ-CP (CGV, 2015). Over the last years, this policy has resulted in the proliferation of BT and BOT project across Vietnam. PPP has been preferably used by local government across Vietnam for public infrastructure development. The involvement of private investors in BT and Bot projects, however, also make land acquisition more complicated and disputes are more likely to occur (Anh Phuong, 2018). Within Tu Son district, several public constructions (e.g. roads and a 
water supply system) were funded by private sources. The provincial government often used land as a "matching capital” to attract private investors for public constructions. The Tu Son incident was in form of claim and petition over land-taking because it lasted long but landholders did not rely on violent acts to protect thier land.

\section{Local context}

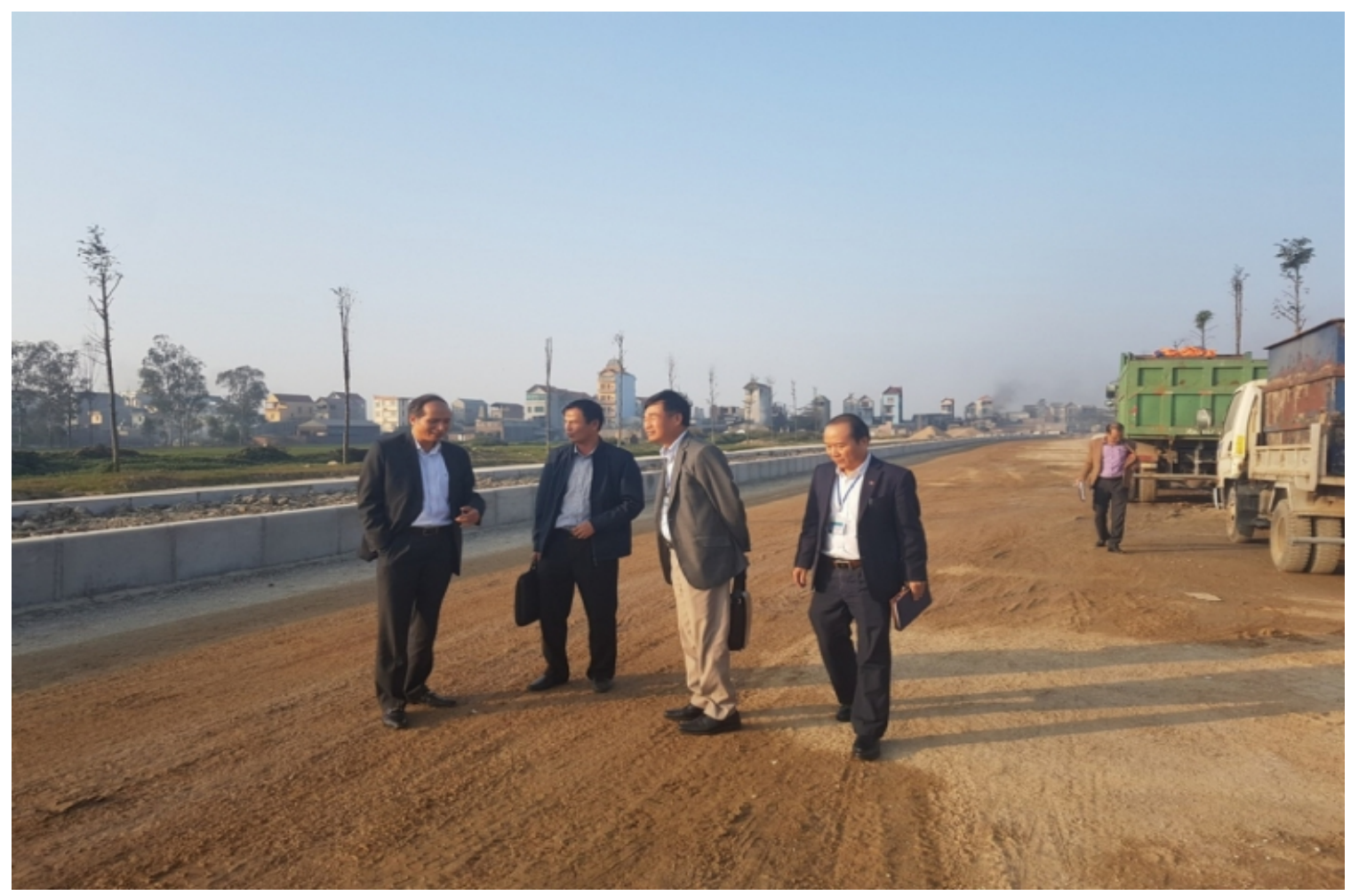

Figure 5. Provincial Road TL 277 in Tu Son district

(Source: tuson.bacninh.gov.vn)

Locating in the North of Hanoi capital city, Tu Son is the second largest district of Bac Ninh province. The district has a natural area of $61,33 \mathrm{~km} 2$, and a population of 163.000 people(TSG, 2017). After nearly two decades of urbanization process, Tu Son district has become a new urban center that increasingly required a modern infrastructure system. In 2012, the district government was approved by Bac Ninh’s PPC to take land 
serving the construction of a road in BT design. However, like other BT and BOT projects across Vietnam, the local government confronted disobedience among affected land users who argued that investors should only receive land in locations that they invested in.

\section{The disputes}

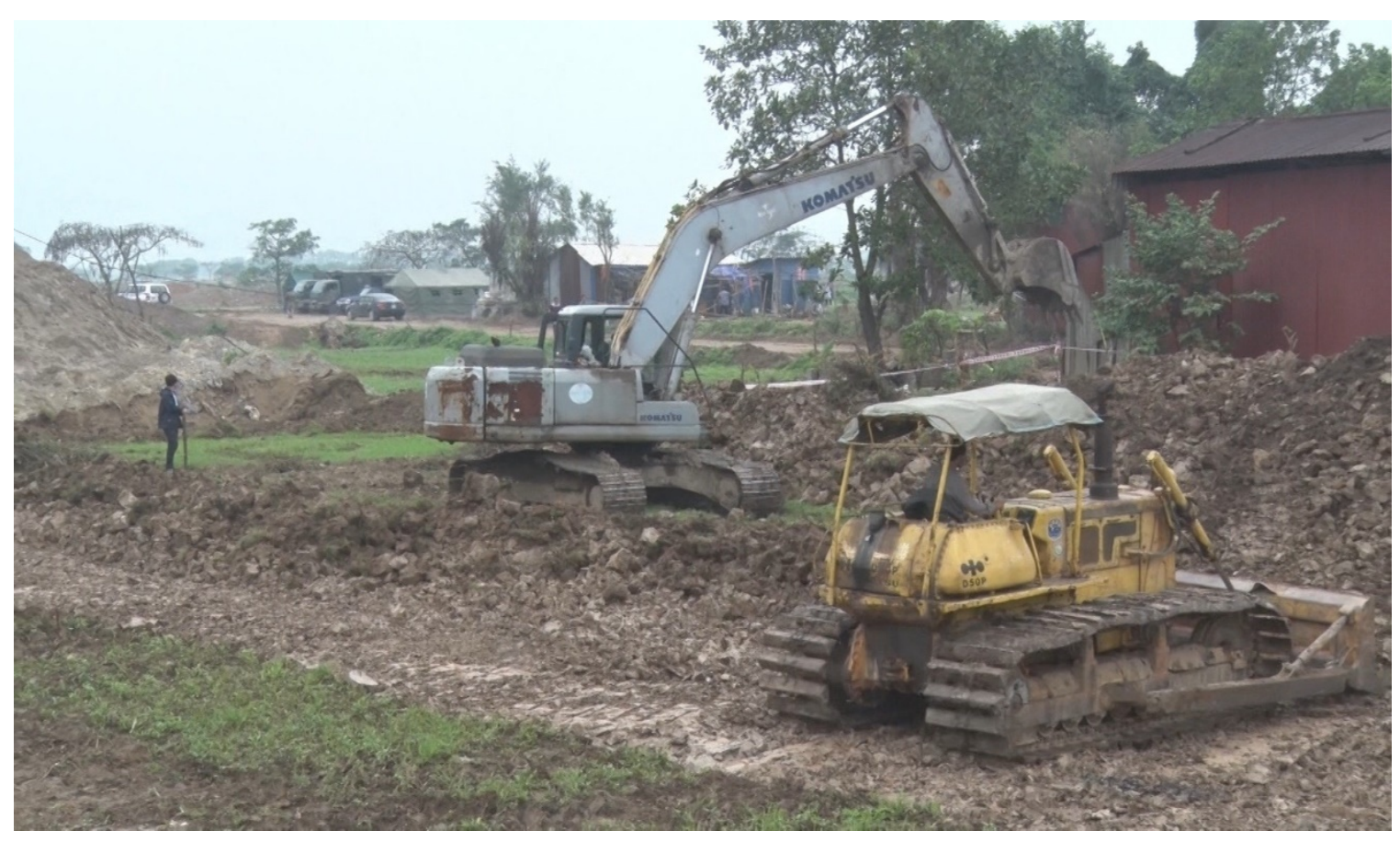

Figure 6. Compulsory land acquisition in Dong Ky ward

(Source: tuson.bacninh.gov.vn)

The Tu Son case was a typical BT land-taking incident that the researcher had chance to get real experiences with policy implementation in the research field. Disputes arose in late 2012 when the provincial government recovered land in two wards of Dong Ky and Trang Ha to construct a provincial road of $9 \mathrm{~km}$ in length. The project was a Build - Transfer Design (BT project) in which a private company, Long Phuong Co., was selected by the provincial government to build the road. A unique characteristic of Tu 
Son incident was that the government had to deal with individual households to recover numerous small plots of land. Since the road went through both residential areas and agricultural field, types of affected land varied between households. Some households had to give up part of their housing land right of way while others were acquired a piece of farming land. More importantly, because landholders knew that the road was in the BT design and investors was assigned another land patch in the same two wards, land acquisition became more complicated. As the researcher leant at the dialogue between $\mathrm{Tu}$ Son district BCGC and affected landholders on September 5, 2018, some landholders did not believe in the public purpose of land-taking. They instead often had doubts about land transactions for profits once the government recovered land for BT projects.

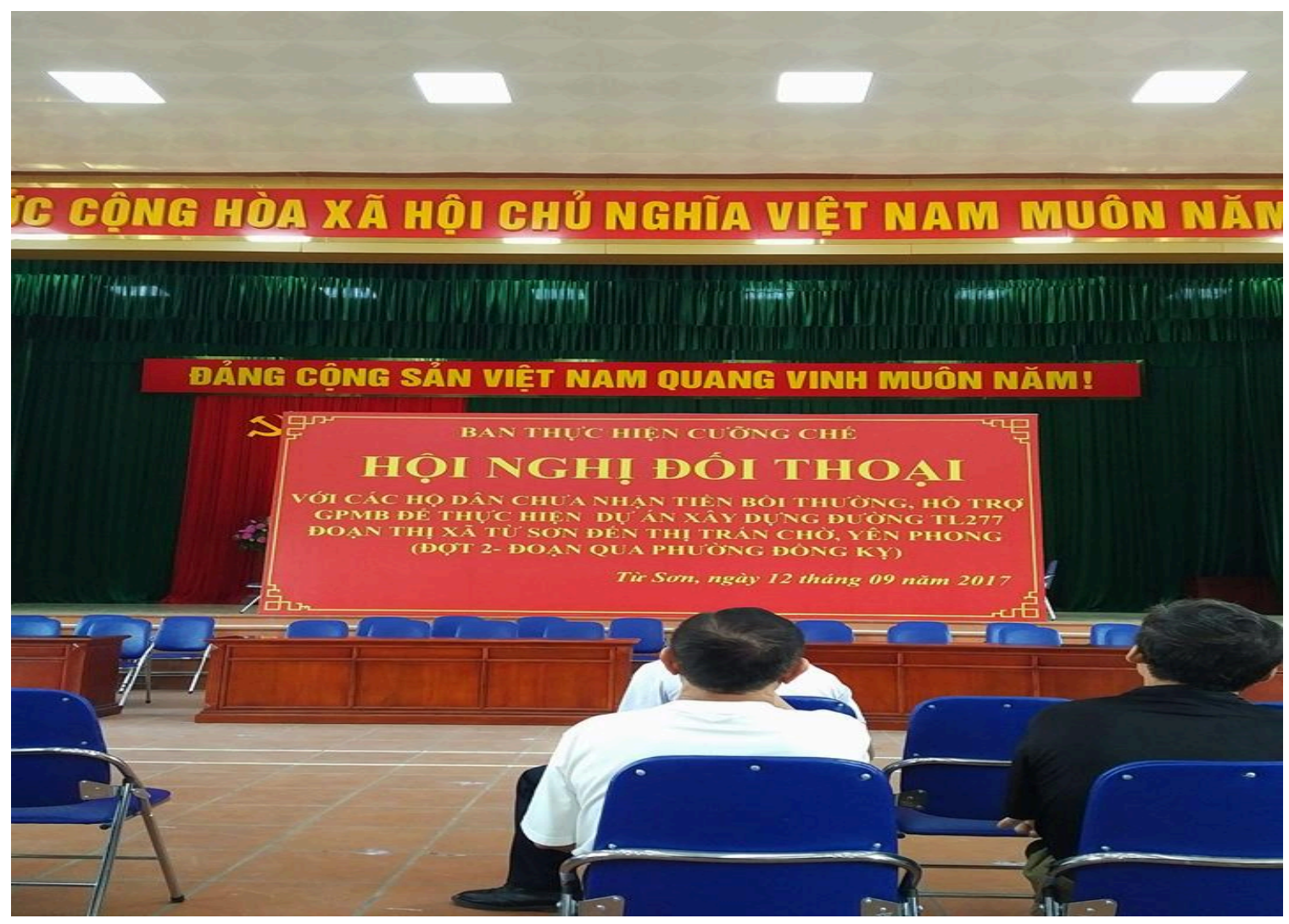

Figure 7. Dialogue with noncompliant land users in Dong Ky ward on September 5, 2018 
There were 323 landholders who had to give up part of their land to the provincial government. The total acquired land area was 86.9 ha of which 39.4 ha was taken by the provincial government while the district government appropriated the remaining 47.5 ha for the road. There were 49 disobedient land holders who did not accept government's compensation offers. Specifically, land-taking that started in 2012, was carried out in two phases: in phase 1, there were 199 affected households of which the government had to forcefully acquire land from 35 . In the $2^{\text {nd }}$ phase, the district government took 1.97 ha affecting 124 households. However, 14 out of 124 households resisted the land-taking plan. Disputes did not last long but affect the road construction. Though the road was supposed to be completed in the first half of 2018, disobedience over land-taking delayed progress until January 2019 (TSG, 2017).

Dealing with noncompliance, public officials were sent to individually convince resistant landholders at their home. The government also organized several dialogues with affected landholders to reach a settlement. Despite government's persuasion efforts, noncompliance over land-taking resulted in disputes and tensions, and critically slowed progress of the road construction. According to land officials, with the involvement of private investors, land users mainly disputed unfair land price and low compensation. They did not really care about the public interest of land appropriation. They instead wanted to directly negotiate with investors for better benefits and higher compensation. This was because affected landholders knew that private investors who built the road will receive another land area for business purposes.

Coercive land acquisition: Long lasting noncompliance resulted in a provincial government's executive order that allowed compulsory land acquisition. The Tu Son 
district government then continued to dialogue with noncompliant land users until September 2017. However, the remaining 14 affected landholders still disagreed with compensation offers. Finally, in late September 2017, the local government acquired the land by force.

\subsection{The case of Thu Thiem - Land Acquisition for Economic Development}

Local context: Thu Thiem is located in Ho Chi Minh City (HCM) - the heart of Vietnam's economy. According to ICB (2018), the general plan of Thu Thiem was approved by the Premier in 1996. The total area covered 930 ha and had a population of 180.000. In June 2002, the HCM city’s Council approved a plan to transform Thu Thiem into an international finance and services center. Thu Thiem was expected to be a key part of the urbanization and development of the city’s Eastern areas. The new urban complex consists of seven functional sub-sections such as office buildings, a recreation and tourism zone, an administrative zone, a financial and trade zone, and a resettlement zone. According to the Investment and Construction Board of Thu Thiem, the HCMC government by 2015 had acquired 930 ha of land in preparation to develop the new urban center. Land acquisition was conducted in five areas: An Khanh, Binh An, Binh Khanh, An Loi Đong, and Thu Thiem. Land-taking affected 14,351 households and over 60,000 residents. By the end of 2015, the city government had compensated 14.251 households, accounting for $99.28 \%$ with total acquired land area of 715.143 ha (98. 97\%).

The disputes: Disputes started in mid-2000s, but the most serious disputes mainly took place over the area of 4.3 ha that was outside of the boundary line of the Thu Thiem complex (Central government's Inspectorate, 2018). The land acquisition of 4.3 ha affected 321 households: 166 accepted compensation and moved to new places while 155 
noncompliant households were compulsorily removed by the city government (Huy Thinh, 2019). These 115 noncompliant landholders owning 7. 4065 ha remained in possession of the land. They disputed the city government's claim that their land was within the borders of the Thu Thiem project (ICB, 2018). Some of the 115 noncompliant land users asked the HCM city government for a separate land-taking plan. Giving the city government did not accept land users' request, disputes lasted over nearly two decades. This made Thu Thiem incident become one of the most serious land-taking conflict that was ranked on top of the intensity-base typology of land-taking noncompliant manifestations.

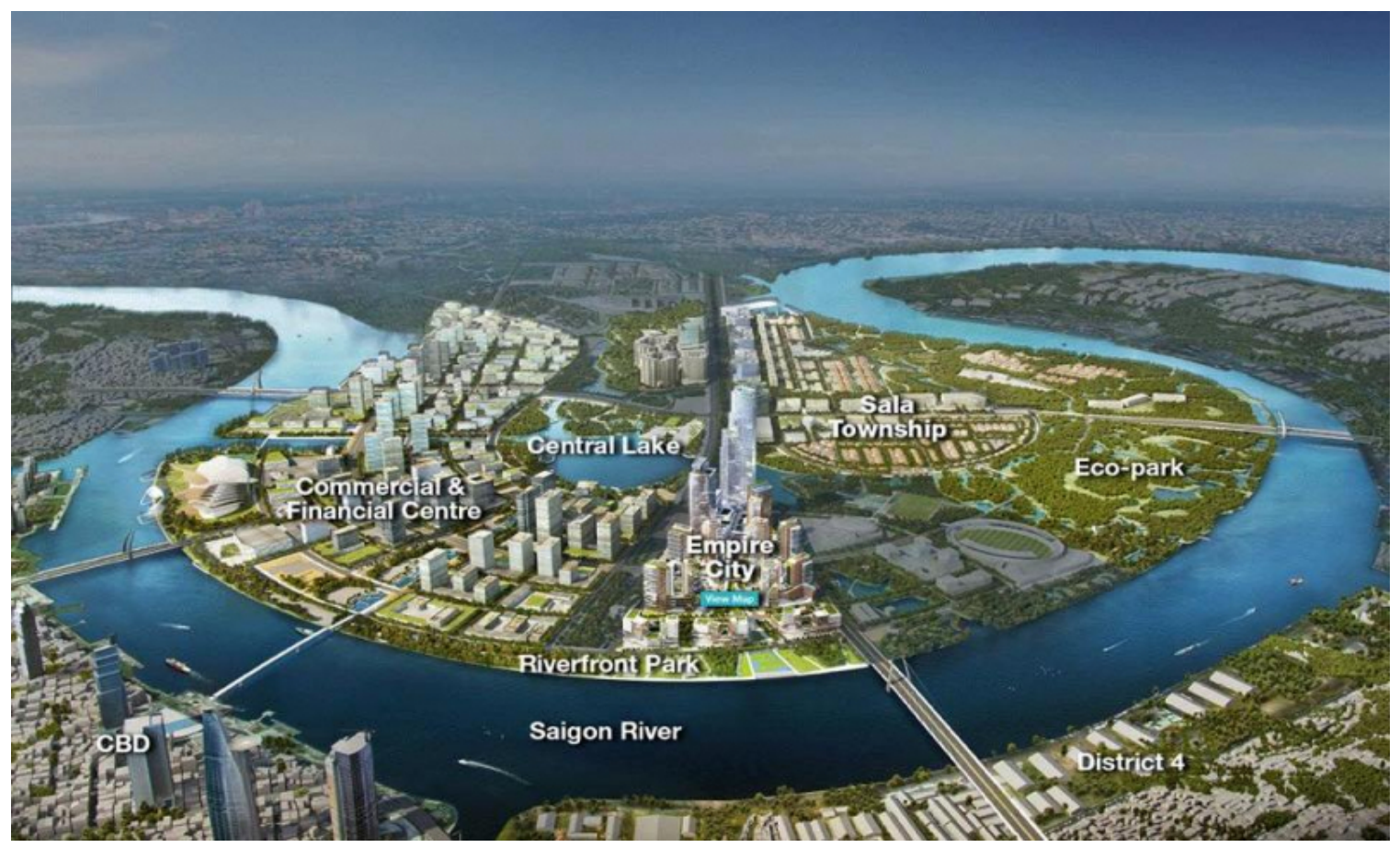

Figure 8. New Urban Area of Thu Thiem (Source: baogiaothong.vn)

. A key reason for disagreement between land users and the city government were the different scales between the map issued in 1996 by the Premier (latter approved by the city government in 2005) and a modified map issued by the Ho Chi Minh City 
government in 2012. According to the original map approved by the central government, these 115 noncompliant households were not affected by the Thu Thiem project while the Ho Chi Minh City’s new land planning map did include them. Tensions rose from 2005 and more serious disputes began in September 2014 when land users sent a collective petition to the City government. Since the city government's response did not meet the land users' demands, they sent the petition to the central government (Minh Quang, 2018). Affected land users' grievances reached a peak between 2016 and 2018 when the district government forcibly remove them in order to take the land.

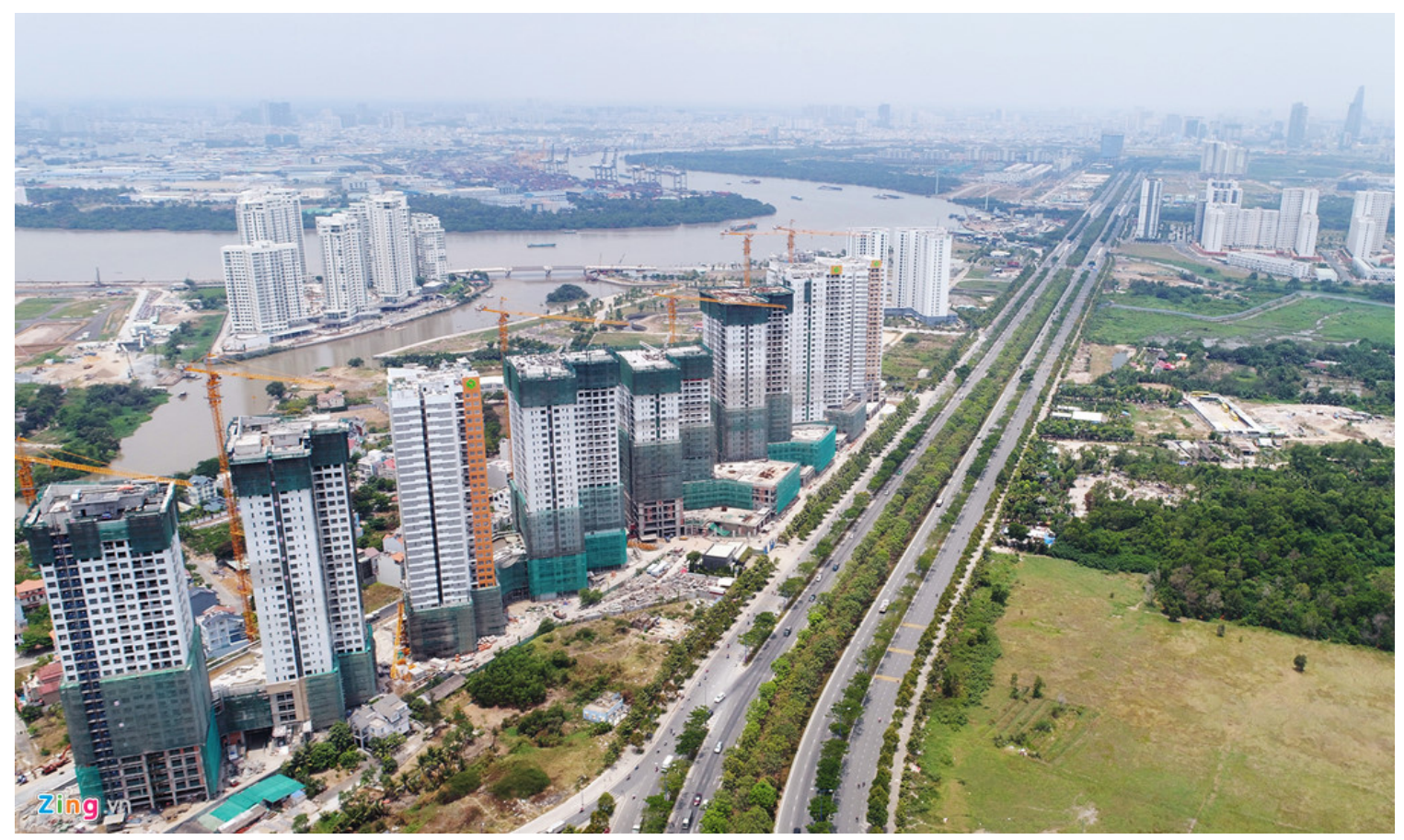

Figure 9. Apartments and Office Buildings under construction in Thu Thiem

(Source: News.zing.vn)

Still seeking a solution: In late 2018, responding to the land users' request regarding the original land planning map, the City government stated that the map was lost. However, the land users had a map copy and made it public. This turned the Thu 
Thiem incident into a "hot land scandal" in Vietnam (Vietnamnet, 2018). After the central government's inspectorate released the inspection report in September 2018, some city's high-ranking leaders were disciplined. The government also issued a commitment that they would make their best efforts to solve disputes in the last two months of 2018. However, until May 2019, the Thu Thiem incident has not been solved yet. At the meeting between representatives of the National Congress and voters on May 7, 2019, affected landholders still aggressively criticized the city government for slow progress of solving the Thu Thiem incident. Many landholders asked representatives to bring this incident to the National Congress.

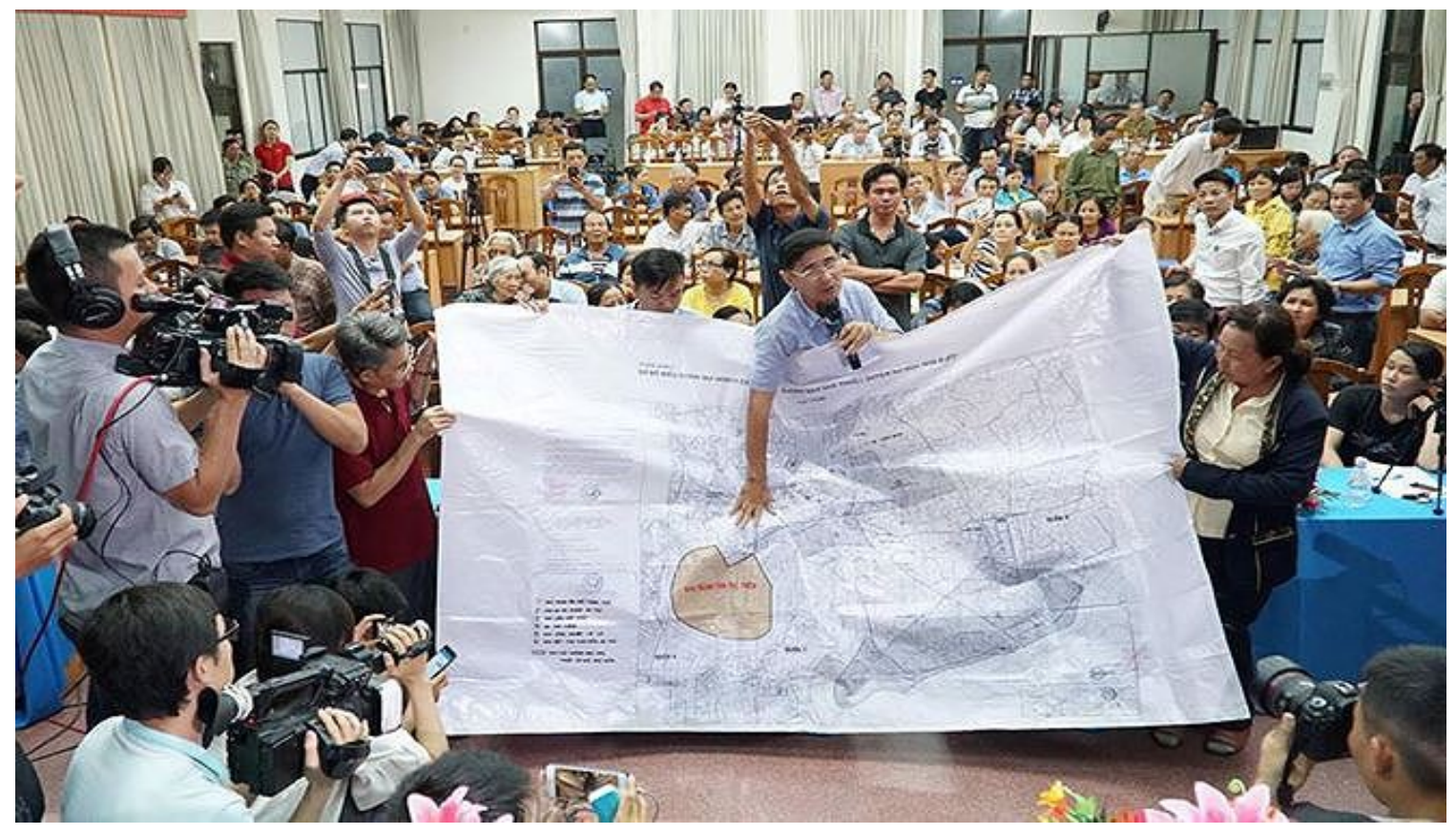

Figure 10. A dialogue between land holders and the HCM city government

(Source: cafebiz.vn)

\subsection{The case of Dong Tam - Land Acquisition for Defense Purpose}

Local context: Dong Tam is a rural community locating $40 \mathrm{~km}$ in distance from the Hanoi's city center. Most villagers work on agricultural field surrounding their 
commune. The Dong Tam event is distinct from other land-taking disputes because the incident was a collective resistance led by a former commune's leader. Thousands of villagers resisted land acquisition for Viettel. Co. owned by the Ministry of Defense. Viettel Co. was founded in 1989 and now is one of the two largest telecommunication corporations in Vietnam. Considering the number of service users, Viettel is among top 15 global telecommunication providers. In addition to the telecommunication service, Viettel Co. is also a defense technology producer - one of the most successful enterprise owned by the State of Vietnam (Viettel, 2019).

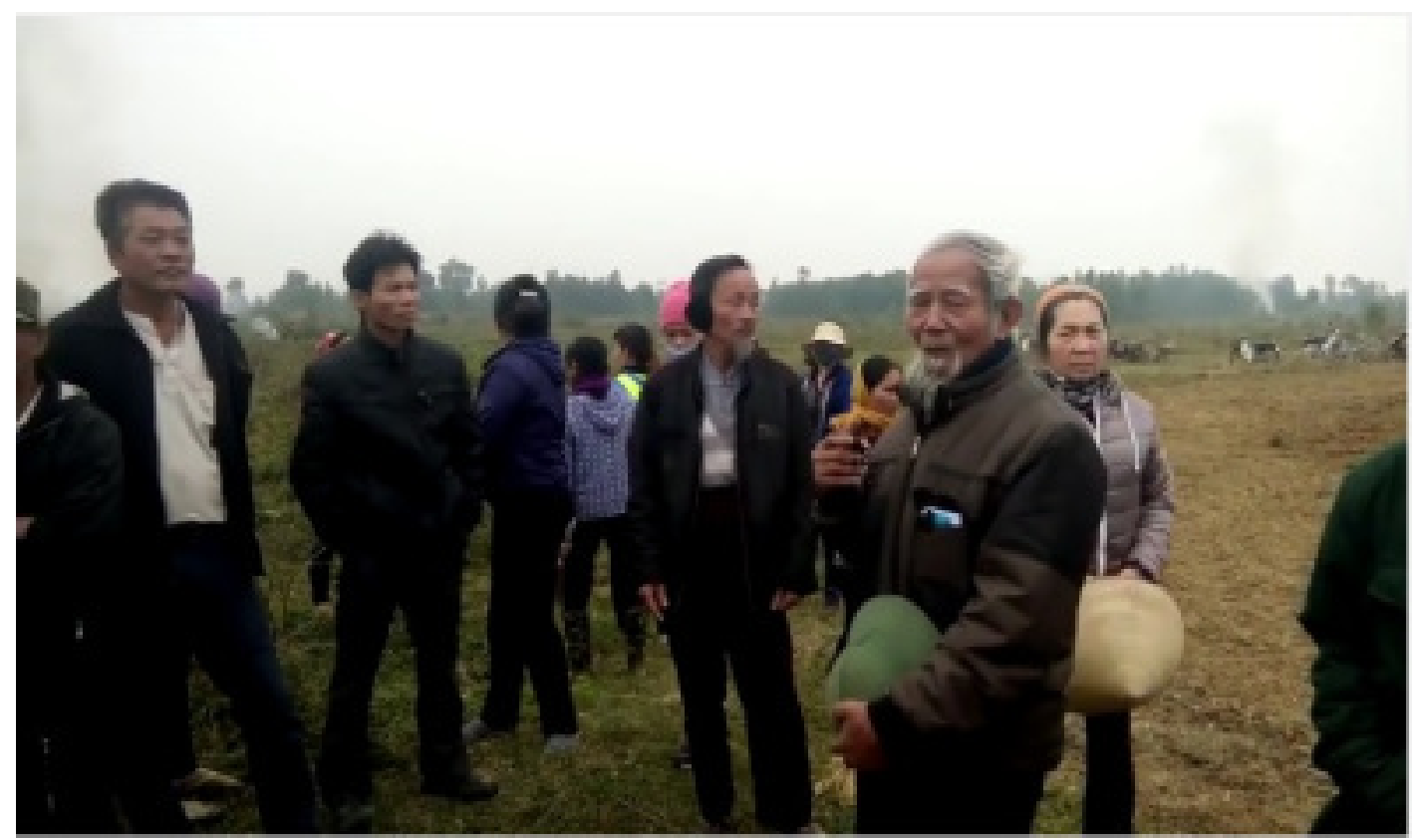

Figure 11. Noncompliant land holders at the disputed field

(Source: vtc.com.vn)

The villagers' collective resistance

In May 2015, the city government authorized the My Duc district government to acquire 50.03 ha of land and assigned the land for Viettel Co. The original source of the 
land-taking dispute in Dong Tam case that took place from 2015, was the question of the boundary lines between defense and non-defense land. While the government asserted Dong Tam farmers illegally used defense land, villagers showed evidences that the land area assigned for the airport construction did not covered the disputed land. Defense or non-defense land was important because the exact boundary could determine if the government could take the land for defense purposes which would minimize compensation. According to Articles 64 and 65 of the 2013 LOL, the State does not compensate landholders for the defense land. This means that Dong Tam villagers might have to give up their land without any compensation (Nghia Hoang, 2017).

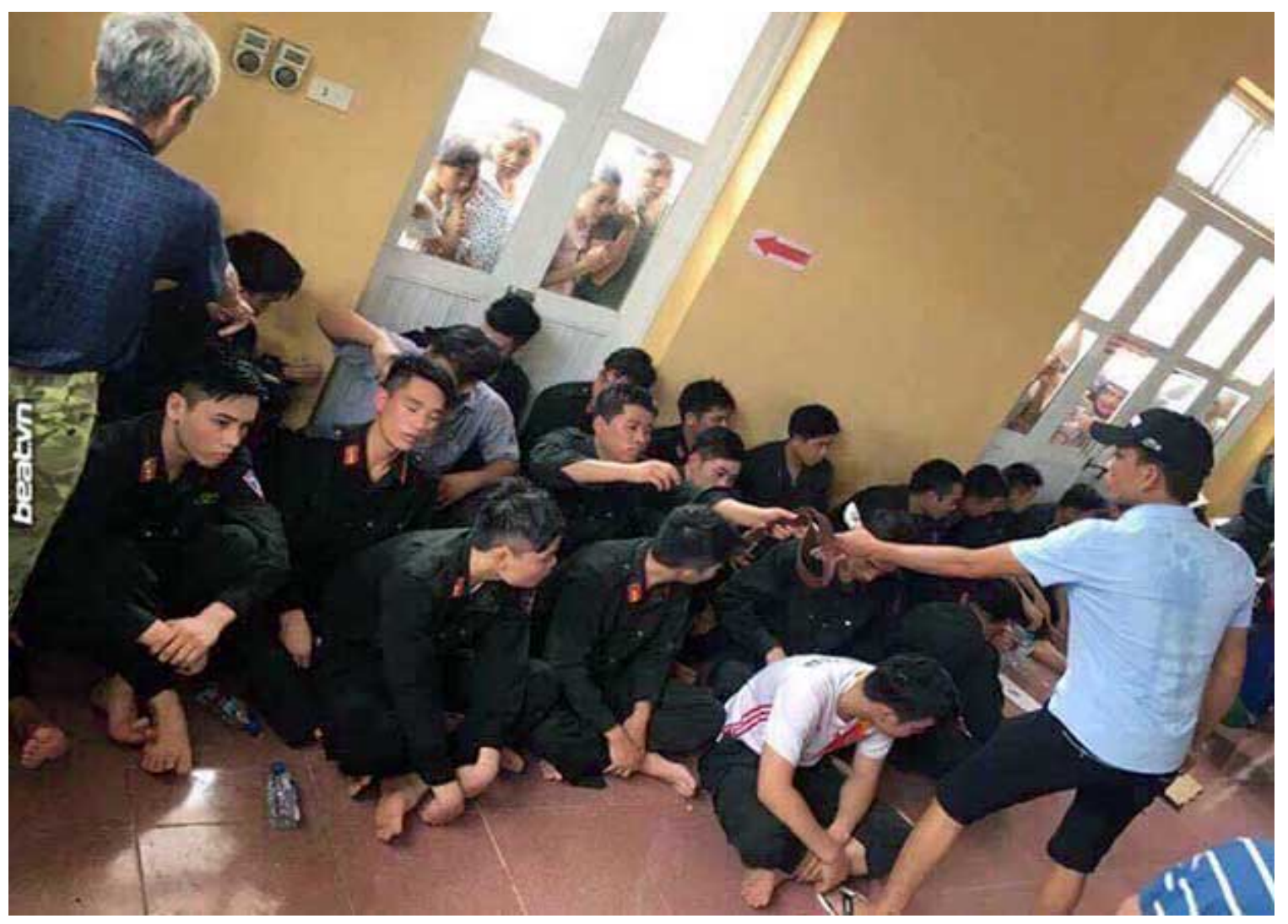

Figure 12. Police hostages in village’s cultural house

(Source: bbc.com) 
As required by the LOL, land-taking was conducted by the district BCGC. From the city's point of view, the land-taking was legitimate because villagers occupied defense land without permissions from government. According to the city, in 1980, the central government acquired a land from four communes: My Luong, Tran Phu, Đong Lac (Chuong My district) and Dong Tam (My Duc district), in order to build a military airport. In 2014, the Ministry of Defense assigned the land area for a military unit for their use. In 2015, to have land for Viettel Co., the Ministry of Defense and My Duc district government announced a recovery of 50.03 ha of defense land, including 46 ha where Dong Tam farmers were doing agriculture. Both the city and district governments asserted that since Dong Tam residents illegally used the defense land for farming purposes, they had to leave the land (Nghia Hoang, 2017).

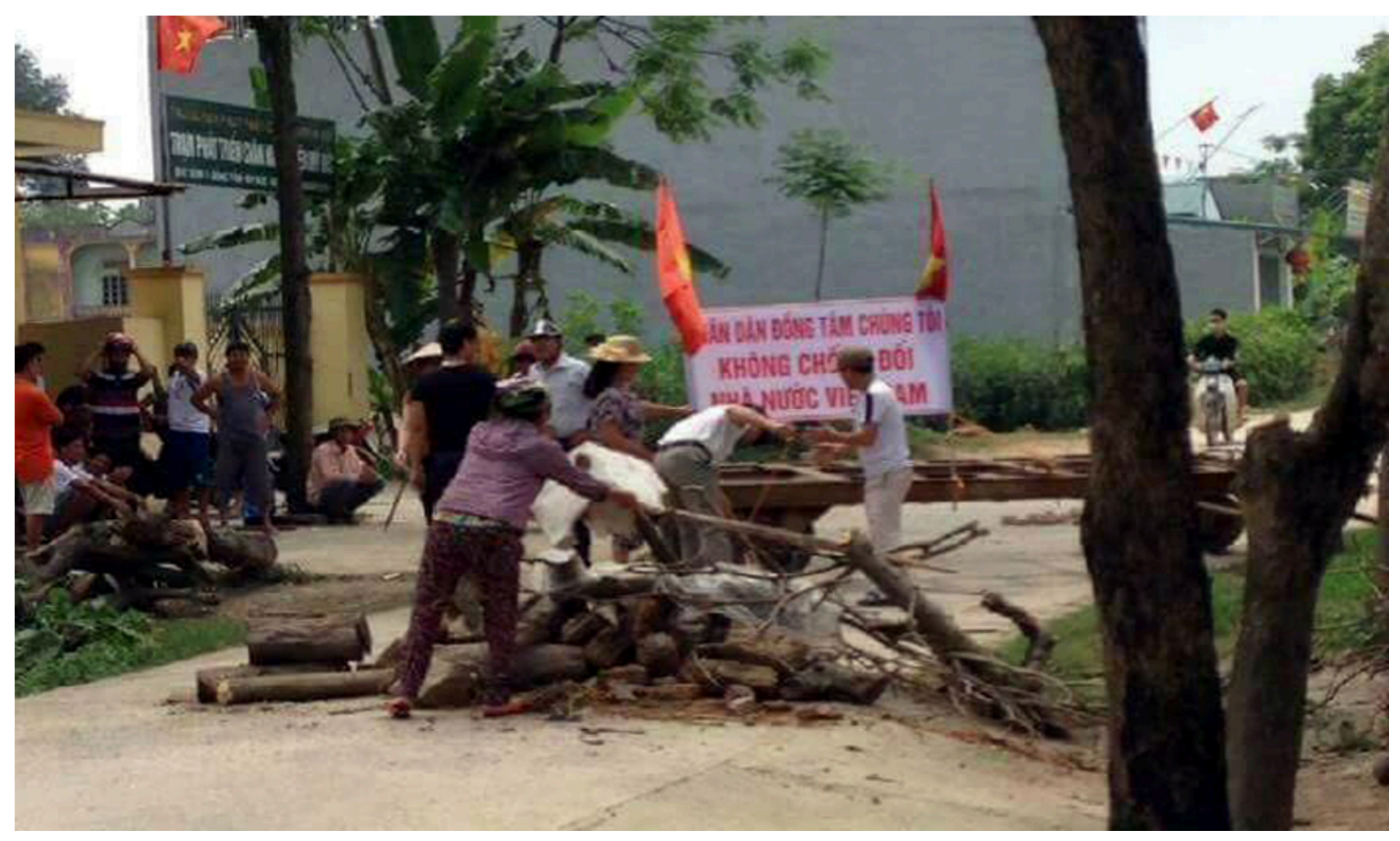

Figure 13. Villagers’ preparations to deal with government’s potential attack (Source: bbc.com) 
Local villagers resisted the land-taking plan because, as they asserted, 46 ha out of 50.03 ha was not land used for defense purposes. In other words, most of the acquired land is non-defense land that should still belong to Dong Tam commune (Hai Long, 2016). According to land holders, in 1980, a land area of 47.36 ha in Dong Tam was acquired by the central government to construct a military airport. However, because the airport construction plan was canceled in 2007, the military unit managing the land returned the total acquired area of 47.36 ha to Dong Tam commune. On July 30, 2007, the district and commune governments certified the borders separating defense land from non-defense land that latter was reverted to land users. Local villagers hoped they would then be able to use the land for agricultural production. However, year after year, the local land holders were not able to access the land. Whereas, some large land transactions were made under the support of district and commune governments. More importantly, Dong Tam farmers found that the transacted land area was not defense land; it belonged to the acquired land area of 47.36 ha that should have been returned to Dong Tam residents.

“As far as I know, all land area here was originally used by Dong Tam residents from the early 1960s. On April 14, 1980, the vice premier signed executive order no. 113/TTg collecting 47.36 ha for an airport construction. Dong Tam villagers remained farming on the area of 59 ha in the East side of the airport. Only 14 households were allowed doing agriculture on the airport land (47.36 ha). Villagers did not occupy or use any other plots of airport land. On the other side of the planned airport, there was an area of 6.8 ha tentatively used for the airport's further development...called "project land", but this area was not included in the defense land area of 47.36 ha. In 2006, since the 
airport plan was canceled, the military unit managing 6.8 ha returned the land area to Dong Tam commune. Dispute took place when Viettel.co started construction in 2015 while Dong Tam villagers were not able to access the land (Le Dinh Kinh, former secretary of the commune government, leader of noncompliant villagers).

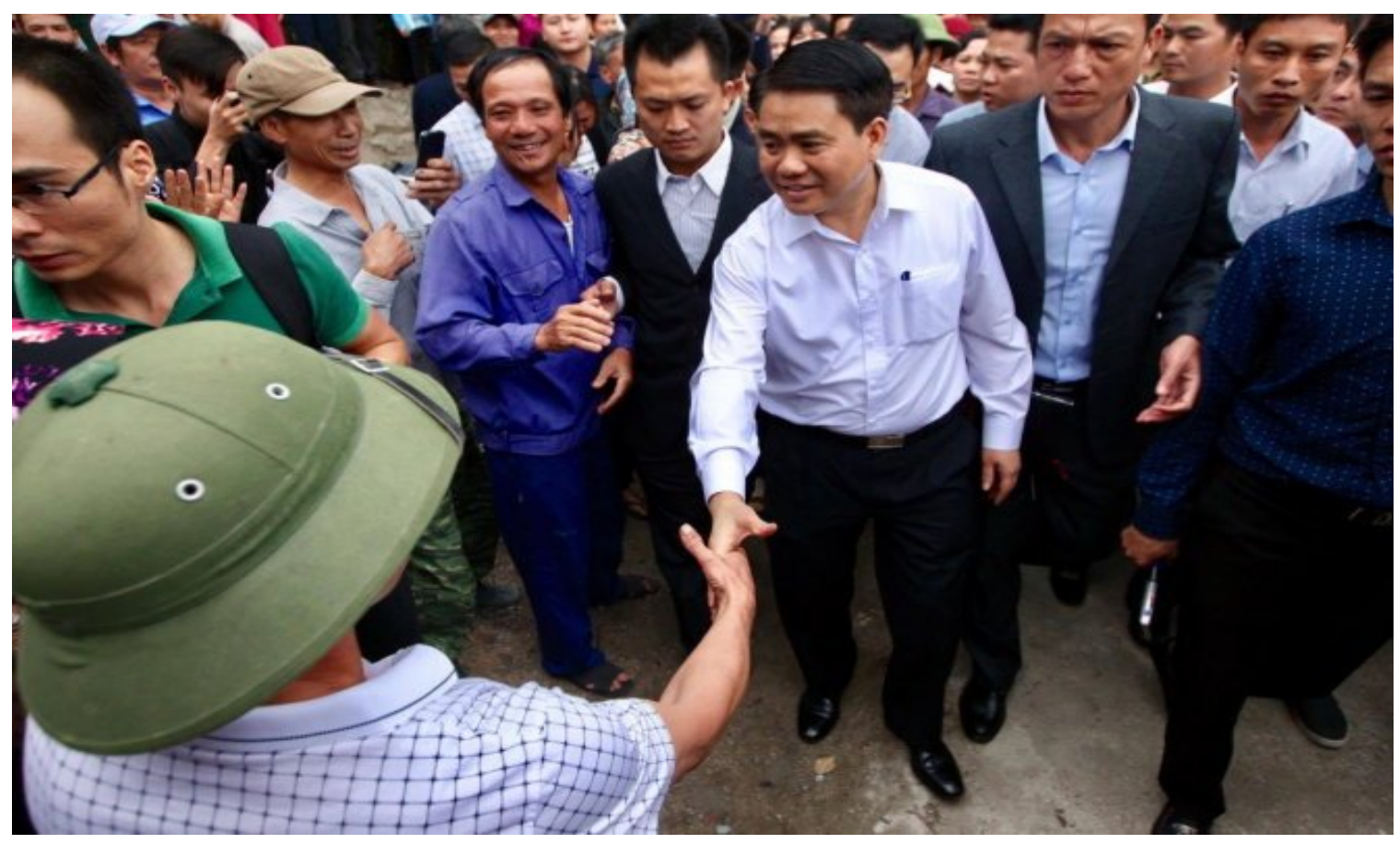

Figure 14. Dong Tam villagers met with Hanoi city’s mayor on April 22 ${ }^{\text {nd }}, 2017$

(Source: vtc.com.vn)

Claims and petitions were sent to the Ministry of Defense, the district government of My Duc, and to the city government of Hanoi. However, land holders' claims were not accepted by local governments and the Ministry of Defense. In 2015, Viettel Co. started their construction on disputed land. Dong Tam villagers disagreed. From late 2016 to February 2017, they camped and occupied the land area of 46 ha to keep delay the construction. In early March 2017, the district government sent delegations to talk to land users. Villagers, however, did not cooperate with government officials. Tensions 
continued to increase when land users occupied the commune government's offices and did not allow government delegations to leave. In order to protect the disputed land and solve the conflicting situation, the city government sent police. On April 15, 2017, Hanoi police arrested four noncompliant land users, including Mr. Le Dinh Kinh - .82 years old, former party secretary of the commune government, leader of affected land users, who severely got injured in the arrest (Bbc.com, 2017).Government's aggressive actions resulted in a serous clash between land users and law enforcement force: villagers damaged police cars and detained 38 public officials to request a dialogue with the city's mayor. Noncompliant villagers stated that they are willing to use violence if the city government attacked them to free the hostages. Local villagers' grievances and tensions were only reduced after the city promised a meeting between villagers and the city's mayor (Ives, 2017).

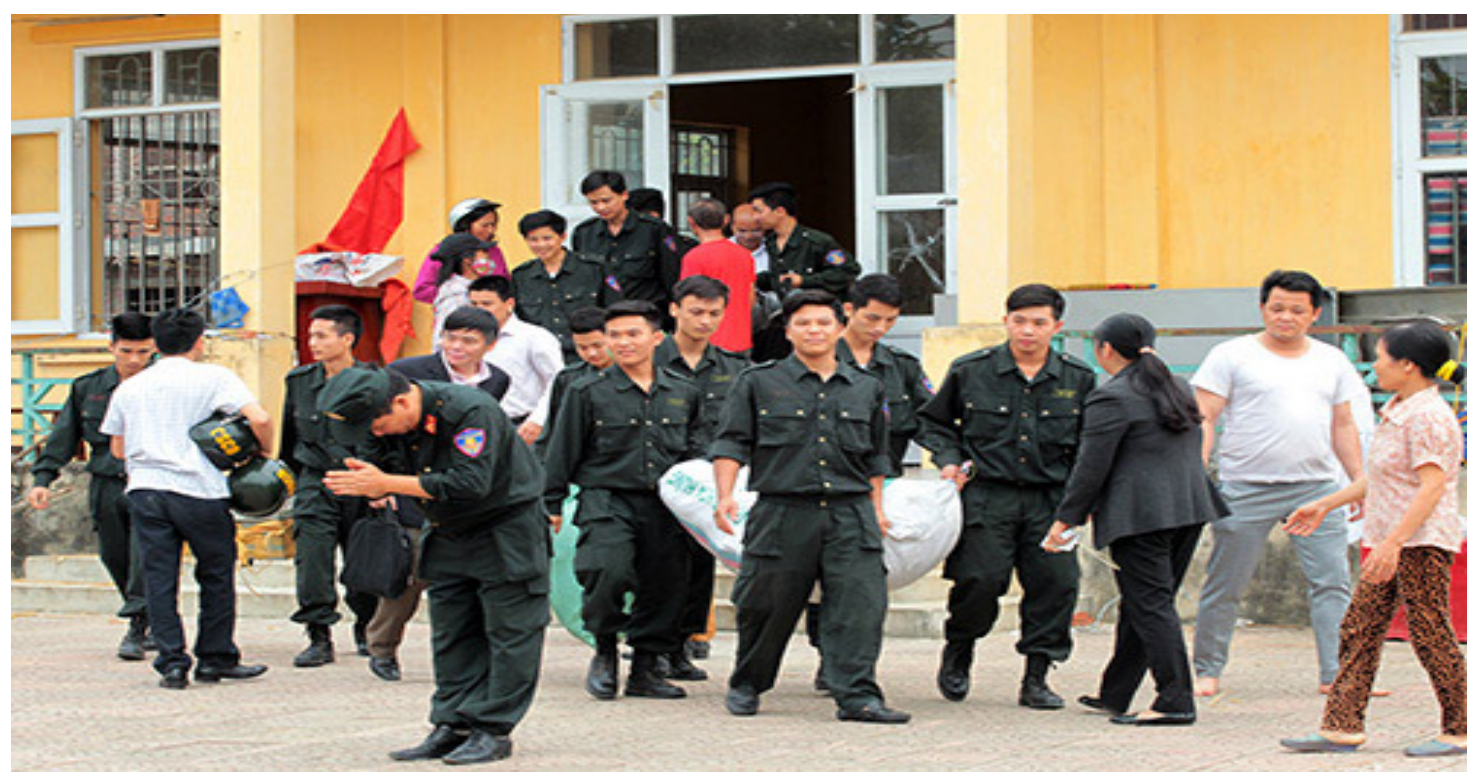

Figure 15. Hostages were freed on April 22 ${ }^{\text {nd }}, 2017$

(Source: vtc.com.vn) 


\section{Authority based settlement}

The high-profile conflict finally was solved by several public meetings and dialogues between the city's mayor and the villagers in April and May 2017. Tensions were minimized; the construction of Viettel. Co was delayed and some corrupt land officials were prosecuted. The city government's inspectorate was required to inspect the land acquisition project in Dong Tam. In late July 2017, city’s inspectorates confirmed that the total area of defense land assigned for the airport construction was 236.7 ha that covered disputed land (Vo Hai, 2019). Noncompliant disagreed and sent a petition to the central government's inspectorate. In April 2019, after reviewing the inspection report published by the Hanoi government's inspectorate, the central government's inspectorate asserted conclusions made by the Hanoi government were correct and legal. The disputed land was defense land. Dong Tam villagers were not invited to information sessions organized by the city government. They were required to give up the land and the city might consider compensate 14 land users who had properties on the disputed land.

\subsection{Summary of the Chapter}

The history of land acquisition in Vietnam officially started with the Land Law of1993. Between 1993 and 2003, compulsory land acquisition by the State was the only form of land recovery. The revised Land Law of 2003 allowed two forms: voluntary and compulsory recoveries/acquisitions that remained in the latest LOL of 2013. All three land-taking projects chosen for this study fall into the second category - compulsory acquisition. This chapter provides a descriptive background of three cases under study.

Three selected land-taking cases represent different types of land-taking noncompliance in Vietnam: if the involvement of private investors in a public - private 
partnership challenged the legitimacy of land acquisitions in Bac Ninh province (Tu Son incident), the unclear boundary of acquired defense land fueled a collective resistance among villagers in Dong Tam (Hanoi city). Whereas, HCMC government confronted with wicked challenges of a large land-taking plan for economic development. The three incidents under study vary in terms of locations, time length, causes of noncompliance, number of affected landholders, number of noncompliant landholders, and level of intensity. A common procedural feature, however, shared by all three incidents is that the government was willing to take land by force after failing in convincing landholders to give up their land. Key facts about the three incidents are summarized in the table below:

Table 4: Facts about three land-taking incidents

\begin{tabular}{|c|c|c|c|}
\hline \multirow[t]{2}{*}{ Facts } & \multicolumn{3}{|c|}{ Land-Taking Incidents } \\
\hline & Thu Thiem & Dong Tam & Tu Son \\
\hline - Acquired land area & 930 ha & 50.03 ha & 86.9 ha \\
\hline - Main purposes & $\begin{array}{l}\text { Economic } \\
\text { Development }\end{array}$ & Defense & $\begin{array}{l}\text { Infrastructure } \\
\text { Development }\end{array}$ \\
\hline $\begin{array}{l}\text { - No. of affected } \\
\text { landholders }\end{array}$ & 14,351 & All villagers & 323 \\
\hline - No. of noncompliant & 115 & All villager & 49 \\
\hline - Time Length & $2005-2019$ & $2015-2019$ & $2015-2017$ \\
\hline $\begin{array}{l}\text { - Types of } \\
\text { Noncompliance }\end{array}$ & Petition \& Dispute & $\begin{array}{l}\text { Land occupation } \\
\text { \& Violence }\end{array}$ & $\begin{array}{l}\text { Daily } \\
\text { resistance, } \\
\text { dispute, and } \\
\text { land occupation }\end{array}$ \\
\hline $\begin{array}{l}\text { - Types of } \\
\text { Compensation }\end{array}$ & $\begin{array}{l}\text { Cash and resettlement } \\
\text { apartments }\end{array}$ & No & Cash \\
\hline
\end{tabular}

Note: There was only 14 landholders who were farming on the affected land area in Dong Tam incident and being required to give up the land. However, the Dong Tam incident was a collective disobedience in which an unverified number of villagers disputed the Hanoi government’s land acquisition. 


\section{CHAPTER V: NONCOMPLIANCE WITH LAND ACQUISITION - A POLICY TOOL FOCUSED ANALYSIS}

"Tools define the set of actors who will be part of the cast during the all-important implementation process that follows program enactment, and they determine the roles that these actors will play. Since these different actors have their own perspectives, ethos, standard operating procedures, skills, and incentives, by determining these actors the choice of tools importantly influences the outcome of the process" (Salamon, 2002: 10)

\subsection{Introduction}

The fifth chapter of the dissertation presents a tool-focused analysis of three landtaking noncompliance. The researcher aims to explore if implementation tools contribute to land users' noncompliance. How? This key research question requires a differentiation between the institutional design of land-taking policy (embedded in land legislation) and actions of implementers in practice. This study, th us, will only be concerned characteristics of tools and local officials' actions (e.g. tool choice, use, and management) in order to acquire land. The researcher proposes that since implementation tools determine interactions and relationships between implementers and target groups, tools’ choice and use might contribute to landholders' policy noncompliance.

Adopting the cross-case analysis approach, the researcher will not present analysis of single cases. Individual cases (incidents) instead serve as the evidentiary base for the multiple case analysis. The analysis, specifically, was guided by sub-analytic 
questions: (i) what were tool mixes used by local implementers to acquire land in Thu Thiem, Dong Tam, and Tu Son? (ii) what were common patterns of tool-based responses to noncompliance? (iv) what were tools used to settle incidents? And (v) how, if any, did tools' characteristics (e.g. strengths, weaknesses, choice, use, and management) contribute to policy noncompliance? Based on sub-questions, the researcher developed three general themes to construct a theme-based analysis: (i) tool mixes in acquiring land, (ii) tool-based responses to noncompliance, and (iii) tool choice to settle incidents. These were common themes arose across three incidents. Each general theme then was divided into sub-themes that covered specific tools such as organizational tools or authoritative tools. With a tool focused perspective in mind, the researcher looked for evidence that linked policy tools and tool adoption, with land users’ noncompliance.

This chapter, therefore, synthesizes lessons from all of three incidents under study. The analysis consists of three theme-based sections: first, the researcher begins the analytic discovery with an examination of implementation tools mixes used by local governments to execute their land-taking projects. Patterns of tools choice and use will be described and generalized in order to assess strengths, weaknesses, and inappropriateness of each tool and tool mixes as well. Next, the second general theme is an exploration of implementers' tool-based responses in dealing with land acquisition noncompliance. The researcher will identify tool preferences and patterns of tool choice/use that might determine outputs and outcomes of the execution of a land-taking project. The third section of this cross-case analysis describes major motifs of governments' tool related actions to settle disputes over land acquisition. The chapter finally ends with a concluding summary of research findings that will be discussed in detail in the sixth chapter. 
Figure 16: Tools framework used to analyze land-taking incidents

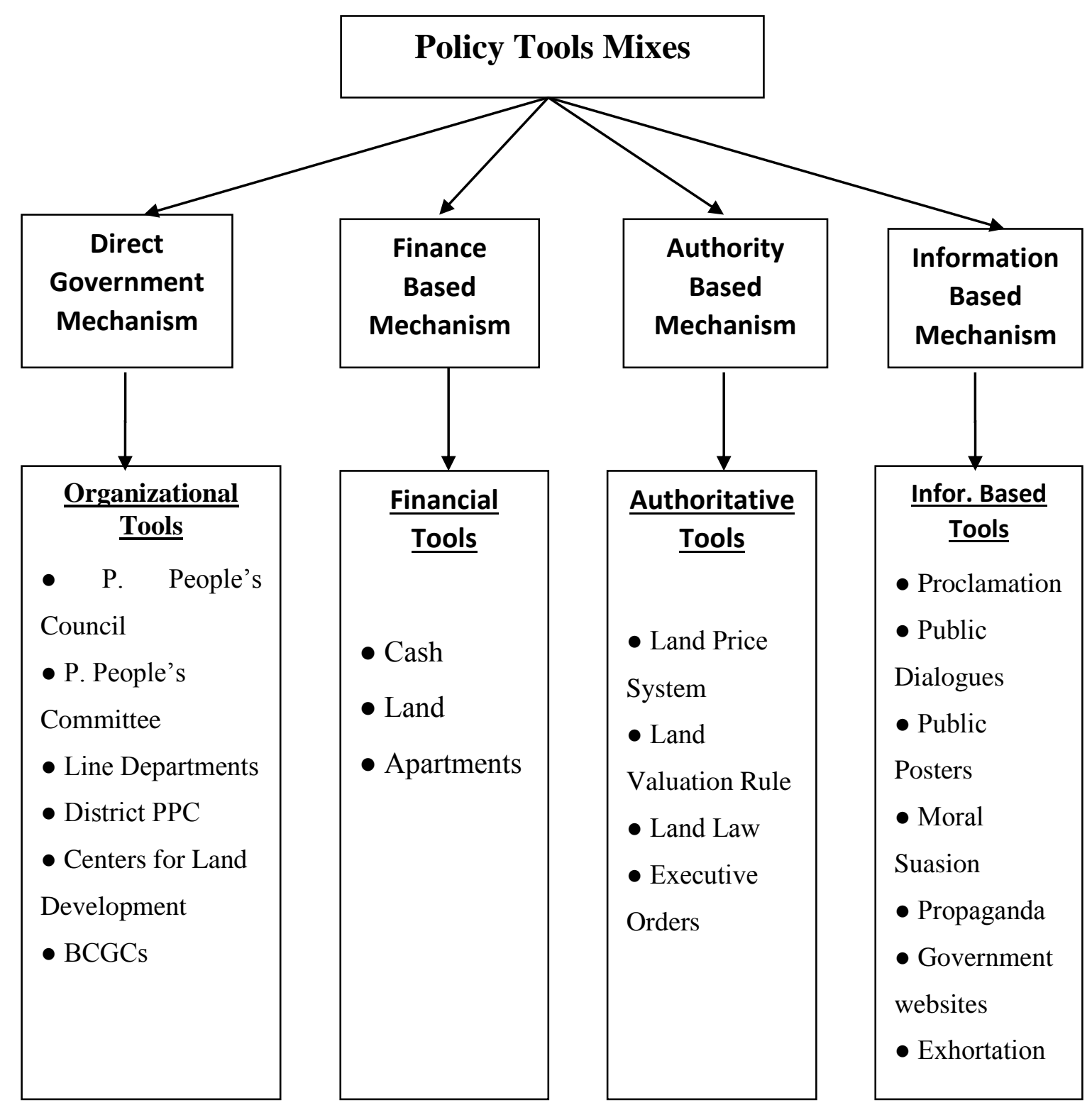




\subsection{Implementation Tool Mixes}

Based on policy tool literature, the researcher developed a theoretical framework of tools used to direct the analysis of three land-taking incidents. The tool framework consists of five major policy mechanism: (i) Direct Government, (ii) Indirect Government, (iii) Authority, (iv) Finance; and (v) Information (as summarized in Figure 2 on page 120). However, the tool based theoretical framework used in this study excludes the “Indirect Government” because Vietnam’s current land legislation does not recognize "Indirect Government" as a land-taking policy implementation mechanism. The remaining four mechanisms define a set of tools available for choice by implementers to execute land acquisition projects (see figure 3 on page 140). The following analysis of tool mixes is structured based on four sub-themes: "Organizational Tools”, “Authoritative Tools”, “Financial Tools”, and “Information-based Tools”.

\subsubsection{Organizational tools}

Organizations are a key component of governing institutions (Scott, 2014). As a policy tool, organizations are not only limited to institutional model, structure, and decision-making rulesbut also include human and financial resources. Forms of organizations, therefore, might reflect cultural beliefs, political contexts, and the level of socio-economic development of a nation. From a tool perspective, organizations are viewed in terms of the extent by which the government gets involved in the realization of policy ideas in practice. Organizational tools that refer to government, quasi-government, or nongovernment organizations will be assessed in relation to interactions between the government and policy targets; effectiveness, efficiency, and consequences of types of organizations used to change targets' behaviors and achieve policy goals. 


\section{Table 5: Members of BCGC - Tu Son Incident}

\section{Members of BCGC}

1. Tran Duc Quyet - DPC’s Vice Mayor, Head of BCGC

2. Nguyen Manh Cuong - Head of DONRE

3. Ngo Dong Vui - Deputy Head of Tax Agency

4. Nguyen The Tuan - Head of Finance and Planning

5. Nguyen Duc Quang - Deputy Head, Office of Urban Management

6. Tran Van Ngoc - President of PCU, Trang Ha ward

7. Tran Khanh Uan -Mayor of Trang Ha ward’s PC

8. Ngo Huu Tu - Vice Mayor, Trang Ha ward’s PC

9. Tran Quang Hung - President, Mother Front Committee, Trang Ha ward

10. Nguyen Hoang Thao - Land Official, Trang Ha ward

11. Ngo Quang Sang - Financial Official, Trang Ha ward

12. Tran Quoc Hoi - Party Secretary, Binh Ha residential unit, Trang Ha ward

13. Ngo Quang Tuong - Head of Binh Ha residential unit, Trang Ha ward.

14. Tran Van Mau - Mother Front Committee, Binh Ha residential unit

15. Nguyen Trong Cai - Land Official, Binh Ha residential unit.

16. Nguyen Dang Toan - Agriculture Official, Trang Ha ward

17. Tran Van Thanh - Representative of affected household

18. Nguyen Ngoc Tan - Investor

19. Le Thi Lan - Investment project official

Source: Executive Order No. 879/QD-UBND, People’s Committee of Tu Son

Issue Date: November 18, 2016

According to Vietnam's land legislation, direct government is a required mechanism to implement land acquisition. Articles 61, 62, and 73 of the 2013 LOL specify a set of government organizations involved in land-takings. If provincial people’s committee (PPC) has authority to approve land-taking proposals, line departments, 
district and commune governments responsible for carrying out land-taking procedures. Currently, there are two types of organizations that have functions of land acquisition: at the provincial level, the "Center for Land Development" (CLD) operates as a service unit that assists PPC in acquiring land in accordance with land use planning or land being used by organizations. At district level, the "Board for Compensation and Ground Clearance” (BCGC) is temporarily established by the district government to take land from households. Each BCGC is responsible for one land-taking project. BCGC is also dissolved right after a land-taking project is completed. In practice, as informed by a manager at Bac Ninh’s CLD, noncompliance rarely occurs in land acquisition managed by CLD. This is because of two main reasons: (i) CLD often carries out land recovery in accordance with land use planning approved by the provincial government; and (ii) the acquired land area then is sold at a public auction. CLDs function as a service unit connecting land users (mostly organizations) with land developers based on market mechanism.

All three land-taking incidents under study were executed by district BCGCs: the $2^{\text {nd }}$ district’s BCG executed the Thu Thiem project; land-takings in Dong Tam commune and Tu Son district were conducted by the My Duc BCGC and Tu Son BCGC, respectively. To have more information about working principles and membership of BCGCs, the researcher searched for instructions and rules used to establish BCGC in Ho Chi Minh City and reviewed the list of BCGC members responsible for the Tu Son incident. In both province/city, as required by the LOL and instructed by the provincial/city government, a vice mayor of the district government served as the head of BCGCs; other members included heads of technical offices and units such as office of 
finance, office of urban management, office of agriculture, district center for land development. Leaders and officials of the commune government, a head of residential unit, representatives of investors and affected landholders also participated in the district BCGC (see table 5). Document review showed that BCGCs were a heavily governmentbased unit. Giving most members of BCGCs were government officials and leaders; the organization operated as an administrative unit. A land official in Dong Ky commune (Tu Son incident) commented that district government's leaders, managers, and officials played the most decisive role in BCGC: "Representatives of the commune government consisted of leaders only; some compliant land users were selected to serve in BCGC. They (selected landholders) were not really representatives of the affected people" (see details in tables 5 and 6). The head of DONRE (Tu Son district) clarified the role of representatives of land users that they were expected to voice land users' demands and preferences. They were also expected to enable fair and transparent decisions over landtakings. However, he asserted, "land users' participation is for transparency purpose, not to change government's decisions”. This was also evident in the HCMC's instructions on establishing BCGC: the majority rule was the principle to make land-taking decision. This rule allowed government officials who outnumbered non-government actors made decisions as they expected. In addition, steps of land-takings described by land officials suggested that affected land users could only engage in policy implementation once a land-taking project was enacted. In addition, as shared by land officials in Tu Son district, the role of investors in BCGCs was mainly to provide funding for ground clearance. One investor shared with the researcher at the dialogue in Dong Ky ward on September 5, 2018 that their primary responsibility was to make funding available for land acquisition 
and infrastructure construction. Otherwise, they did not play any significant role in convincing land users give up their land. All land-taking activities were conducted by local government officials. While sitting in the meeting, the researcher observed two investors and found that they almost kept silent; situationally, they only talked few words. Both did not respond to landholders' questions though those questions targeted at them. Representatives of investors encouraged disobedient landholders to accept compensation, so that they could complete investment projects on time. All these make BCGC become a short-term and task-based government's administrative unit.

\section{Table 6: Principles of BCGCs}

a) Each BCGC consists of 1-2 representatives of affected landholders. If the landtaking project affects 100 households or more, the maximum number of landholders' representatives is not more than 4 .

b) Only affected landholders can participate in BCGCs as representatives who are voted by landholders. If affected landholders cannot select anyone for their representatives, the district government will introduce some selected people for voting.

c) Representatives of affected landholders have responsibilities to: (i) voice landholders’ demands; (ii) convince landholders to accept land acquisition policy, move out and give up their land on time.

d) Working mechanism of BCGCs is collectivism: decision-making is based on the majority rule. In case the majority rule cannot determine an option/decision, the head of BCGCs will make the final decision.

Source: Article 39, Executive Order No. 28/2018/QD-UBND (HCMC, 2018) 
Since the sole role of direct government organizations in executing land-takings is clearly stated in land legislation (article 66, LOL of 2013), field interviews and focus groups with land officials and the local government's managers/leaders aimed to find out weaknesses, strengths, and implementers 'organizational preferences. Field visits in Bac Ninh and Vinh Phuc province revealed implementers' preference over the direct government organization. They believed that the government is the only legitimate actor who can take land in Vietnam's current context. Government organizations are the most effective and efficient devices to carry out land acquisition. A Deputy Director of the Center for land development (Bac Ninh province) asserted: "we must first follow legal procedures as required by the LOL that emphasizes the role of the government...we adopt articles 61, 62, 63, and 66 of the 2013 LOL”. Accordingly, he clarified, the government has authority to convert land for important purposes such as serving defense and security purposes, economic development and infrastructure; or serving large projects invested by foreign investors. Depending on the size of investment projects, land-takings will be conducted by either the district government or the provincial center for land development. In either way, the government agencies, officials, and managers at every level are premier actors responsible for land-taking enforcement.

Local managers and leaders in both Vinh Phuc and Bac Ninh provinces where the researcher visited multiple times to experience policy implementation in real settings also believed that, considering current context of Vietnam, without the direct involvement of the government, investors and landholders are hardly to achieve agreements for land recovery. In their explanations, giving land is owned by the State, government agencies have legitimate authority to take land for public purposes. In disputed situations, the 
government can apply compulsory form of land acquisition. In addition to political legitimacy of public authority and institutions, land management agencies and government officials have technical expertise and experiences in local land sector. They know the history of even a small piece of land within their management responsibilities. A high-ranking land manager in Bac Ninh province (Deputy Director, Department of Natural Resources and Environment) stated: "I think the central government should only adopt compulsory land recovery. The practice of land-takings in Bac Ninh province indicates that there have been few land transactions of small land plots that investors directly discussed compensation with land users. Some could reach agreements because their projects just affected a very small number of landholders. For bigger projects, for example, that affected several dozens or hundreds of households, land acquisitions were impossible without the involvement of government authorities". Similarly, the head of DONRE in Binh Xuyen district (Vinh Phuc province) shared that: "we have conducted lots of land-taking projects because our district has been rapidly industrialized in the last two decades. We constructed many industrial zones that affected farming land owned by many landholders. Without the government, no investor could deal with numerous landholders for land recovery. To attract investors, the government must go first to make land ready for use".

However, from landholders' perspective, many people preferred non-government actors that operate in accordance with market mechanism. When were asked about reasons that made non-state actors a preferred choice, some land users in Tu Son (Bac Ninh province) and Vinh Yen city (Vinh Phuc province) said they did not resist the government but they wanted fairer land prices and higher compensation. That was why 
they requested to directly deal with investors for land conversion. Corruption was another common worry emerged in discussions with land users. Since the unrealistic land price resulted in very low compensation; landholders doubted that government officials could abuse land-takings for their private interests. In the eyes of affected landholders, both local businesses and government greatly benefited by exploiting the cheap land price system. This made landholders untrusted in government. Similar situations also occurred in Thu Thiem.At a dialogue with city's top leaders, Mr. Hinh, a landholder, stood up and talked to the city's leaders: "the city government must clarify why only a road of $12 \mathrm{~km}$ in length costs 12.000 billion VND” (Zing, 2018b). The researcher found that landholders supported market-based negotiations because without the involvement of the government, they could leverage their power in dealing with investors. Non-government actors could help landholders balance power relationship with the government and investors. Such a power relationship would enable a fairer compensation for affected land users.

The researcher also interviewed government managers and leaders working in the land sector in provinces of Vinh Phuc and Bac Ninh for "indirect government" as an alternative land-taking mechanism. Currently, as they reported, there is no legal provision for land-taking policy implementation by non-government organizations. In other words, land conversion is the sole function of the government. The head of DONRE (Tu Son district) clarified that non-government organizations could only participate in land valuation. Article 115 of the 2013 Land Law allowed eligible and qualified nongovernment actors to provide land valuation services. This type of organizations, however, did not represent the indirect government mechanism because non-government organizations were not offered funding for service provision: "Eligible private 
organizations can conduct land valuation services, but their results can be used only for reference by government agencies. This means that land valuation by non-government organizations is only a factor that we consider when we value land and calculate compensation. In actuality, all land valuation activities are undertaken by government's agencies and staff” (head of DONRE, Tu Son district).

\subsubsection{Authoritative tools}

A unique characteristic of authoritative tools is the "threat of state-enforced sanctions” (Howllet, 2011: 83). This is because authoritative tools such as regulations and executive orders are "backed by the legitimate authority of government that grant permission, prohibit, or require action under designated circumstances” (Schneider and Ingram, 1990).Target groups will be punished if they violate regulations or disobey policy decisions as stated in executive orders. The use of authoritative tools, thus, involves significant coercion. Unlike institutions and laws, themselves, authoritative tools are embedded in the institutional and legal framework of land policy. Authority based tools represent the actions rather than rules. They are not the same things as rules and laws as written. They instead are implemented rules and laws in practice. For instance, while land prices are established by the LOL as having to be determined by the provincial people's council, but in practice, land prices are determined by regulatory tools and through those tools the setting and change of land prices are often determined by local context and government officials. The institutional perspective might point out the unrealistic land price system that results in low compensation as a key cause of landtaking noncompliance. It, however, is impossible to explain why, for any land-taking instance, the percentage of resistant land users only account for around 15 to $20 \%$ of the 
total number of affected landholder (as estimated by a land official in Bac Ninh province). Therefore, the tool approach adopted in this study is not interested in authoritative tools themselves (e.g. specific land price regulation). The researcher instead is more interested in strengths, weaknesses, and the use of tools in real context; how are authoritative tools mixed with other tools and linked to noncompliance (e.g. the use of regulation to determine land value).

\section{Table 7: Land Valuation and Land Price Framework}

Article 112: Land valuation must comply with following principles: (i) based on land use purposes at time of valuation; (ii) based on land use time; (iii) equal to common land prices on the market. The government determines methods of land valuation.

Article 113: The central government issues a five years land price framework for each type of land in each region. When a land price framework is effective, the central government will adjust the land price framework if land price on the market increases by $20 \%$ of the highest land price or decreases by $20 \%$ of the lowest land price as regulated in land price framework.

Article 114: PPC develops land price system and send to PPCU for approval. PPC issues land price system on the first day of five-year timeframe.

Source: Law on Land of 2013

To explore the use of authoritative tools, the researcher reviewed background history of three incidents and discussed the choice and use of authority-based tools with land officials in research sites. In addition to reviewing government's documents, 
interviews and focus groups revealed that land-taking policy implementers largely relied on authoritative tools to achieve land-taking goals. "Executive orders" and "Regulations" played a prominent role in land-taking enforcement. While "executive orders" were used to legalize the government's land-taking decisions, implementers' activities in specific situations were guided by rules and regulations issued by both the central government and provincial/city government. Law on Land, land price regulation, and regulations regarding land valuation, land price, compensation, support, and resettlement were the first authoritative tools mentioned by implementers. As shared by the head of the DONRE (Tu Son district): "We have to strictly adopt rules as stated in the LOL and executive orders issued by both the central government and provincial government. As you mentioned, we know there are unrealistic aspects of land-taking regulations and rules, but we have to act in accordance with those regulations and rules”. The head of the DONRE (Binh Xuyen district, Vinh Phuc province) emphasized the effect of local contexts on the province's regulatory institutions. Each province issued its own regulations relevant with the provincial context. Provincial regulations were used to specify general rules stated in LOL and localize the central government's directives and executive orders over land-takings: "Though we must comply with the same regulations issued by the central government, provincial contexts make land-taking regulations differ between provinces. As you shared, Bac Ninh provincial government could offer higher compensation than Vinh Phuc government. Land users of course knew the difference because the two provinces shared the border. Land users also reported to us that the compensation in Ha Noi city was much higher than compensation in Vinh Phuc province. We all knew the difference, but we here were not able to do as in Bac Ninh and Ha Noi. 
We must follow our own regulations”. The head of land management agency (PDNRE, Bac Ninh province) specifically listed a set of regulatory tools available for policy implementers to act in practice: "when a land-taking project is enacted, we are required to refer to 2013 LOL, Circular 37 of the ministry of finance, the central government's decrees 01 and 47, Bac Ninh PPC’s executive order no. 528 regarding the land price system that is valid from 2015 to 2019 ”.

Table 8: Rules of Compensation, Support, and Resettlement

1. Compensation for land: $70,000 \mathrm{VND} / \mathrm{m} 2$

2. Compensation for groceries: $9,000 \mathrm{VND} / \mathrm{m} 2$

3. Financial aid for stabilizing livelihoods and production: $10,000 \mathrm{VND} / \mathrm{m} 2$

4. Financial aid for seeking job and changing career: 350,000 VND/m2

5. Total compensation for $1 \mathrm{~m} 2: 439,000 \mathrm{VND} / \mathrm{m} 2$

6. Total compensation for a plot (360m2): 158,040,000 VND

Source : ONRE, Tu Son district (2017)

The most disputed authoritative tool regarding land acquisition in Vietnam is the land price system. From the tool approach, land price system is a 'regulation' that directs behaviors of both implementers and landholders. Implementers are required to develop a land price equal to common land price on market at time of compensation. However, how to determine a 'market price' is still an unclear issue. This method of price calculation resulted in large difference between land price controlled by the State and land price on 
market (World Bank, 2009 \& 2011a).In Bac Ninh province, implementers adopted executive order no. 522/2014/QD-UBND about land price and executive order no. 528/2014/QD-UBND about compensation, support, and resettlement (see table 7). Based on these two executive orders that have been valid from 2015 to 2019, the district government of Tu Son issued an administrative document notifying landholders about level of compensation that they would receive. According to land officials involved in Tu Son incident, in order to compensate landholders, BCGC first had to value land and land embedded properties such as houses, trees, and groceries. "Small pieces of land, normally, are valued by the government's technical officials but if a land area values above 20 billion VND (around 900.000\$), we are required to use land valuation service provided by an independent organization” (Head of ONRE, Tu Son). Though Tu Son government adopted the highest land price, the real compensation was much lower than land value on market. "But we could not violate the land price regulations", he concluded. In big cities such as the Ho Chi Minh City where the value of land has continuously changed over time, the researcher found that land officials had to deal with a complex system of authority-based rules and orders directing land valuation and compensation. Before 2003, the Ho Chi Minh city applied LOL of 1993, amendments of LOL (1998\&2001), PPC’s executive order no. 135/2002/QĐ-UB (2002) regulating compensation and support for residents affected by the Thu Thiem project. After 2003, the city enforced compensation rules based on executive order no. 123/2006/QĐ-UBND (2006) and then executive order no. 06/2009/QĐ-UBND (CGI, 2018). Overall, the analysis of government documents and field experiences suggested that land acquisition was a highly regulated process in which implementers were required to strictly follow 
land legislation, administrative rules, and executive orders. This was a major cause of land-taking problem in Vietnam. According to Dang Hung Vo, a land policy official, "land price system issued by PPCs is much lower than land price on market. Local implementers often explain that low compensation is because of PPC's land price system. This is original cause of risky situations regarding land acquisition. We need to modify the land price regulation” (Thu Ha, 2019).

A common feature of the three land-taking incidents in Thu Thiem, Dong Tam, and Tu Sonis the use of "executive order" by local governments to execute land-taking projects. In Tu Son, each affected landholder received a package of documents (proclamation) from the district government. Of those documents, two executive orders issued by PPC and DPC informed landholders the land-taking project and they were required to collaborate with the district BCGC to enforce the orders. In Dong Tam incident, the district government of My Duc responded to land claim made by villagers by issuing an executive order to take the disputed land. Le Dinh Kinh, leader of resistant villagers in Dong Tam, recalled: on October 20, 2016, mayor of the My Duc district government signed an executive order to acquire the land area of 6.8 ha. Dong Tam land users notified the district government that the land was in dispute, but the land acquisition continued. Eleven days later, while the city inspectorate's inspection report (released on October 31, 2016) only concluded that defense land would be transferred between military units, the My Duc government employed inspection conclusions to legitimate land-taking actions. According to the city's inspection report, only 14 households farming on the airport land were required to leave. However, the district government enforced land-taking with households farming on the area of 6.8 ha that was not covered 
by the airport land. On this area of 6.8 ha, land users made land transactions that were certified by the Dong Tam commune government. Villagers paid government for land use fee. These indicated that the area of 6.8 ha was not land for defense as claimed by the My Duc district government (Luan Nguyen, 2017).

In Ho Chi Minh City, the Thu Thiem incident was a consequence of a serial abuses of authoritative tools. The city government issued multiple executive orders to undertake land-taking projects and modify land-taking plans. The researcher reviewed the history of the city government's actions and found that, on June 4, 1996, the Thu Thiem planning proposal was approved by the premier, with total area of 930 ha, including 770 ha of new urban area and 160 ha used for resettlement. On September 16, 1998, chief of the city's office of architecture issued order no. 13585/KTST-QH approving the land planning of Thu Thiem, with an area of 748 ha. On December 27, 2005, the city's vice governor signed the executive order. No 6565 in which article 2 stated: "this order replaces the order no. 367 dated April 6, 1996 by the premier”. On the same day, the city people's committee also issued the executive order no. 6566 and article 2 of this order also noted: "this order replaces the order no. 13585 issued on September 16, 1998 by chief of the city's office of architecture”. The executive order no. 6566 also specified land planning of Thu Thiem as developed by Sasaki Associates - a Japanese Consultant in collaboration with the City's Institute of Architecture and Planning (Huu Nguyen, 2018). Two years later, in 2007, the city people' committee issued executive or no. 5945 canceling amendments as stated in the two orders above. According to the central government's inspectorate (CGI, 2018), the city government's executive orders dramatically changed the original land use plan of the Thu Thiem project. These changes 
resulted in serious violations that caused long lasting disputes and tensions between the government and affected landholders.

With executive orders, implementers could take land by force. The main cause of noncompliance in Thu Thiem incident was the unclear boundary of the affected land areas. Disobedient landholders reported that they were required to move out even though their land was not covered by the Thu Thiem project. In order to figure out how the city government's acts resulted in land users' disobedience, the researcher reviewed some “case profiles” and found evidences indicating a serious abuse of authority-based tool of executive orders. As an affected landholder, Mrs. Mao questioned the city about the project of 87 ha in An Phu ward. As she remembered, the project was first approved with a land-taking project of 87 ha. The city then expended the land-taking area to 88 ha and issued multiple executive orders of land acquisition. (Zing, 2018b). In the same situation, one of her neighbors whose small house was destroyed on April 7, 2016, reported: “I just opened the door and saw lots of cars, trucks, and government officials surrounding my house. They then asked me to move out and destroyed my house. If I were wrong, please shoot me. Why did the city remove my house without any official order? They took my properties away and I do not know where they are now”” (Truong Minh, 2019a). Nguyen Dung (Binh An ward) recalled her compulsory land acquisition taking place at $8.00 \mathrm{am}$, March, 1, 2012: "I have not ever seen land-taking order...I have not received any compensation... but they forced me to leave. I did have properties and incomes, but I lost everything (Zing, 2018b).

The researcher's visits to research sites also suggested that BT and BOT constructions and land acquisition often started at the same time. This put time pressure 
on local governments that often led to forced acquisition. The abuse of land-taking authority was evident in the Thu Thiem incident. Vo Viet Thanh, vice governor (19961997) and governor (1997-2001), recalled: "Regarding Thu Thiem, about 4-5 years ago (2013-2014), I used to talk to the city leaders that why the city destroyed all people's houses...why it looked like a bombing in a war. The city acquired only 20-30 ha but the land-taking affected thousands of households. The people here were acquainted with traditional ways of living...how they earn for living after being moved to apartments (Zing, 2018a). Some land developers and policy experts figured out that while land acquisition was strictly regulated, the lack of clear regulations regarding the authority of land assignment was the main contributor to land users' resistance over land-taking projects in BT and BOT designs. Mr. Tran Ngoc Hung - Chairman of the Vietnam Construction Association commented at a recent national conference on the land market: "investors often receive land from provincial governments at a much lower price in comparison with the land price on the market. They, government leaders, and land managers can benefit from cheap land price because investors often are assigned land without auction (Anh Phuong, 2018). According to Mr. Dang Hung Vo, former vice minister, Ministry of NRE, the loosely regulated authority of land assignment motivated the abuse of land-takings that resulted in the increase of policy noncompliance in recent years: "the biggest gap of LOL is the way to exchange land for investors as a matching capital. For building and transfer projects, the Land Law only defines the authority to assign land but no regulation regarding land valuation. In practice, the most important issue of building and transfer projects is not the authority of land assignment. It instead is the authority to value land. Land Law, however, does not state who has responsibilities to 
audit values of land and constructions developed by investors. This is a big gap in the management of building and transfer projects” (Anh Phuong, 2018). Mr. Vo’s argument was supported by evidence collected from the Thu Thiem incident: while the central government approved a resettlement area of 160 ha, the city people's committee allocated 144.6 ha for 51 investors to construct apartments, office buildings, and public infrastructure...As a consequence, the city did not have enough land for resettling affected landholders (Truong Minh, 2019b). It was estimated that 71\% of land plots in Thu Thiem was officially assigned for investors. Currently, $45 \%$ of useable area of land was officially transferred to developers through the form of public-private partnership (Ha Thanh, 2018). This reality explains why recent noncompliance mainly took place with land acquisitions in BT and BOT designs, as a statement of the head of Tu Son's DONRE.

In the inspection report released in 2018, the central government's inspectorate pointed out the Ho Chi Minh City government's violations: "The city government, especially the $2^{\text {nd }}$ district government, did not follow legal procedures and requirements regarding land-taking enactment. The government did not develop compensation proposal. The BCGC relied on the city's executive orders no. 135/2002/QĐ-UB, no. 123/2006/QĐ-UBND and no. 06/2009/QĐ-UBND to calculate expenses for compensation, support, and resettlement instead of preparing an overall proposal to compensate all affected landholders” (CGI, 2018). Regarding land acquisition and assignment, the city government also abused public authority when issuing two executive orders no. 1997/QĐ-UB (2002) and no.13585/KTST-QH (1998) that increased the land acquisition area of 4.3 ha (CGI, 2018). The use of numerous executive orders changed 
the land planning in Thu Thiem and enabled effective land acquisitions. However, the coerciveness of executive orders also increased land users' resistance that led to long lasting tensions.

\subsubsection{Financial tools}

A key feature of financial tools is the use of financial or financial-equivalent incentives to alter target groups' behaviors (Howlett, 2011: 101). The financial tools are embedded in the political economy and economics of land policy in Vietnam. These tools, however, are not the same as the political economy and economics themselves because they represent the actions rather than the economic conditions. They are the implemented financial and economic compensation rather than the economic valuations in theory. For example, in any given land-taking instance, most households may accept compensation below what they could rationally obtain, while others will resist if they believe the government will offer more the longer, they do not comply. The economic approach lacks the ability to explain how financial tools succeed or fail. Behavioral economics, for instance, shows how it is the perception and social interpretation of various economic rewards rather than their objective levels that often explain human behavior, in this case meaning how financial compensation is managed in the governance process. Instead of the economic and financial value of compensation, the tool-based approach adopted in this study pays more attention to characteristics (e.g. forms of compensation, strengths and weaknesses), the management of compensation, and how those factors might contribute to land-taking policy acceptance or noncompliance.

Currently, as stated in the 2013 LOL, cash, land, and apartments are three forms of compensation. From a tool perspective, those forms of compensation are three finance- 
based tools used by government to convince policy target groups give up their land. The focus of tool approach is not the value of compensation. The main interest of the researcher was if the use of three tools (forms of compensation) were effective to change land users' attitudes and behaviors. Were tools' characteristics related to noncompliance over land-takings? The researcher, more specifically, wanted to find out why, being subjected to the same land-taking project and received compensation based on the same land price system, some land users still did not accept compensation. Controlling the level of compensation, could implementers increase land-taking policy compliance by simply making changes of tool choice and use in practice? In addition to reviewing media publications such as interviews and press releases available online, talks with research participants during field visits in Bac Ninh and Vinh Phuc provinces revealed the ineffectiveness of finance-based tools. This was first because local governments had to follow rules and regulations that resulted in unfair land valuation and low compensation. The low compensation, however, was not the only prominent cause of noncompliance considered in this study. The government's bad management of finance-based tools (land, cash, resettlement apartment) instead played a more critical role.

According to articles 74, 75, 79 of 2013 LOL, "land and resettlement apartment” are the first financial-equivalent tools used for land acquisition. Implementers in HCMC, more specifically, are required to compensate affected landholders with the same type of land. Cash is only the second option if the government is unable to provide a similar piece of land for landholders (HCMC, 2018). In practice, similar situations also commonly occur in other provinces such as Bac Ninh: implementers rarely adopt landbased compensation due to their inability to find another land area. The head of land 
management agency (Bac Ninh province) reported that many affected landholders preferred compensation in land. With a land plot within the same location, they could sell it on the market for higher price or used for small business purposes. However, he added, land-based compensation was unrealistic: "In the past, the Bac Ninh government could offer compensation in land but now we cannot. The most common form of compensation is cash. The government only construct resettlement apartments if land acquisition affects a large number of households”.

In Ho Chi Minh City, for large project such as Thu Thiem incident, the city government offers land and apartments to encourage land users’ policy acceptance. However, as regulated by the city government, affected landholders will only be received financial support for $30 \mathrm{~m} 2$ of the new apartment and $45 \mathrm{~m} 2$ of the new piece of land. Landholders are responsible to pay for additional costs if they accept compensation in land or apartment (HCMC, 2018). These regulations make land and apartments at the same area less attractive because many affected people cannot pay for their new apartments. Vo Viet Thanh, former governor, the Ho Chi Minh City government, pointed out problems of compensation in land and apartment: "Landholders should be resettled within the same location. Taking them far away from old places, so who will stay here? New resettlements should be better than the old one. If they have a small shelter of $20 \mathrm{~m} 2$ here and the city compensates them with the same $20 \mathrm{~m} 2$ shelter in another place, who will go? For people receiving another piece of land, the city requires them to build standard urban houses within 6-12 month after receiving land. If they cannot build new houses, the city will collect their land. But how poor people can build new houses as required by the city” (Zing, 2018a). 


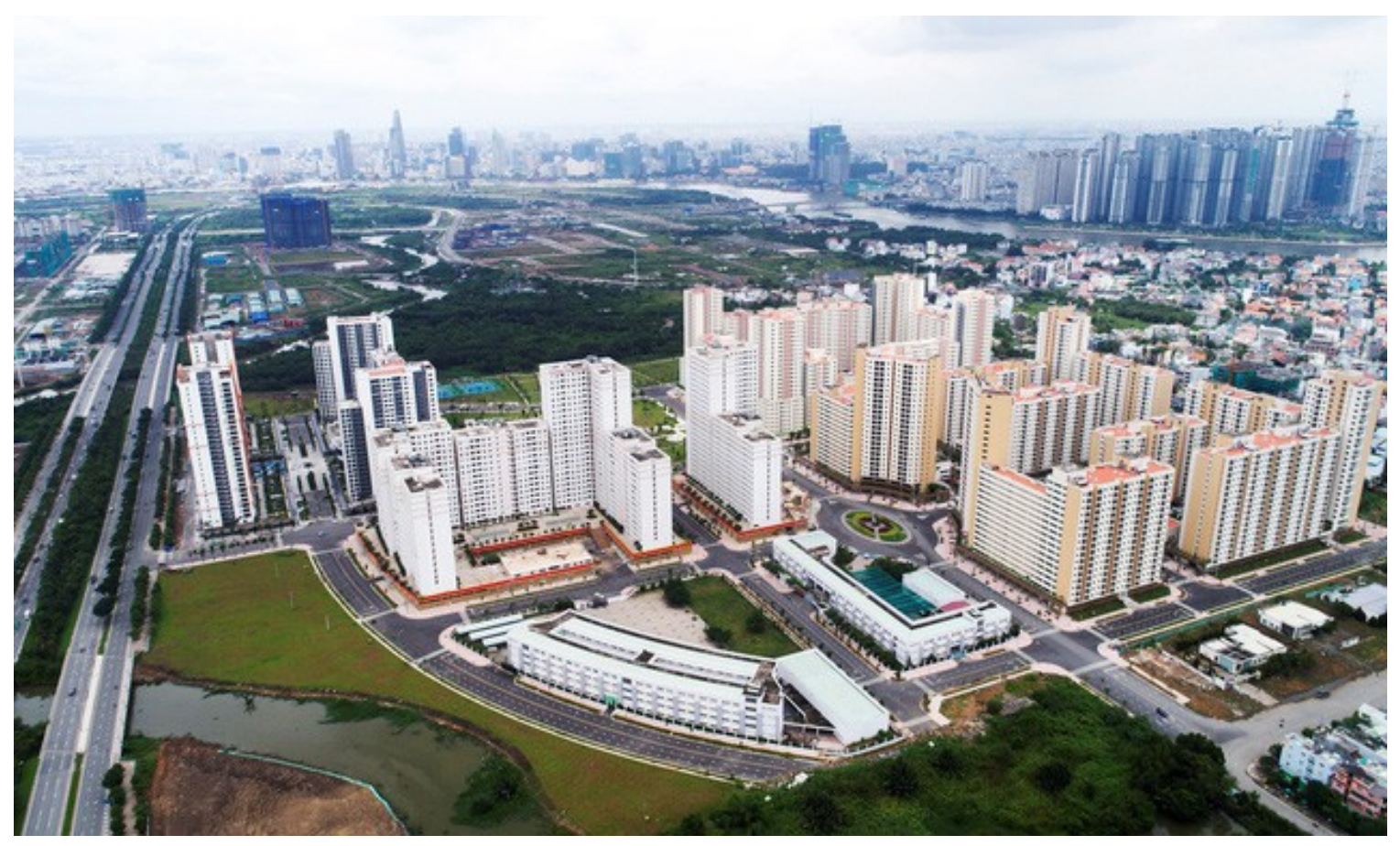

Figure 17. New apartments in Thu Thiem

(Source. news.zing.vn)

In reality, poor land users in Thu Thiem faced lots of challenges if they received land or apartment in a new urban area. Tran Van Truyen (Binh An ward) whose house was destroyed in 2015 recalled: "the government sent us the land-taking order in 2012 and we agreed moving to the city's new resettlement apartment. We were compensated 2 million $\mathrm{VND} / \mathrm{m} 2$ but in order to move in new accommodation, the city required us to pay an additional amount of 40 million VND. As explained by the city government, new apartments had better conditions and located near city center. However, we did not need those better conditions because we were not affordable” (Zing, 2018b). Similarly, Mrs. Nguyen Ngoc Thanh who received 94 million VND for her house was asked to pay 800 million VND for her new apartment (Zing, 2018b). Thao, a poor woman, said she did not want to move in her new apartment. Her current location was more convenient for her 
low skill job. In the same situation, Phong (An Khanh ward) who wanted to get back his old house, said: "Several generations of our family have been living here in Thu Thiem. The land price now increases...everything has dramatically changed but local residents have to move to other resettlement places... wedo not benefit from the development of Thu Thiem. Is it an injustice? (Zing, 2018b).

\section{Table 9: Failure of new apartments used for land acquisition}

HCMC built 12,500 new apartments to resettle landholders affected by Thu Thiem project. However, according to HCMC, up to June 2018, only 1847 affected landholders moved in resettlement apartments in new urban area. Since landholders were not interested in new apartments, the city government decided to sell apartments by auction. Reasons for failure: expensive prices (same locations), poor living conditions and inconvenient locations (new locations).

(Source: Ha Vy, 2019)

"Cash" was the most common financial tool used to compensate landholders across three incidents. In Ho Chi Minh City, implementers adopted land-taking legislation and rules (e.g. articles 75 and 114 of 2013 LOL, article 18 of Circular no.44/2014/ND-CP, articles 31 and 32 of Directive no.36/TT-BTNMT). Accordingly, landholders who subjected to land acquisition in Thu Thiem were compensated for affected land, properties on land, and moving fees...Compliant landholders also received financial support in cash prior the execution of a land-taking project. If landholders did 
not comply with land acquisition, compensation funding was transferred into a bank account managed by the government, and landholders were still required to give up their land. Landholders only received compensation based on the latest land price system if a payment was delayed due to the government. However, in disputed situations like Thu Thiem incident, violations always belonged to noncompliant landholders.

In Thu Thiem, for example, since landholders disputed with the city government, they had to accept compensation at the same rate as the first installment. Nguyen Thi Mao (An Phu ward) shared her situation: "I received compensation of 4 million VND/m2 in $1997 . .$. the project lasted until now, 18 years, but the compensation has not changed...it is the same as 18 years ago” (Zing, 2018b). Mrs. Doan Ngoc Thuy (Binh An ward) told her story: the city government promised to compensate 330 million VND for her land area of $1000 \mathrm{~m} 2$, and a resettlement aid of 170 million VND. However, she has not received the funding as promised: "the amount of money was not too much...we also did not require additional funding. However, why the city government did not pay us for the acquired land area? Why they took our land without payment?' (Zing, 2018b). Nguyen Thi Tam (An Khanh ward) was in another situation. Her house was removed from 2003 and she received compensation in three installments but now nothing remained (Truong Minh, 2019d). The researcher discussed compensation in cash with land officials in Bac Ninh and found that the government often make installments based on progress of land acquisition. A landholder could own several small land parcels. He thus would receive multiple installments because his land is not acquired at a time. Another reason is that the government cannot arrange enough funding. This might result in late compensation. 
Another theme mentioned in group discussions and interviews in Bac Ninh and Vinh Phuc provinces was the prospect of the "market mechanism”. The researcher was interested in exploring if the market can be used as an effective alternative for land-taking policy implementation in Vietnam's context. As a policy mechanism, the market allows investors to directly deal with land users for land conversion. Instead of engaging in land negotiations and transactions (ex. transfer, lease, or land as a capital contribution), the government only certifies if market-based land conversions comply with administrative rules and LOL. All interviewed land officials in the two provinces of Bac Ninh and Vinh Phuc shared that the market mechanism was encouraged by the government. Land legislation did not prohibit market-based transactions of land rights. In practice, however, the market mechanism was not really an effective measure for land-takings. The deputy director of the provincial center for land development in Bac Ninh explained: “A characteristic of the land sector in Northern provinces like Bac Ninh is that each household only owns a small area of land; and this area can consist of multiple plots or parcels. All investment projects, whereas, often require large area of land that affect many land holders. These characteristics make direct negotiations with land users become very complicated. Market based negotiations are impossible for big investment projects”. Though investors were not interviewed, informal conversations at the community meeting in Tu Son district suggested additional challenges that resulted in the rarely use of the market mechanism. According to investors, they regularly confronted various difficulties during direct negotiations with numerous landholders. Most commonly, land users often requested high land price-based compensation that investors were not able to afford. Unexpected situations that delayed progress of investment projects also took place 
regularly. An investor shared with the researcher: "we have to deal with many landholders. Each of them has their own requests, especially land compensation. In nature, direct negotiation is a measure that we buy land use rights from individual landholders. It really takes time and we sometime cannot afford land users' requests. Some might change their mind even if we did reach agreements before”.

\subsubsection{Information based tools}

Information-based tools refer to devices used by the government to communicate information or knowledge to policy target groups (Howlett, 2011: 115). Unlike authoritative tools that involve coercion, a key feature of information-based tools is persuasion. Implementers provide information to influence target groups' thinking and attitudes that might result in behavioral changes. To get expected results, implementers are not necessarily required to provide correct, true, and accurate information. They instead can influence target groups by persuasive justifications and messages regardless of whether their claims have cognitive and normative contents (Weiss, 2002: 219). This tool focused study did not survey information availability, land users’ ability in accessing information, or transparency. The researcher instead examined specific communication devices used by implementers to interact with landholders, how effective those devices could make information available to landholders, strengths and weaknesses of different devices, and their capability in altering target audiences’ behaviors. The researcher also looked for implementers’ preferences over information-based tools and linkages between preferred forms of communication and behavioral changes among landholders.

At the beginning of data collection, the researcher proposed that communication means might relate to policy target groups 'noncompliant attitudes and behaviors. To 
identify information-based tools, the researcher reviewed administrative and legal procedures required to implement a land acquisition project in research sites. There were no differences regarding the procedural enactment of a land-taking project between the two provinces (Bac Ninh and Vinh Phuc) where the researcher spent time to get real experience of policy implementation. According to land officials, implementers were required to follow the same procedures. Typically, the execution of a land-taking project at district level followed steps as required by the LOL:

(i) PPC issues executive order approving DPC’s land-taking request.

(ii) District government (DPC) establishes BCG

(iii) BCGC develops land-taking proposal in detail

(iv) BCGC submits land-taking proposal to PPC for approval

(v) BCGC establishes propaganda and land valuation units

(vi) BCGC meets with affected land users to clarify land-taking plan

(vii) BCGC conducts inventory of properties and land for compensation

(viii) BCGC meets with affected landholders to verify all issues regarding compensated properties and land areas.

(ix) DPC submits compensation proposal to PPC for approval

(x) Report to PPC noncompliant cases

(xi) District government conducts coercive land acquisition over noncompliant landholders.

"Proclamation "was the first information-based tool used by BCGCs to inform landholders about land-taking project. In Tu Son incident, each affected landholder received a document package that consisted of all official information regarding the land 
acquisition plan. Those documents included "PPC executive order" approving DPC's land-taking request, "DPC executive order" establishing BCGC, a list of affected households accompanied by a map, and compensation rules approved by PCC. After receiving the "land-taking proclamation", landholders subjected to land acquisition had right to ask BCGC for further clarifications on any issues that they were concerned. Interviewed landholders, however, said they were only concerned compensation, acquired land area, and time that they had to hand over their land. Land officials in Tu Son district also commented that landholders often did not really care about the landtaking proclamation until the government began listing properties on land and measuring their acquired land areas. "The proclamation aims to officially inform affected landholders that the government is going to take part of their land. They are required to be ready to hand over the land to government", the head of Tu Son ONRE said.

"Public poster" is a tool displaying all information regarding land-taking plans in public places. According to land officials involved in the Tu Son incident, public posters showed details of land acquisition project such as name and address of affected landholders, land-taking purpose, acquired land area, types and origin of land, basis for calculating compensation, time frame for land acquisition...etc. Such a public poster was required to be publicly hung at communal committee's office or public places such as village's cultural houses. Communal authorities, representatives of community, affected landholders, and investors were also required to confirm the availability of public posters. All public posters showing land-taking project remained in public places for at least 20 days. The researcher, however, did not find any public poster in Dong Ky and Trang Ha 
wards. As reported by local land officials, someone took them off because the land-taking project started for a long time and people did not care about public posters.

"Government's information portal” is an official device that landholders could access for information about three incidents. The researcher, however, was not able to find any information about the land-taking projects in Dong Tam and Tu Son on district governments' websites. There was some news regarding the two projects posted on information portals of Hanoi city and Bac Ninh province's governments. When was asked about the role of the government's information portal as a policy implementation tool, the head of Tu Son district's ONRE explained that online sources of information such as government's websites were not a useful tool because most people did not have a habit for searching online information: "Tu Son district in nature is still a rural area. Though the urbanization process has taken place over the last two decades, most people are still living in former rural villages. So, they prefer face to face meetings for landtaking information. We send all information to them once we start a land acquisition project”. Only the Ho Chi Minh city government created a separate section for the Thu Thiem project on the city's information portal. The availability of an online source of information, however, was not necessarily associated with transparency. This was because all land-taking information was controlled by the government. The government was the only actor who could decide what type of information available to the public. In Thu Thiem, for example, landholders were most concerned the original map, but such a map was never found on the city' websites. Le Van Lung, a Thu Thiem resident, said he consistently requested the city government to show the map, but the government refused. Finally, he got news about the map at a dialogue with the city's leaders: "we asked them 
for the 1/5000 map to verify boundaries, but they said the map was lost. This pushed us into long lasting disputes and petitions from 1996 until now (Vietnamnet, 2018).

"Public dialogue" is a required information session to clarify affected land areas and compensation with landholders. According to the head of the center for land development (Tu Son district): "the district BCG is required to conduct at least 01 public dialogue to inform affected land users about details of land-taking plan”. Additional public meetings and dialogues could be organized if disputes took place. However, it depended on particular situations, he added. In reality, BCGC members did not preferred public meetings and dialogues because such an information session often made situation became more complicated. As the researcher observed at the meeting and dialogue in Dong Ky ward (Tu Son incident) on September 5, 2018, government officials tried to convince land users calm down while affected land users aggressively criticized BCGC members. Some land users stood up and said they did not sell land; compensation was too low. Some others blamed the government and investors for telling lies. Whereas, representatives of investors did not say anything though lots of questions were sent to them. In Thu Thiem incident, public dialogues became a nightmare with HCMC leaders and managers because they not only received aggressive criticism but also could not clearly answer landholders' questions regarding land-taking plan. Nguyen Thi Bach Tuyet spoke loudly at a meeting with top leaders of the Ho Chi Minh City’s government: "over the last ten years, we now only can talk in five minutes...give us more time to say”. Another landholder, Tran Thi My, 77 years old, insisted: "let me say, I am old and going to die soon” (Zing, 2018b). 
Moral suasion, exhortation, and intrusive propaganda emerged from discussions between the researchers and local implementers in Bac Ninh and Vinh Phuc as the key information-based tools. The researcher differentiated moral suasion and exhortation from intrusive propaganda. Both moral suasion and exhortation were unofficially conducted by individual government officials who could employ any means, at any time, and in anywhere to persuade landholders, urging them to follow government's decisions. Whereas, intrusive propaganda was an official means in which government authorized agencies and officials to formally conduct persuasive communications with landholders. All three means relied on persuasion schemes to convey messages which may or may not contain factual information to motivate target audiences and modify their behaviors (Adler and Pittle, 1984: 160). The emphasized role of moral suasion, exhortation, and propaganda was evident in Tu Son DPC's land acquisition documents. Once an executive order for land-taking was issued, landholders were expected to accept the government's executive orders. Persuasion, thus, was the most important communication strategy that BCGC members were required to do. Tu Son district government asked individual members of BCGC and the unit of propaganda for efforts to persuade landholders. In Tu Son district, propaganda unit that consisted of government officials and community leaders was a key component of BCGC. At the beginning of the land-taking project, their responsibility was to communicate with landholders, either through public dialogues or face to face meetings at land users' home. According to land officials, because land price was controlled by the State, most landholders were not willing to give up their land. While the government was not able to increase the compensation or offers other financial-equivalent compensations, the only way to convince landholders was moral 
suasion, exhortation, and propaganda. "We encouraged them to cooperate with the government for public benefits. We had to come to their home at any time, often in the evening. We shared with them that compensation was regulated by the State. The district government simply implemented the provincial government's executive orders"”' (Head of Tu Son's ONRE).

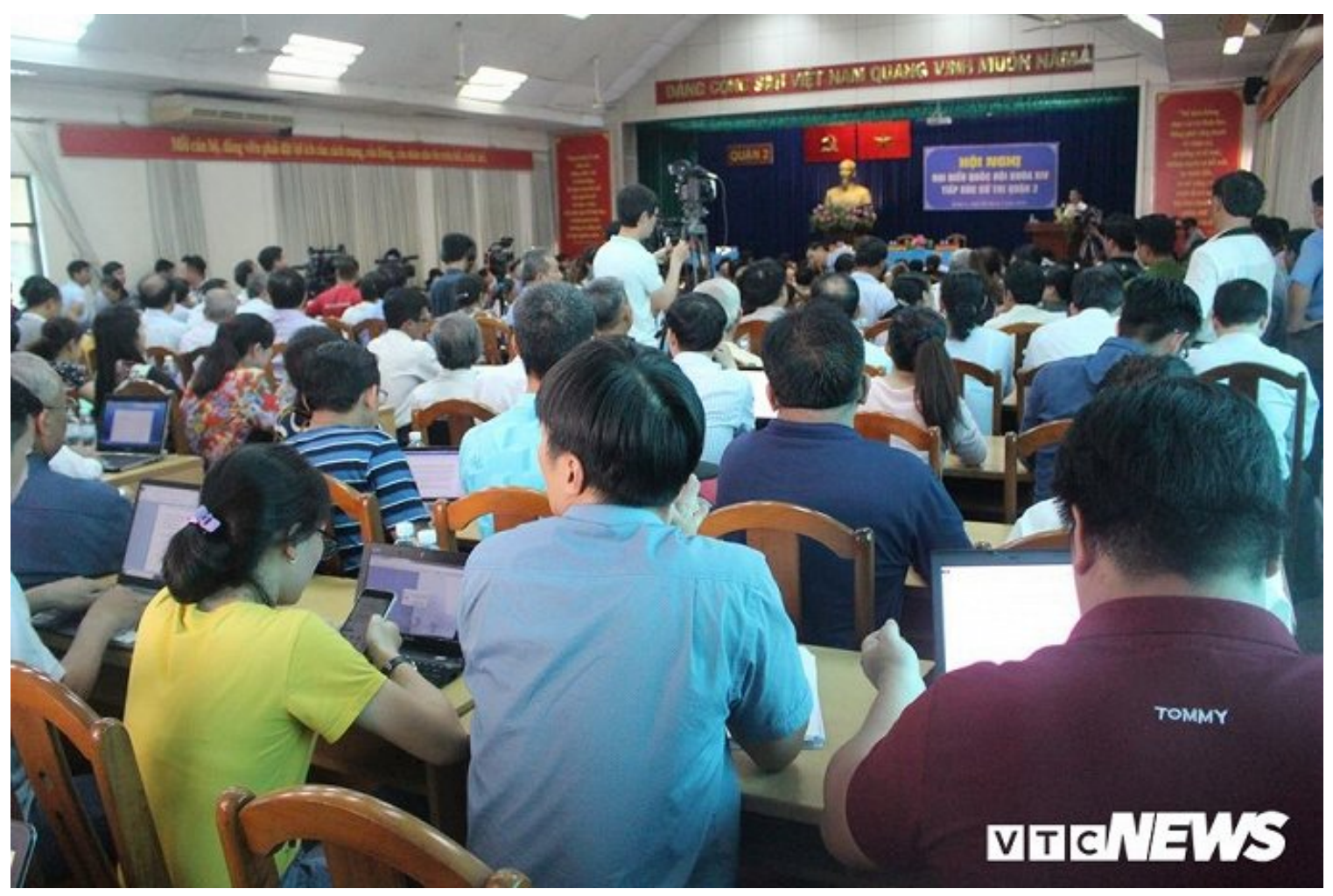

Figure 18. A public dialogue in Thu Thiem on May 9, 2018

(Source: vtc.vn)

However, though following the same procedures, local governments did not always act as required by the LOL. In Thu Thiem incident, the city government conducted land-taking while affected landholders were still unclear about the land-taking plan. Le Thi Hong Van, a Thu Thiem resident, reported: her house was not covered by the Thu Thiem project. The city destroyed her house and acquired land without land- 
taking order. Mrs Nguyen Thi Tam (Binh Khanh ward) questioned: "without project map, why did the city destroy my house? (Zing, 2018b). Mr Nguyen The Vinh (Binh An ward) did not leave his house because he strongly believed that his house was not affected by the Thu Thiem project. He requested the city government showing the original map to support the city's land-taking plan. He emphasized that he did not resist the city government, but he asked for transparency (Minh Hai, 2018). In the inspection report released in 2018, the central government's inspectorate concluded that the Ho Chi Minh city's official documents did not display properly boundaries and locations of land-taking plan. The additional area of 4.3 ha in Binh An ward was not included in the land planning of the new urban area (CGI, 2018). This in part explains why the city government ignored landholders’ request for information about land acquisition plan.

The heavy reliance on propaganda, exhortation, and moral suasion resulted in negative attitudes among landholders. This was because instead of providing clear information, the government tried to morally convince landholders. In Thu Thiem incident, for example, according to Decree no. 91/ND-CP issued in 1994, only the city people's committee has authority to approve master plan (1/2000) for Thu Thiem project. However, the city government could not explain why the Thu Thiem's master plan was approved by the head of architecture department. More importantly, organizations and individuals affected by the Thu Thiem project were not publicly informed about the master plan (1/2000). In addition, another pattern of using moral suasion, exhortation, and propaganda was that HCMC government officials and leaders always promised economic and infrastructure development once they met with landholders. What happened in practice, however, reduced landholders' trust in government. Mr. Hinh, a 
Thu Thiem resident, got shocked because he did not see square, recreational structures, hospitals, or schools as promised by the city's leaders and investors. He instead only saw skyscrapers and luxury apartments while he was required to move. In a similar situation, Mr. Quang questioned: "we have map showing that we are not covered by the Thu Thiem project. We comply with government's decisions if the State needs land to expend the city and develop new urban complexes. However, after 20 years, we have not seen anything except land transactions and luxury apartments” (Zing, 2018b).

\subsection{Tool based Responses to Noncompliance}

A major research interest of this qualitative study is to find out patterns of the government's tool-based responses to noncompliance. The researcher was interested in if implementers changed tool choice and use in order to reach a settlement. How effective were tool-based responses? What arose from three incidents was the role of authoritybased tools and information-based tools such as moral suasion and propaganda used by government in responding to noncompliance.

\subsubsection{Information-based responses}

As disputes and tensions progressed, local governments first relied on information-based tools such as moral suasion, propaganda, and public dialoguesas the most preferred tools. The government's preference over information-based tools was evident in the Dong Tam and Thu Thiem incidents. Prior and during the dispute in Dong Tam, the city consistently conducted a propaganda campaign on public mass media asserting that the disputed land was defense land; Dong Tam villagers illegally occupied defense land. On April 18, 2017, Hanoi’s CPV publicly asserted that Dong Tam villagers violated LOL, illegally occupied defense land, threatened public safety, prevented 
people's daily works, resisted law enforcement force, and illegally held hostages. The government asked villagers to free hostages and leave the disputed land (Ngoc Huyen, 2017). The propaganda campaign, however, did not reduce tension. It instead increased landholders' grievances.

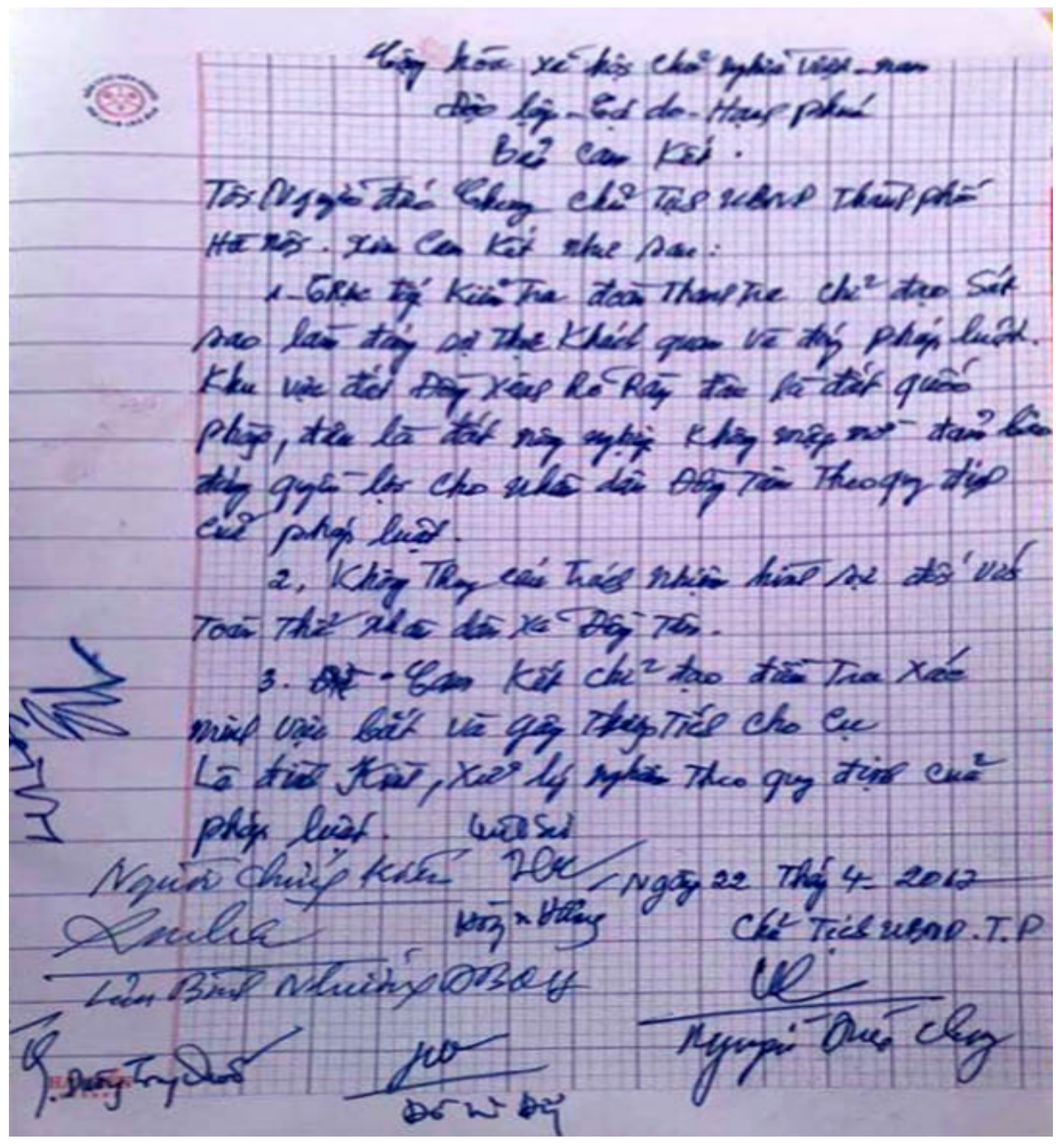

Figure 19. Handwritten commitments by Hanoi’s governor on April 22, 2017

(Source: vov.vn) 
After villagers held hostages on April 15, 2017, the city government started a moral suasion and exhortation campaign in Dong Tam. The city's governor was assigned by the Hanoi's CPV for seeking a settlement. On April 17, 2017, the governor communicated by phone with noncompliant landholders. On April 19, a Hanoi's representative to the National Congress met with villagers in Dong Tam. The city's mayor, on April 20, invited representatives of villagers to My Duc district government for a dialogue. Villagers, however, refused. They asked the governor coming to Dong Tam commune for a public meeting. In response, the governor asserted the government would not attack villagers to free hostages; and all land issues in Dong Tam would be inspected. After numerous communications by phone, the city's governor came to Dong Tam on April 22 for a public dialogue. At the public meeting, he received villagers' complaints and requests. He also signed a document written by hand committing that (i) the government would monitor the inspection of land issues in Dong Tam, (ii) the government would not arrest and prosecute noncompliant landholders; and (iii) the government would investigate the illegal arrest of Le Dinh Kinh, the leader of noncompliant villagers. Per request of villagers, the city also stopped propaganda campaign that labeled villagers as deviant citizens who illegally occupied land for defense. On July 7, 2017, the city's inspectorate released the draft of inspection report. As committed with villagers on April 22, 2017, the governor came to My Duc district on July 7, 2017 to inform Dong Tam villagers about the inspection report. At a meeting that limited the number of participants, the city's governor confirmed that the land area assigned for defense purpose in 1980 was 239.9 ha. After the government used land for constructing a road, the remaining land area for defense was 236.8 ha. Total land area of 
Dong Tam commune acquired for the airport project in 1980 was 64 ha, not 96 ha or 106 ha as claimed by Dong Tam residents. The governor said at the information session: "I assert the city's land acquisition is legal. If you still dispute, the city government will assign inspectorate agency to dialogue with villagers”. The governor emphasized that defense land was for defense. The government was not required to make the total defense land area public. He added: "It is not necessary to tell everyone about what belongs to national secrets. If the people know everything, our enemy knows, too. So, how can we defend our nation?” He asked Dong Tam commune government to continue dialogues with landholders, listen to villagers, and encouraged landholders send requests, if any, to the city's inspectorate. The city government would clarify every issue regarding noncompliant villagers’ requests (Cong Khanh, 2017). Although villagers really wanted to participate in the information session, they were not invited. Only Dong Tam commune government's leaders and officials, heads of residential units, and 10 residents selected by the city government participated in the information briefing.

"Press conference” was a tool used by HCMC and Hanoi governments when land disputes lasted long and attracted public concerns. Responding to landholders' information requests about the resettlement area of 160 ha, the HCM city government was not able to provide clear information. According to the original land planning, Thu Thiem new urban complex consisted of two sections: (i) a new urban area - 770 ha; and (ii) a resettlement area - 160 ha. The city government, however, did not use 160 ha for resettlement purpose. Affected land users in reality were moved to four different places: An Phu (90ha), Cat Lai (50ha), Thạnh My Loi (6,4ha) and Binh Khanh (15,5ha). Among these four resettlement areas, only Binh Khanh was inside the boundary of Thu Thiem 
project. However, before the central government's inspectorate released the inspection report on land disputes in Thu Thiem, the city's leaders always asserted at public dialogues with landholders that the city government acted in accordance with the original plan approved by the central government. All resettlement areas were within or nearby the Thu Thiem project. Since landholders did not accept this explanation, disputes lasted long and tensions increased (Quoc Phong, 2017). Public pressure forced the HCMC government to organize a press conference, informing the public about the original map. However, Nguyen Thanh Nha, Director of HCMC Department of Planning and Architecture talked at the press conference on May 2, 2018: “the city people’s committee currently is looking for the map. We check with city departments and central government's agencies. Documents stored at our department do not include the map” (Thy Hue, 2018).

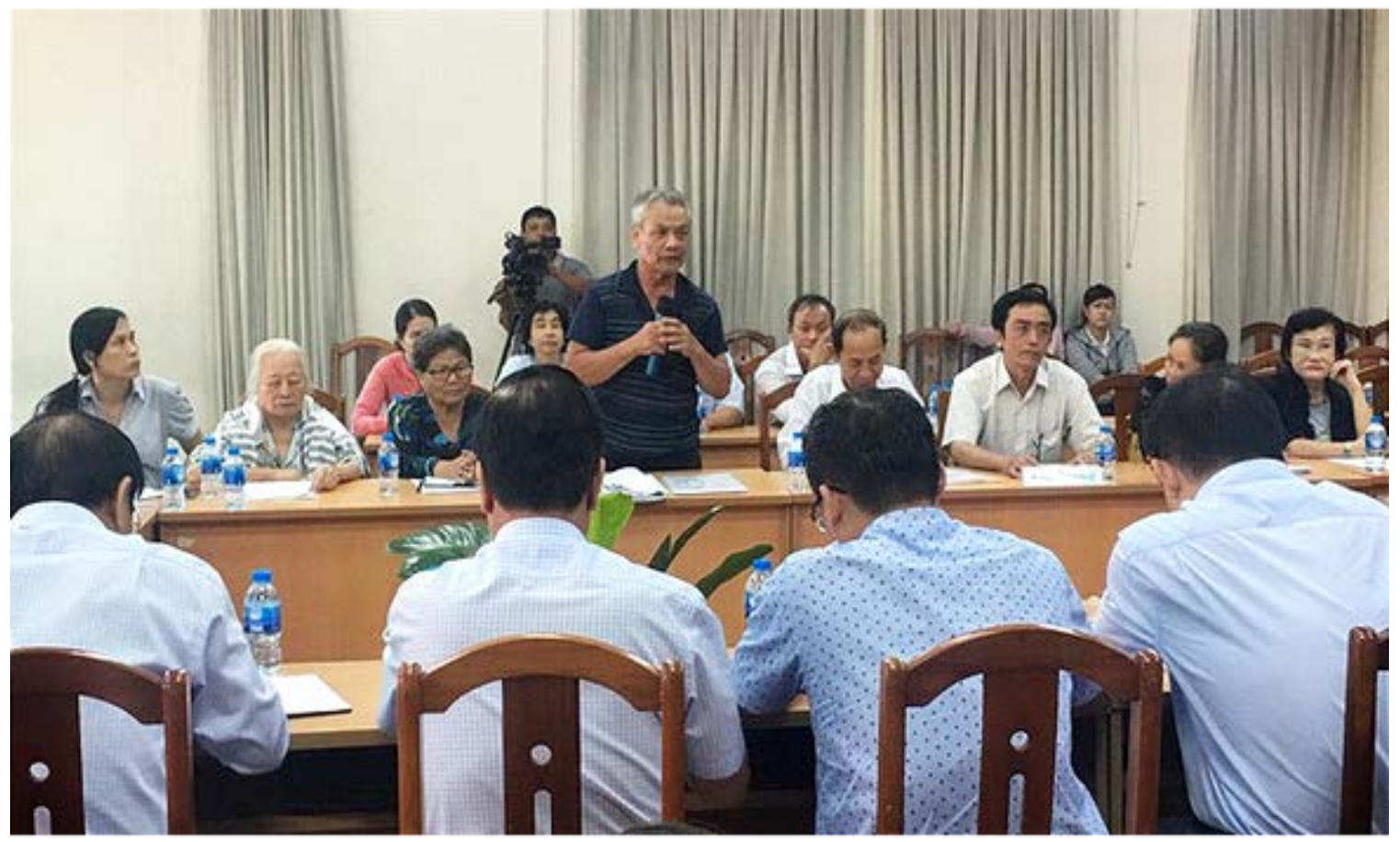

Figure 20. Dialogue between the city’s mayor and Thu Thiem resident on Oct. 18, 2018 (Source: tuoitre.vn) 


\section{Table 10: Commitments by Ho Chi Minh City’s Government}

\section{At press conference on September 21, 2019}

- Meet with noncompliant households by October 30, 2018

- Complete legal procedures regarding urban planning of Thu Thiem by October 15, 2018

- Develop compensation and support proposal for affected households in area of 4.3 ha by November 30, 2018.

- Review responsibilities of individuals and organizations and prosecute violations by October 15, 2018.

- Review and monitor investment projects in resettlement area by November 1, 2018

(Source: Zing.vn, 2018c)

\section{Mr. Nguyen Thien Nhan - CPV's general secretary in HCMC}

Compensation options for affected landholders

By January 15, 2019, government agencies will meet all 321 households in the area of 4.3 ha to figure out specific solutions. 155 landholders whose land were coercively acquired and 114 landholders who already moved out will be offered three options if they want to get back Thu Thiem:

- Receive an apartment in the resettlement area of 4.3 ha

- Receive a piece of land nearby Thu Thiem

- Resettle by their choice in another place

(Source: Thien Ngon, 2018)

Tensions in Thu Thiem was only reduced after the central government's inspectorate issued the inspection report on September 7, 2018. Multiple dialogues and moral suasions then were conducted by the city government's top leaders to convince landholders that the government would review every affected case for interests of the people. Late September 2018, at a press conference, representatives of HCMC 
government excused affected landholders and committed that the city would complete a set of goals by the end of 2018 to solve disputes in Thu Thiem (see table on page). In early 2019, Mr. Nguyen Thien Nhan - CPV Secretary of HCMC, talked to the public that "It has never been more convenient like now to properly solve land disputes in Thu Thiem, after the central government released the inspection report. We have to make challenges become opportunities to re-gain trust from the people” (Thien Ngon, 2018).

\subsubsection{Authority-based responses}

One unifying pattern of government's response to noncompliance emerged in three incidents was the use of public authority-based tools(e.g. executive orders)to solve land-taking disputes. According to article 71, LOL of 2013, after failing in convincing landholders to give up their land, local governments could take land by force. This resulted in tensions between affected landholders and government but not necessarily settled disputes. Bac Ninh provincial authority was the only government among three local government that was not confronted by angry crowds who resisted coercive land acquisition. This was because Tu Son incident only affected small number of affected landholders and small acquired land area.

Coercive land acquisition led to more serious consequence in Dong Tam incident. When disputes began in 2015, Hanoi government relied on the city's inspectorate agency to investigate Dong Tam incident. On October 31, 2016, the city inspectorate released the inspection report no. 47/KL-U'BND stating that there was no evidence to consider land claims made by Dong Tam residents. On November 14, 2016, the My Duc district government sent a law enforcement force of around 600 public officials, including police and military forces, to surround the area of 6.8 ha. Local villagers were prevented from 
accessing the disputed land. The district government claimed 6.8 ha for defense land and started counting properties for compensation. This, however, was unrealistic and injustice in the eyes of Dong Tam residents. As explained by Mr Kinh, leader of noncompliant villagers, if the area of 6.8 ha was the land for defense purpose, military units could easily make transfers without compensation. Why did the district government of My Duc list properties and calculate compensation? In contrast, 14 households farming on 47.36 ha of airport land stopped their farming and left the land without any disputes. It was because the area of 47.36 ha apparently was defense land. Tensions increased in early 2017 when villagers occupied the disputed land to prevent Viettel. Co.'s constructions. In order to stop the dispute, on April 15, 2017, the city’s police arrested four disobedient land users, including Le Dinh Kinh - an elder villager who seriously got injured in the arrest (Ngoc Huyen, 2017). This government's coercive action unleashed villagers' grievances. They held 38 public officials, being ready for an attack from the city government, and demanded a dialogue with the city’s governor. Tensions were only reduced after a face to face meeting and dialogue between the city's governor and villagers held on April 22, 2017.

Together with the investigation of land dispute in Dong Tam, in August 2017, the city’s court prosecuted 14 government managers and land officials for violations of LOL and land management rules. The trial was a signal sent by the city to Dong Tam villagers that the dispute over land acquisition in Dong Tam was originally because of violations in land management. The disputed land was defense land. On July 27, 2017, the city's inspectorate issued the inspection report no. 2346/TB-TTTP (P5), concluding the Dong Tam incident: "the disputed land is defense land. The land area serving the airport 
construction previously used by Dong Tam residents belongs to the Mistry of Defense. There is no agricultural land within the disputed area as claimed by Dong Tam villagers”. According to the city government, between 1981 and 2012, due to loosely land management of the military units and the Dong Tam commune government, some villagers used the defense land for farming purpose. Between 2003 and 2010, some land transactions were illegally certified by the Dong Tam commune government. Regarding 14 households claiming land use rights for compensation, the city inspectorate also notified that the district government of My Duc canceled land-taking proposal that intendedly compensated affected land users. This indicated that these 14 landholders would not be compensated as the land-taking plan previously implemented by the My Duc district government. The city inspectorate asked the Hanoi city to work with the Ministry of Defense in order to recover all 236.7 ha serving the construction of the military airport (Anninhthudo.vn, 2017). Dong Tam villagers, however, disagreed with the city inspectorate's conclusions. They sent petitions to the central government's inspectorate. On April 25, 2019, after reviewing the Hanoi inspectorate's inspection report, the CGV's inspectorate officially confirmed that conclusions made by Hanoi city's inspectorate was correct and legal. The disputed land (6. 8 ha) was included in 236.7 ha of defense land (Hanoi, 2019). Dong Tam villagers were not invited to attend the city’s information session and later press conferences.

Similarly, authority-based responses made compulsory land acquisition became daily worries of Thu Thiem residents. Mrs Hong shared that after receiving coercive land-taking announcement in 2012, she could not sleep: "We could be forced to move at any time because our neighbors had to go already” (Manh Doan, 2018). Mr Tuan, whose 
family consists of 30 people said his family had to move to a new temporary apartment after being notified by the city government that our houses and land could be coercively acquired (Manh Doan, 2018). According to Khoa (Binh Khanh ward), on March 9, 2011, the city's vice governor signed executive order no. 1089/QĐ-UBND claiming his land for the Thu Thiem project. Khoa could send petition to the city's court but if he did nothing within 30 days, HCMC's executive order would be effective. Khoa had two options of compensations (apartment or cash) but he did not accept. On January 8, 2010, the $2^{\text {nd }}$ district government issued executive order no. 1067/QD-UBND compensating him 723 million VND. On June 8, 2010, hundreds of public officials came to his home, destroyed house while none was at home. They took away everything (Truong Minh, 2019a).

\subsection{Summary of the Chapter}

This chapter presents a cross case analysis of three land acquisition incidents taking place in Tu Son (Bac Ninh province), Dong Tam (Hanoi city), and Thu Thiem (Ho Chi Minh City). The analysis relies on two types of data: (i) primary data collected by the researcher in Bac Ninh (and Vinh Phuc) provinces and (ii) secondary data published by other authors and agencies. The theme-based analysis covers similarities and variations about tool choice and their use in executing land acquisition. Following are the summarized research findings drawn from three land-taking incidents under study.

Qualitative evidences revealed a similar tool mix used by local implementers in Hanoi, HCMC, and Bac Ninh to acquire land. The tool mix included a direct government organization (BCGC), authoritative tools (most importantly, executive order and land price regulations), information-based tools (e.g. proclamation, public poster, moral suasion and exhortation, propaganda, public dialogue, information portal) and three 
financial or financial equivalent tools of cash, land, and resettlement apartment. All three local governments in Hanoi, Bac Ninh, and HCMC relied on BCGC as the only organizational tool in implementing land-taking projects. BCGCs were a temporary taskbased unit established by the DPPC, recovered land assigned for households. Though representatives of affected land users and investors could serve in BCGCs, their role was minimal. They were largely expected to support government in convincing other affected landholders giving up their land. The fact that BCGCs were outnumbered by government leaders, managers, and officials made it like a temporary government agency.

Another shared feature across three incidents was the prominent role of authoritative tools and information-based tools. In order to execute land-taking projects, implementers used a same set of authority-based tools such as LOL, land price system and land valuation rules issued by city/provincial governments, executive orders issued by PPC and DPPC, central government's land price framework. The heavy use of authoritative tools helped implementers acquire land as scheduled. On the other hand, moral suasion, exhortation, and propaganda were most popularly used by implementers to convince affected land users. BCGCs organized public meetings and dialogues as required by LOL. Press conference was only used when tensions increased such as in Dong Tam and Thu Thiem. Field visits in Bac Ninh and Vinh Phuc provinces also helped the researcher further understand limited influence of proclamation, public posters, and government's information portals on landholders' attitudes and behaviors. Overall, the combination of authoritative tools and information-based tools helped implementers completed land-taking projects on time and, thus, enabled implementation effectiveness and efficiency. 
Three financial or financial-equivalent tools used in land-takings included: cash, land, and apartments. Dong Tam incident became an outlier because villagers did not dispute compensation. Their primary concern was whether the acquired land is defense land or not. Only the Ho Chi Minh City's government compensated Thu Thiem landholders with another plots of land and new apartments. However, affected landholders' responses and statistics showed that land and apartments were not an effective means of land acquisition. Most affected residents in Thu Thiem did not choose to move in new apartments because they were not able to afford expensive land and apartments. Noncompliance was more likely to increase if resettlement areas located far from landholders' old locations. Cash, thus,becamethe financialtool used in both incidents of Thu Thiem and Tu Son. Affected landholders in Tu Son incidents had only 01 option of cash because their acquired land area was small; the government was not required to resettle them in another location. Like other land disputes, residents in Dong Ky and Trang Ha wards did not comply with the government's land acquisition because of low compensation. Form of compensation did not play any role in Tu Son incident. A significant finding regarding compensation in cash in Thu Thiem was that compensation management did matter. Delayed payments and splitting cash-based compensation into several installments discouraged landholders' compliance with land acquisition. The fact that noncompliant landholders mainly disputed compensation showed the very limited role of financial and financial-equivalent tools in altering landholders’ behaviors.

Dealing with policy noncompliance, implementers largely relied on "executive order", "propaganda", and "moral suasion and exhortation". Once disputes took place, implementers' first choice was information-based tools. Members of BCGCs first were 
sent to each household to individually convince noncompliant landholders. BCGC members mainly relied on ideological and moral justifications to persuade landholders giving up their land. Public media controlled by the State was used as the key propaganda device to create public opinion that encouraged Dong Tam landholders' acceptance over land acquisition. Public dialogues between BCGC members and disobedient landholders were situationally organized when disputes lasted a long time; landholders’ grievances and tensions increased. Another shared pattern of three incidents was that after information-based tools failed in persuading landholders, the government was willing to coercively take land using executive orders and government agencies such as policy and military forces.

Factors affecting tool choice and use varied across province/city and depended on specific context of land-taking projects. Although governments in Hanoi, HCMC, and Bac Ninh used the same tool mixes to start land acquisition, they differed in tool choice when disputes took place. Hanoi authorities relied on direct government organizations (e.g. city’s inspectorate, city people’s committee, city court) and authoritative tools such as city PC's executive order and city inspectorate's inspection report to resolve the dispute. This was because Hanoi authorities could legitimately justify land-taking by defense and national security purposes. In contrast, HCMC and Bac Ninh governments largely relied on information-based tools such as propaganda, public dialogues, and press conference to reach settlements. Overall, land legislation, scope, intensity, and purposes of land acquisition projects were among the most significant factors influencing implementers’ tool choice and use. 


\section{CHAPTER VI: CONCLUSIONS AND IMPLICATIONS}

"Another reason for its attraction (tools approach) is that it suggests a solubility to policy problems, just as most problems around the house can, actually, be fixed with a reasonably simple tool box that may be purchased at DIY store, or most dental problems be fixed by a dentists wielding a limited range of custom-built instruments" (Margetts and Hood, 2016)

\subsection{Introduction}

Globally, land disputes and conflicts are inevitable in rapidly urbanizing and industrializing nations (Wehrmann, 2008). Vietnam is no exception. In the last three decades, the implementation of land acquisition policy has created contested relationships between the government, investors, and landholders (World Bank, 2009 \& 2011a). To conduct study on land acquisition problems, the researcher defines disputes and conflicts over land-takings as manifestations of policy noncompliance. The general research problem is: why Vietnamese landholders do not comply with land acquisition? Unlike other influential theories (e.g. intuitional, economic, and good governance approach), this study is motivated by a research puzzle about potential linkages between policy tools and policy noncompliance. The main research questions is: "when and how do implementation tools help to explain noncompliance with land acquisition in Vietnam”? 
To address this question, the researcher treats government as "a black box and focusing on how it interacts with society" (Margetts and Hood, 2016). A tool-centered research, thus, allows the researcher to explore process dimensions of land-taking policy implementation. More specifically, the researcher's attentions turn into "the mechanisms of rule and the relationship between government and the governed” (Le Gales, 2011). The primary research interest, thus, involves policy tools that define interactions and relationships between implementers and target groups. Three land-taking incidents taking place in Hanoi city, HCMC, and Bac Ninh province are used as instrumental cases for a discovery of those means of interactions and relationships.

This concluding chapter consists of three main sections: (i) discussion of research findings; (ii) conclusions; and (iii) policy implications. In the first section, research findings drawn from three incidents will be placed in available literature for an in-depth discussion. The tool centered discussion will clarify and assess research findings. Noncompliance with land acquisition will be explained in relation with characteristics, strengths, and weaknesses of implementation tools used by local implementers. The researcher will also point out contributions of the tools approach to literature of landtaking policy problems in Vietnam. The concluding section summarizes this study and provide an answer to the research question. From a tools perspective, the last section presents implications for Vietnamese policy makers, implementers, professionals, and academic researchers who are interested in policy tools.

\subsection{Discussions of Research Findings}

In policy literature, looking at tools is helpful to understand the change in service provision (Weaver, 1989), the improvement of policy implementation (Bertelmans- 
Videc, Rist and Vedung, 1998), or the identification of policy change (Le Gales, 2011). However, the most attractive feature of tools approach is its capability to break down the complex policy problems into constituent components and provide alternative options for public choices (Margetts and Hood, 2016). By looking at a tool mix and its results, we can find out what works and what does not work in particular context. The selection of instrument, thus, can impact policy success or failure. From a tool perspective, argued by tool supporters, primary concerns of policy makers and implementers is whether tool choices are "the best possible ones for meeting the objective set; and the central set of issues is around the effectiveness of instruments” (Lascoumes and Le Gales, 2007).

What arises from the three incidents analyzed in this study isthe role of government organizations as the only organizational tool used in executing land acquisition policy. This research finding is consistent with the World Bank's research on the organizational structure responsible for land-taking policy implementation (World Bank, 2011a). The use of direct government organizations offers implementers with some advantages. The government first can save budget because land-taking policy implementation relies on available employees and resources. Most BCGC members are government officials and managers who already get paid from the government for their daily works. Second, the direct involvement of government organizations allows the exercise of legitimate force when implementers confront resistance. This ensures that the execution of a land-taking project is not left for chance. The government, therefore, can reach desired land-taking objectives as scheduled. However, as pointed out by numerous researchers, the fact that public officials dominate BCGCs make this type of organizational tool less responsive to emerging needs (De Wit et al, 2012; World Bank, 
2011a; T\&C, 2014). This is because BCGCs are not independent organizations that operate based on the market mechanism. As a temporary task focused unit, BCGCs represent the State's interests that might conflict with target groups' interests. BCGCs first act in the interests of the State. Due to limited participation of non-State actors such as landholders, legal experts, and land policy professionals, BCGCs can make decisions that do not meet affected landholders' demands and preferences. In practice, direct government organizations are more appropriate where no effective market exists to supply service or good (Salomon, 2002: 61-62). For political consideration, tensions and clashes between government and citizens are another consequence of the use of direct government organizations in acquiring land. Landholders only dispute land price and compensation - a purely economic dispute. They do not resist the government and the policy. Landholders only act to protect their legitimate economic interests that the government should also do. However, since government officials and agencies are the only actors to implement policy, landholders target at them once their interests are affected, and have a grievance against public officials. This easily turns economic disputes over land-takings into political tensions that might threat Vietnam's sociopolitical stability. Direct government organizations, thus, are not an appropriate choice, especially when acquired land is then assigned for private investors.

This case study reveals an authority-intensive tool mix used in land-taking policy implementation. Authoritative tools such as "executive order" and "land price regulations" play decisive role. A key feature of authoritative tools is the threat of sanctions backed by the State. Target groups will be punished if they do not comply with the State's policy. The use of authoritative tools, thus, involve a significant coercion 
(Howlett, 2011: 83). On the one hand, the coerciveness of authoritative tools might help implementers achieve implementation efficiency and effectiveness. As evident in three incidents under study, local governments in Hanoi, Bac Ninh, and HCMC largely relied on executive orders to legalize land-taking decisions. The government also controlled compensation through land price regulations. Affected landholders were expected to act in accordance with the government's desired ways: accept compensation based on a fixed land price system and leave their land. Landholders involved in three incidents had no choice except receiving compensation. If they did not comply with government's decisions, executive ordersand government's law enforcement forces were used to forcefully take land as scheduled. Theoretically, a heavy reliance on authoritative tools, on the other hand, will increase resistance over land acquisition. Landholders disobey government's actions because from their point of view, those coercive actions are not legitimate. The use of executive order makes land-takings legal, but it is not necessarily a legitimate action of government. Legality is only one element of legitimacy (Gilley, 2009: 6-7). It only shows that government’s actions conform to political community's laws, rules, and customs. The use of public power or authority is recognized by legislation. Citizens, however, may doubt rules followed by governing authorities or they simply think that following rules is not enough. This might derive from insufficiencies of legality or unclear information regarding land acquisition plans. In addition, compensation refusal and coercive land acquisition indicate landholders' non-consent. Without their consent, landholders might act against government that often results in long lasting disputes and tensions. Therefore, the use of public authority is only legitimate if government's actions are transparent and consistent with shared norms of conducts that 
reflect political community's moral consensus. Government will only convince landholders voluntarily give up their land if actors (government)“holds and exercises political power with legality, justification, and consent from the standpoint of its citizens” (Gilley, 2009: 11).

This qualitative study shows the inappropriate choice of land price regulation as an implementation tool. Article 112 of LOL (2013) requires implementers to develop land price equal to common land price on the market at time of land acquisition. However, land price regulations issued by PPC set price ceiling applied for land acquisition. Regardless of land price calculation formularies, there are no way implementers can offer landholders with land price and compensation that are equal to market-based value. This is because regulations are "rules written by appointed public officials to implement often vaguely worded statutes that delegate rule making authority to an agency” (Salamon, 2002: 119). In other words, regulations are agency-made law backed by legislation and judicial decisions. Government relies on regulations to govern private behaviors or set price ceiling as in land acquisition. In practice, land price systems issued by city/provincial governments aim to control implementers' land valuation behaviors. By using land price regulation, government can control compensation in a desired way. This, however, conflict with a requirement as stated in Law on Land that land price and compensation should be close to land value on market. Local implementers, in practice, are unable to develop a market-based land price because they cannot violate the fixed land price ceiling as stated in land price regulations. This research finding demonstrates shortcomings of economic explanation that unfair land price and low compensation are two key contributors to noncompliance with land 
acquisition (World Bank, 2009\&2011a). It becomes clear that unrealistic land price and compensation are only consequences of a wrong tool choice. The fixed land price regulation is the first factor causing disputed compensation, leading to noncompliance. What government needs to do is not simply to increase land price and compensation. Government instead needs to create a more stable tool that can be flexibly used in different situations. Such a tool will help implementers determine real value of land that is associated with local contexts.

Dealing with noncompliance, this study discovers governments' enforcement efforts using authoritative tools and information-based tools. Once noncompliance took place, local governments did not change their decisions. They tried to enforce land-taking procedures and rules as stated in LOL and people's committee's executive orders. Public policy literature has documented the important role of financial incentives in government's policy enforcement efforts (Gofeng, 2015). This research, however, suggests minimal role of financial incentives in government's efforts to solve noncompliance with land acquisition. There were no changes of compensation (e.g. increased payment in cash). Landholders had to accept the same rate of compensation even if their land had been acquired long time ago. While the researcher did not find significant evidence regarding relationship between forms of compensation (e.g. cash, land, and apartments) and noncompliance, the management of compensation did contribute to landholders' disobedience. The fact in Thu Thiem that local governments began land-takings while resettlement apartments were not ready for landholders to move in increased noncompliance. Also, delayed payments or paying compensation in multiple installments affected landholders' policy compliance. Field interviews and observations' 
evidences also indicate implementers' tool preferences over information-based tools such as moral suasion and propaganda. However, information-based tools are not helpful tools in noncompliant situations. This is because, by using of information-based tools, implementers are not required to provide clear and exact information. They can inform landholders anything that might alter target groups’ thinking and behaviors (Weiss, 2002: 217; Howlett, 2011: 115-118). As shown in Thu Thiem and Dong Tam incidents, despite governments' efforts, moral suasion and propaganda failed in reaching a settlement. The more governments talked; the more landholders got angry because they did not know what they really wanted to know. After information-based tools failed in convincing landholders' compliance, executive orders issued by district government became implementers' final tool choice to forcefully take land. The use of government agencies and executive orders to acquire land by force was a common pattern of tool-based response across three land-taking incidents. This pattern of coercive response to noncompliance did not conclude disputes. It instead increased target groups' grievances and tensions between government and affected landholders.

It becomes clear that "coercion", "instrumentality", and "routinization" are common features and patterns of tool choice and use in land acquisition in Vietnam. By instrumentality, according to Capano and Lippi (2017), implementers select tools to “keep with the policy makers' pursued goals”. Whereas, routinization is a pattern that implementers adopt "the same policy instruments in the same way". Previously adopted instruments are preserved by implementers, without any change. These patterns of tool choice and use ensure implementation effectiveness but not necessarily result in a shared sense and a common acceptance that construct policy legitimacy. Form a tool 
perspective, three features of coercion, instrumentality, and routinization might help government achieve policy effectiveness and efficiency. However, such a model of tool choice and use is not necessarily responsive to policy target groups' demands. Current tool mixes and tool preferences instead would be associated with two negative consequences: (i) low responsiveness and (ii) direct confrontation between the government and citizens.

\subsection{Research Conclusions}

A challenge for the policy tools approach as a new research direction within the context of Vietnam is how does it help to understand noncompliance with land acquisition? Research results suggest that implementation tools do matter. Tool choice and use might contribute to policy noncompliance. The tools lens sheds light on noneconomic and non-institutional aspects of policy noncompliance. It supports an explanation of policy noncompliance that goes beyond institutional and economic conditions. Accordingly, policy noncompliance will be minimized if government acts legitimately. This requires government to take into account legitimate voice, demands, and interests of various actors involved in land acquisition.

Tools approach, thus, further explains landholders' noncompliance that current tool mixes are not associated with legitimate actions. Available tools allow preferences over direct government organizations, authoritative tools, and information-based tools while ignore financial incentives to acquire land. This tool preference not only define a one-way relationship between government and target groups but also legitimate coercive actions in land acquisition. As can be seen in Thu Thiem incident, the availability of tools encourages the abuse of public authority in coercive land acquisition. Implementers can 
recover land regardless the legitimacy of government's actions. This is also clear in all three incidents under study that government justifies compulsory land-takings by defense purpose or economic development purposes and then assign land for private investors. In theory, tools are institutions (Le Gales, 2011). However, tool choice and use are not intuitional issues. They are actions in practice. Tools approach, therefore, suggests, that implementers can increase landholders' compliance with land acquisition if they remove inappropriate tools, change tool use towards more collaborative interactions, and consider the legitimacy of government's actions in practice.

Giving this dissertation research is in a qualitative case study design, research conclusions are applicable to cases considered in this study only. This means that implementation tools are not necessarily related to noncompliance in other land-taking projects. Also, the tools approach needs to be tested with compliant land-takings. The question for tools approach is why adopting the same tool mixes, many local governments can successfully acquire land without resistance? Research in future, thus, can further explore variations and patterns of tool choice and use in a large sample to verify this study's conclusions. More importantly, in order to confirm this dissertation's research findings, researchers should look for land-taking projects in which implementers can settle disputes by only changing tool choice and use.

\subsection{Policy Implications}

Tool supporters might be questioned: to what extent can tool perspective be used to improve policy implementation, make policy implementation more effective, more efficient, more equitable, and more responsive? In other words, considering current tool mixes used to acquire land in Vietnam, how do implementers minimize policy 
noncompliance by changing tool choice and use? This case study suggests some implications and recommendations for policy makers, policy implementers, and professionals and academic researchers who are interested in the tools approach. The most general implication for all is that compulsory land-taking does not mean acquiring land by force and at any cost. Policy makers and implementers should be aware that by compulsory land-taking, the State has authority to recover land for legitimate purposes. Landholders' obligation is to return land to the State. However, policy makers and implementers should not only think about implementation effectiveness and efficiency. They instead need to consider responsiveness and legitimacy of government's actions in order to reach policy compliance.

\section{Policy makers}

To increase responsiveness of policy implementation, policy makers should consider the role of "market" and non-state actors in land acquisition. Direct government organizations should only take land for public purposes (e.g. defense and national security). Non-state actors that operate based on market mechanism should have more chance to participate in land acquisition for economic development. The central government should limit the number of public officials participating in BCGCs and the number of affected landholders that each BCGC can serve. Affected landholders should be allowed to select anyone who has knowledge and prestige to serve in BCGC. The requirement that only affected landholders can serve as landholders' representatives should be removed. The number of representatives should account for $5 \%$ of affected landholders instead of only 1-2 people. To ensure fairness of compensation, land price regulation should be replaced by other means of land valuation and price calculation. 
Instead of fixed land price regulations, the government should create a formula that can be used to calculate land price in specific situations associated with variations of local contexts and changes of land price on market.

\section{For policy implementers}

Considering institutional conditions of current land-taking policy, BCGC should be more inclusive in order to operate as an advisory unit. Membership of BCG are not necessarily limited to government officials, leaders, and affected landholders. Instead of being solely decided by the government, the selection of non-government actors should be voted by both affected landholders and representatives of the government. To develop a land price system that reflect the latest value of land on the market, implementers should consult with non-state actors who provide land valuation service. The authority of district governments in land acquisition needs to be controlled. The provincial government should not only approve land-taking proposal submitted by district governments but also need to monitor every land-taking act of district governments. This requires a more centralized process of decision-making for land acquisition: district governments' executive orders need to be approved by the provincial or city government to prevent the abuse of authoritative tools. Implementers should start land acquisition once funding, land, or resettlement apartments are available. This rule needs to be strictly enforced, so that affected landholders are able to move in their new homes right after the government starts land acquisition projects. New resettlement areas should offer better living conditions than the old places. Giving cash is the most common financial tool, funding transfer should be completed in one installment prior the time that landholders are required to move out. Non-material losses such as job opportunity and the 
convenience of old living locations should be considered and added in compensation. Public meetings should be used as the main information-based tool because of its transparency and ability to force government officials be accountable for their actions. The government, however, should not organize meetings with all affected landholders in one time. Multiple meetings with different groups shared the same concerns might be the most effective form of communication.

\section{Policy professionals and academic researchers}

Further research based on the tools approach is necessary to confirm the relationship between policy tools and noncompliance with land acquisition. First, policy professionals and academic researchers who are interested in tools approach to policy noncompliance might also apply tool perspective in other policy fields. In the land sector, the tools approach should be applied to examine government's actions in different contexts of land acquisition (e.g. scale of land-takings, purposes, actors, funding...). Also, since public policy, after all, is "the business of understanding, dealing with, and even changing the world outside government” (Margetts and Hood, 2016), an important research direction is to discover the impact of changing context on interactions between government and citizens. This is because, in recent two decades, internet and social media has become widespread in Vietnam. Digital technologies not only have transformed daily life of ordinary citizens but also the way they interact with government. In a rapidly changing society, policy makers and implementers need to take into account of challenges to governance brought about by technological changes. Vietnamese policy makers should be aware of a reality that it becomes more difficult for the authority-based tools to wield in society where citizens find internet, social media, and mobile 
communications a powerful device to voice their demands and preferences. Internetbased platforms provide citizens a network-based environment in which they are capable to interact (e.g. receive, share, disseminate information) in large-scale spaces. This context might challenge traditional perspectives in policy implementation.

\subsection{Summary of the Chapter}

This chapter concludes the dissertation study. The researcher argues that implementation tools do matters. To clarify linkages between implementation tools and noncompliance with land acquisition, the researcher discusses research findings in relation with available literature. Qualitative research results suggest that tools contribute to landholders' noncompliance. This first is because available tools used in acquiring land allow coercive land acquisition once implementers face resistance. Second, case analysis shows unsuitable tool choices such as the land price regulation or inappropriate tool use such as authority-intensive responses to solve noncompliance. Overall, tool preferences over direct government organizations, authoritative tools, and informationbased tools define a one-way relationship between policy implementers and affected landholders who have no choice except receiving compensation and giving up their land. Coercion, instrumentality, and routinization are three prominent features of Vietnamese implementers' tool choice and use in land acquisition. These characteristics ensure implementation effectiveness and efficiency but are not necessarily associated with responsiveness and legitimacy of government's actions. These, from a tool perspective, explains why and how government's actions contribute to noncompliance with land acquisition in Vietnam. 


\section{References}

ADB (1995). “Governance:sound development management”. Retrieved from https://www.adb.org/sites/default/files/institutional-ocument/32027/govpolicy.pdf

Adler, Robert S., \& Pittle, R. David. (1984). Cajolery or command: Are education campaigns an adequate substitute for regulations? Yale Journal on Regulation, 1(2), 159-193.

Agranoff, Robert and McGuire, Michael (2003).Collaborative Public management: new strategies for local governments. Georgetown University press, Washington DC.

Anderson, C. (1971). Comparative Policy Analysis: The Design of Measures. Comparative Politics, 4(1), 117-131.

Anderson, J. (2014). Public policymaking (8th Ed.). Australia: Wadsworth. Anninhthudo.vn (2017, July 25). Ket luan thanh tra dat Dong Tam. Anninhthudo.vn. Retrieved from https://anninhthudo.vn/chinh-tri-xa-hoi/ket-luan-thanh-tra-datdong-tam-dieu-tra-xu-ly-nghiem-vi-pham-thu-hoi-dat-quoc-phong-bi-lanchiem/734581.antd

Anh Phuong (2018, June 27). Can cong khai, minh bach co che giao dat doi voi cac du an BT. Sggp.org.vn. Retrieved from http://www.sggp.org.vn/can-cong-khai-minhbach-co-che-giao-dat-doi-voi-cac-du-an-bt-529180.html

Arrow, K.J (1958). Utilities, Attitudes, and Choices: A review Note. Econometrica, Vol. 26.

Bac Ninh PPC (2014). Decree No. 528/2014/QD-UBND about compensation, support, and resettlement for land acquisition and procedures of land acquisition, land assignment, and land lease. 
Bazeley, P. (2013). Qualitative data analysis: practical strategies. Los Angeles: SAGE Publications.

Bbc.com (June 19, 2017). Ong Le Dinh Kinh ke lai vu bi hanh hung vi dat nong nghiep. Retrieved from https://www.bbc.com/vietnamese/vietnam-40320819

Bemelmans-Videc, M., Rist, Ray C, \&Vedung, Evert. (1998). Carrots, sticks \& sermons: Policy instruments and their evaluation (Comparative policy analysis series). New Brunswick, N.J., U.S.A.: Transaction.

Bevir, M. (2011). The SAGE handbook of governance. Los Angeles [i.e. Thousand Oaks, Calif.]: SAGE Publications.

Bell, C. K (2014). A review of the land sector in East Asia: lessons for land governance and the spatial enablement of government and societies. Paper presented at the “2014 World Bank conference on land and poverty”. Retrieved from http://www.oicrf.org/document.asp?ID=13517

Beresford, M. (2008). DoiMoi in review: The challenges of building market socialism in Vietnam. Journal of Contemporary Asia, 38(2), 221-243.

Birkland, T. (2016). An introduction to the policy process: Theories, concepts, and models of public policy making (4th Ed.). New York: Routledge.

Bloor, M\& Wood, F. Key words in qualitative methods: a vocabulary of research

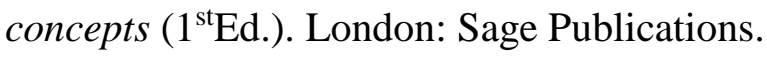

Butler B. S (2009). Developing Land Markets within the constraint of state ownership in Vietnam. In Ingram, G.K and Hung Hong, Y. “Property rights and land policies”. Lincoln Institute of Land Policy, pg 137-175. 
Boone, C (2013). Land regimes and the structure of politics: patterns of land-related conflict. Africa, Vol. 83, No. 1: 188-203.

Braun, V \& Clarke, V. (2006). Using thematic analysis in psychology. Qualitative Research in Psychology, 3(2), 77-101.

Brinkerhoff, W \& Crosby, B (2002). Managing policy reform: concepts and tools for decision-makers in developing and transitioning countries. Bloomfield, CT: Kumarian Press.

Brown, D (2012, February 2). Vietnam’s Contentious Land Law. Asia Sentinel. Retrieved from http://www.asiasentinel.com/society/vietnams-contentious-landlaw-part-2/

Brown, D (2013, February 6). Vietnam's contentious Land Law. Asia Sentinel. Retrieved from http://www.asiasentinel.com/society/vietnams-land-law-reform-is-it-enough/

Bryman, A. (2012). Social research methods (4th Ed.). Oxford; New York: Oxford Uni. Press.

Capano, G., \& Lippi, A. (2017). How policy instruments are chosen: Patterns of decision makers’ choices. Policy Sciences, 50(2), 269-293.

CECODES, VFF-CRT, RTA \& UNDP (2018). The 2017 Viet Nam Governance and Public Administration Performance Index (PAPI 2017): Measuring Citizens’ Experiences. A Joint Policy Research Paper by the Centre for Community Support and Development Studies (CECODES), Centre for Research and Training of the Viet Nam Fatherland Front (VFF-CRT), Real-Time Analytics, and United Nations Development Programme (UNDP). Ha Noi, Viet Nam. 
CGI - Central Government’s Inspectorate (September, 7, 2018). Ket luan thanh tra khu do thi moi Thu Thiem. Retrieved from https://vietnamfinance.vn/toan-van-ket-luanthanh-tra-khu-do-thi-moi-thu-thiem-20180504224212652.htm

CGV - The Central Government of Vietnam (2014a). Decree No. 44/2014/ND-CP about land price.

CGV - The Central Government of Vietnam (2014b). Decree No. 47/2014/ND-CP about compensation, support, and resettlement for land acquisition.

CGV - The Central Government of Vietnam (2014c). Decree No. 104/2014/ND-CP about land price system.

CGV - The Central Government of Vietnam (2015). Nghi dinh ve dau tu theo hinh thuc doi tac cong tu. Retrieved from https://thuvienphapluat.vn/van-ban/Dau-tu/Nghidinh-15-2015-ND-CP-dau-tu-theo-hinh-thuc-doi-tac-cong-tu-266213.aspx

Cialdini, R., \& Goldstein, N. (2004). Social influence: Compliance and conformity. Annual Review of Psychology, 55, 591-621.

Chotray, V., \& Stoker, Gerry. (2009). Governance theory and practice: A crossdisciplinary approach. Basingstoke [England]; New York: Palgrave Macmillan.

Cooper, P (2018). Policy tools in policy design. California: Melvin \& Leigh

Cong Khanh (July 7, 2017). Chu tich Hanoi: toi mong ba con thuong ton phap luat. News.zing.vn. Retrieved from https://news.zing.vn/chu-tich-ha-noi-toi-mong-bacon-dong-tam-thuong-ton-phap-luat-post761033.html

Creswell W. J (2013).Qualitative Inquiry and Research Design: Choosing among five approaches.( $\left({ }^{\text {rd }}\right.$ ed.). Thousand Oaks: Sage Publications. 
Creswell, J. (2014). Research design: qualitative, quantitative, and mixed methods approaches. (4th Ed.). Thousand Oaks, California: SAGE Publications.

Denhardt, J., Terry, L., Delacruz, E., \&Andonoska, L. (2009). Barriers to Citizen Engagement in Developing Countries. International Journal of Public Administration, 32(14), 1268-1288.

Denhardt, R. (2011). Theories of public organization (6th Ed.). Boston, Mass.: Wadsworth/Cengage Learning.

De Wit, J. W; Sang, L.V; Chien, L.V; Hien, L.T; Hung, H.V; Tuyet, D.T; Bau, D.N (2012).Assessing decentralized policy implementation in Vietnam: The case of land recovery and resettlement in the VungAng Economic Zone.International Institute of Social Studies. Netherlands. ISS Working Paper Series/General Series (Vol.546, pp. 1-55). Erasmus University Rotterdam.

Retrieved from https://repub.eur.nl/pub/32910/

De Wit, J.W. (2013). Land governance of suburban areas of Vietnam (No. 561). ISS Working Paper Series/General Series (Vol. 561, pp. 1-34). Erasmus University Rotterdam.Retrieved from http://hdl.handle.net/1765/40476

Deininger, K and Jin, S (2005). Land Sales and Rental Markets in Transition: Evidence from Rural Vietnam. Paper presented at the American Agricultural Economics Association Meeting. Rhode Island.

Deininger, K; Selod, H; and Burns, A (2012). The land assessment Framework:

Identifying and monitoring good practice in the land sector. Washington DC. The World Bank

Dodds, A (2013). Comparative public policy.New York: Palgrave Macmillan 
Dunn, W. (2012). Public policy analysis: An introduction (5th Ed.). Boston: Pearson.

Elo, S., \&Kyngäs, H. (2008). The qualitative content analysis process. Journal of Advanced Nursing, 62(1), 107-115.

Embassy of Denmark, World Bank, and Embassy of Sweden (2011). Recognizing and reducing corruption risks in land management in Vietnam. Hanoi: National Political Publishing House.

Enemark, Stig; McLaren, R; and Molen, P (2009). Land governance in support of the millennium development goals. Conference Report by FIG and World Bank: Washington DC.

Ellickson, C.R (1993). Property in land. The Yale Law Journal, Vol. 102, No. 6: 13151400.

FAO-UN (2012). Land tenure and rural development. Land Tenure Service of the Rural Development Division.

FAO-UN (2007). Good governance in land tenure and administration. FAO Land Tenure Studies

Fu, H., \& Gillespie, J. (2014). Resolving land disputes in East Asia: exploring the limits of law. Cambridge:Cambridge University Press

Gales, P (2011). Policy instruments and governance. In Bevir, M. The SAGE handbook of governance. Los Angeles [i.e. Thousand Oaks, Calif.]: SAGE Publications.

Gillespie, J. (2011). Exploring the Limits of the Judicialization of Urban Land Disputes in Vietnam. Law \& Society Review, 45(2), 241-276.

Gillespie, J (2014). Public landdisputes in Vietnam: A multi-actoranalysis of five case studies with an Asian comparative. Research Report 
Gilley, Bruce (2009). The right to rule: how states win and lose legitimacy. New York, Colombia University Press.

Glaser, B., \& Strauss, Anselm L. (1967). The discovery of grounded theory: Strategies for qualitative research (Observations (Chicago, Ill.)). Chicago: Aldine Publishing.

Gofen, A. (2015). Reconciling policy dissonance: Patterns of governmental response to policy noncompliance. Policy Sciences, 48(1), 3-24.

Grbich, C. (2007). Qualitative data analysis: An introduction. London; Thousand Oaks, Calif.: SAGE Publications.

Hall, D (2013). Land. Cambridge: Polity Press.

Hanoi (April 25, 2019). Ket luan cua thanh tra thanh pho Hanoi phu hop voi quy dinh phap luat. Hanoi.gov.vn. Retrieved from https://hanoi.gov.vn/tintuc_sukien//hn/ZVOm7e3VDMRM/3/2825493/ket-luan-thanh-tra-cua-thanh-tra-tp-ha-noive-viec-quan-ly-su-dung-at-tai-xa-ong-tam-chinh-xac-phu-hop-voi-quy-inh-phapluat.html;jsessionid=dWApUA2EGcG9Lo+b7gbswh-x.app2

Hare, D. (2008). The origins and influence of property rights in Vietnam. Development Policy Review. 26 (3): 339 - 363.

Hai Long (January, $1^{\text {st }}$, 2016). Xa Dong Tam, huyen My Duc, Ha Noi: Xe dat cong de ban? Nguoi Cao Tuoi (Printed Newspaper).

Ha Thanh (2018, May 12). Nhung du an ti do o Thu Thiem. Vnexpress.net. Retrieved from https://vnexpress.net/kinh-doanh/nhung-du-an-ty-usd-o-thu-thiem3746591.html 
Ha Vy (2019, February 2). Chuong trinh 12.500 can ho khu do thi moi Thu Thiem con nhieu vuong mac. Cafef.vn. Retrieved from http://cafef.vn/chuong-trinh-12500can-ho-tai-dinh-cu-khu-do-thi-moi-thu-thiem-con-nhieu-vuong-mac20190213141455234.chn

HCMC (2018). Executive Order No. 28/QD-UBND about compensation, support, and resettlement regarding land acquisition. Retrieved from http://www.donre.hochiminhcity.gov.vn//Lists/vanbanmoi/Attachments/834/28_2

\section{8_Q\%C4\%90-UBND.pdf}

Heywood, A (2007). Politics. (3 ${ }^{\text {rd }}$ ed.). New York: Palgrave

Hill, M., \&Hupe, Peter L. (2002). Implementing public policy: Governance in theory and practice (Sage politics texts). London; Thousand Oaks, Calif.: Sage.

Hill, M., \&Hupe, Peter L. (2009). Implementing public policy: An introduction to the study of operational governance (2nd Ed.). Los Angeles [Calif.]; London: SAGE.

Huang, X. (2009). Politics in Pacific Asia: An introduction (Comparative government and politics. Basingstoke; New York: Palgrave Macmillan.

Hui, C.M.E \& Bao, H (2013). The logic behind conflicts in land acquisitions in contemporary China: a framework based upon game theory. Land Use Policy, Vol.30:373-80.

Huu Nguyen (May, 5, 2018). Quy hoach Thu Thiem thay doi the nao sau 22 nam? Retrieved fromhttps://vnexpress.net/thoi-su/quy-hoach-thu-thiem-thay-doi-thenao-trong-22-nam-3745564.html 
Huy Thinh (April, 1, 2019). 85\% ho dan khu 4.3 ha dong tinh giai phap sua sai o Thu Thiem. Retrieved from http://cafebiz.vn/85-ho-dan-khu-43-ha-dong-tinh-giaiphap-sua-sai-o-thu-thiem-20190104165853229.chn

Hsieh, H., \& Shannon, S. (2005). Three approaches to qualitative content analysis. Qualitative Health Research, 15(9), 1277-1288.

Ho, P (2005). Institutions in Transition: Land Ownership, Property Rights, and Social Conflict in China. New York: Oxford University Press.

Ho, D.H and McPherson, M (2010). Land Policy for socio-economic development in Vietnam. ASH Centre for Democratic Governance and Innovation, Harvard Kennedy School and UNDP. Retrieved from

\section{http://ash.harvard.edu/files/vnm_landpolicypaper.pdf}

Hood, C. (1983). The tools of government. London: Macmillan.

Hood, C. (1995). The "new public management" in the 1980s: Variations on a theme. Accounting, Organizations and Society, 20(2 3), 93.

Howlett, M. (1991). Policy Instruments, Policy Styles, and Policy Implementation. Policy Studies Journal, 19(2), 1-21.

Howlett, M. (2009). Governance modes, policy regimes and operational plans: A multilevel nested model of policy instrument choice and policy design. Policy Sciences, 42(1), 73-89.

Howlett, M., Ramesh, M., \& Perl, A. (2009). Studying public policy: policy cycles \& policy subsystems (3rd Ed.). Don Mills, Ont.; New York: Oxford University Press. 
Howlett, M. (2011). Designing public policies: principles and instruments (Routledge textbooks in policy studies). Abingdon, Oxon; New York: Routledge.

ICB (2018). Ho Chi Minh City Government’s website. Retrieved fromhttp://www.thuthiem.hochiminhcity.gov.vn/dat-dai-moi-truong?t=197-thuchien-cong-tac-boi-thuong-giai-phong-mat-bang-va-tai-dinh-cu-trong-khu-do-thi$\underline{\text { moi-thu-thiem }}$

Im, T., Cho, W., Porumbescu, G., \& Park, J. (2014). Internet, Trust in Government, and Citizen Compliance. Journal of Public Administration Research and Theory, 24(3), 741-763.

Institute for Research on Policy, Law, and Development (2013). Conciliation of Land Disputes in Vietnam: A critical Analysis of Current Law and Practice with Recommendations for Reform. Research Report

Ingram, G. K and Hung Hong, Y (2009). Property rights and land policies. Lincoln Institute of Land Policy

Ives, M. (2017, April 21). Villagers hold official hostages in Vietnam land dispute. The New York Times. Retrieved from https://www.nytimes.com/2017/04/21/world/asia/vietnam-hostages-protest-landdispute-eviction.html

Kerkvliet, B. (2018). An Approach for Analyzing State-Society Relations in Vietnam. Sojourn: Journal of Social Issues in Southeast Asia, 33(1), S156-S198. Kjær, A. (2004). Governance (Key concepts). Malden, MA: Polity Press. Jones, N. (2010). Investigating the influence of social costs and benefits of environmental policies through social capital theory. Policy Sciences, 43(3), 229-244. 
Kim, A. (2011). Talking back: the role of narrative in Vietnam's recent land compensation changes. Urban Studies, Vol.48, No.3, pp 493-508.

Lascoumes, P., \& Le Gales, P. (2007). Introduction: Understanding Public Policy through Its Instruments—From the Nature of Instruments to the Sociology of Public Policy Instrumentation. Governance, 20(1), 1-21.

Labbé, D. (2015). Media Dissent and Peri-urban Land Struggles in Vietnam: The Case of the VănGiang Incident. Critical Asian Studies, 47(4), 495-513.

Le Gales, P (2011). Policy instruments and governance. In Bevir, M. The SAGE handbook of governance. Los Angeles [i.e. Thousand Oaks, Calif.]: SAGE Publications.

Levi, M., \& Sacks, A. (2009). Legitimating beliefs: Sources and indicators. Regulation \&Governance, 3(4), 311-333.

Linder, S., \& Peters, B. (1989). Instruments of Government: Perceptions and Contexts. Journal of Public Policy, 9(1), 35-58.

Lipton, M (2009). Land Reform in Developing Countries: Property Rights and Property Wrongs. New York: Routledge.

Lodhi, A.H.A (2004). Are landlords taking back the land? An essay on the agrarian transition in Vietnam. The European Journal of Development Research, Vol.16, No.4:757 -89.

London, J. (Ed.). (2014). Politics in Contemporary Vietnam: Party, State, and Authority Relations. New York: Palgrave Macmillan

Luan Nguyen (2017). Su buc xuc cua ba con Dong Tam. Youtube.com. Retrieved from https://www.youtube.com/watch?v=zpmOmwd5YpY 
Manh Doan (2018, May 9). Cuoc song co cuc cua nguoi dan lang Thu Thiem tai Ha Noi. Vtc.vn. Retrieved from https://vtc.vn/cuoc-song-co-cuc-cua-nguoi-dan-lang-thu$\underline{\text { thiem-tai-ha-noi-d397531.html }}$

May, P. (1992). Policy Learning and Failure. Journal of Public Policy, 12(4), 331-354. May, P. (2004). Compliance Motivations: Affirmative and Negative Bases. Law \& Society Review, 38(1), 41-68.

May, P. (2005). Regulation and Compliance Motivations: Examining Different Approaches. Public Administration Review, 65(1), 31-44.

McDonnell, L., Elmore, Richard F (1987). Alternative policy instruments. Santa Monica, CA: Center for Policy Research in Education; Publications Dept., Rand McPherson, F.M (2011). Land Policy in Vietnam: Challenges and Prospects for Constructive Changes. Journal of Macro-marketing, 0000(00): 1-10

Markussen, Tarp, \& Van Den Broeck. (2011). The Forgotten Property Rights: Evidence on Land Use Rights in Vietnam. World Development, 39(5), 839-850.

Marsh S.P., MacAulay T.G. and Hung P.V. (Eds. 2007).Agricultural development and land policy in Vietnam. Policy briefs. Retrieved from http://aciar.gov.au/publication/mn123

Margetts, H and Hood, C (2016). Tool Approaches. In Peters, Guy and Zittoun, Phillippe (Eds.). Contemporary approaches to public policy: Theories, controversies, and perspectives. London: Palgrave Macmillan

Maxwell, J. (2013). Qualitative research design: An interactive approach (3rd ed., Applied social research methods series; v. 41). Thousand Oaks, Calif.: SAGE Publications. 
Mazmanian, D., \& Sabatier, Paul A. (1983). Implementation and public policy(Scott, Foresman public policy analysis and management series). Glenview, Ill.: Scott, Foresman.

Meier, K., \& Morgan, D. (1982). Citizen Compliance with Public Policy: The National Maximum Speed Law. Western Political Quarterly, 35(2), 258-273.

Merriam, S. (2002). Qualitative research in practice: Examples for discussion and analysis (1st ed., Jossey-Bass higher and adult education series). San Francisco: Jossey-Bass.

Minh Quang (May 5, 2018). Du an Thu Thiem da thu hoi duoc bao nhieu dat?

Viettimes.vn. Retrieved from https://viettimes.vn/du-an-kdt-moi-thu-thiem-dathu-hoi-duoc-bao-nhieu-dat-260145.html

Minh Quan (2018, October, 18). Nguoi dan Thu Thiem khong doi 4,3 ha ma doi 5 khu pho ngoai quy hoach. Laodong.vn. Retrieved from https://laodong.vn/xahoi/nguoi-dan-thu-thiem-khong-doi-43ha-ma-doi-5-khu-pho-nam-ngoai-ranhquy-hoach-636739.ldo

Minh Quan (2019, May 9). Cu tri chat van ba Nguyen Thi Quyet Tam lam duoc gi cho Thu Thiem. Laodong.vn. Retrieved from https://laodong.vn/thoi-su/cu-tri-chatvan-ba-nguyen-thi-quyet-tam-lam-duoc-gi-cho-dan-thu-thiem-731807.ldo

Minh Hai (2018, May 5). Dan Thu Thiem de nghi cho xem quy hoach 1/5.000. vtc.vn. Retrieved from https://vtc.vn/buc-xuc-ve-dat-dai-dan-thu-thiem-tap-trung-som$\underline{\text { tai-diem-tiep-xuc-cu-tri-cho-giai-dap-d397900.html }}$ 
Mintz, Alex (2005): Applied decision Analysis: Utilizing Poliheuristic Theory to Explaining and Predicting Foreign Policy and National Security Decisions. Special symposium papers in International Studies Perspectives. 6 (1): 94-150

Mintrom, M. (2012). Contemporary policy analysis. New York: Oxford University Press. MONRE - Ministry of Natural Resources and Environment (2014a). Circular No. 36/2014/TT-BTNMT about land valuation, creation and adjustment of land price. MONRE - Ministry of Natural Resources and Environment (2014b). Circular No. 37/2014/TT-BTNMT about compensation, support, and resettlement for land acquisition.

Morgan, D. (1993). Qualitative Content Analysis: A Guide to Paths not Taken. Qualitative Health Research, 3(1), 112-121.

Morgan, D and Shinn, C (2014). The foundations of public governance. In Morgan, D., \& Cook, Brian J. New public governance: A regime-centered perspective. Armonk, New York: M.E. Sharpe.

Morgan, D., Ingle, Marcus, \& Shinn, Craig W. (2018). New public leadership: Making a difference from where we sit. New York, NY: Routledge.

Mukherjee, I., \&Howlett, M. (2016). An Asian perspective on policy instruments: Policy styles, governance modes and critical capacity challenges. Asia Pacific Journal of Public Administration, 38(1), 24-42.

National Congress of the Socialist Republic of Vietnam (2013). Law on Land. Hanoi: Agriculture Publishing Hose.

NEU and UNDP (2017). A Sectorial Study of Transparency and Corruption in Land Acquisition. A Joint Policy Research Paper on Governance and Participation 
commissioned by Asia-Pacific Institute of Management (the National Economics University) and the United Nations Development Program (UNDP) in Viet Nam. Hanoi, Viet Nam.

Nghia Hoang (April, 18, 2017). Hanoi thong tin chi tiet ve vu viec o Dong Tam (My Duc). Retrieved from https://plo.vn/thoi-su/ha-noi-thong-tin-chi-tiet-ve-vu-viec-odong-tam-my-duc-696382.html

Ngoc Huyen (2017, April, 18). Thong tin chinh thuc toan canh dien bien vu viec o Dong Tam. Infornet.vn. Retrieved from https://infonet.vn/thong-tin-chinh-thuc-toancanh-dien-bien-vu-viec-tai-dong-tam-my-duc-post225659.info

Osborne, S. (2006). The New Public Governance? Public Management Review, 8(3), 377-387.

Osborne, S. (2010). The new public governance: Emerging perspectives on the theory and practice of public governance. London; New York: Routledge.

O'Toole, L. (2000). Research on Policy Implementation: Assessment and Prospects. Journal of Public Administration Research and Theory: JPART, 10(2), 263-288.

Ostrom, E; Cox, M; and Schlager, E (2014). An assessment of the institutional analysis and development framework and introduction of the social-ecological systemsin Sabatier, P., \&Weible, Christopher M. (2014). Theories of the policy process (3rd Ed.). Boulder, CO: Westview Press, a member of the Persus Books Group.

Palmer, D., Fricska, S., and Wehrmann, B (2009). Towards improved land governance. Land Tenure Working Paper, 11. Retrieved from https://unhabitat.org/wp- 
content/uploads/2014/06/TOWARDS-IMPROVED-LAND-GOVERNANCE-

\section{Land-and-Tenure-Working.pdf}

Pestoff, V., Brandsen, Taco, \& Verschuere, Bram. (2012). New public governance, the third sector and co-production (Routledge critical studies in public management; 7). New York: Routledge.

Pincus, R. J (2012). Vietnam's Reforms: the road to market Leninism. Legatum Institute Working Report. Retrieved fromhttps://lif.blob.core.windows.net/lif/docs/defaultsource/country-growth-reports/prosperity-in-depth-vietnam-39-s-reforms---the$\underline{\text { road-to-market-leninism.pdf?sfvrsn }=0}$

Phong, D (2009). Fence-breaking in economy prior to DoiMoi. Hanoi: The Knowledge Publishing House (in Vietnamese).

Pons-Vignon, N. and H. SolignacLecomte (2004). Land, violent conflict and development. OECD Development Centre Working Papers, No. 233, OECD Publishing, Paris.Retrieved from http://dx.doi.org/10.1787/717151268534

Pressman, J., Wildavsky, Aaron B (1973). Implementation: How great expectations in Washington are dashed in Oakland. Berkeley: University of California Press.

Quoc Phong (2017, Octorber 24). Khu do thi Thu Thiem dung dang 160 ha tai dinh cu. Tuoitre.vn. Retrieved from https://tuoitre.vn/khu-do-thi-thu-thiem-dung-dang160ha-tai-dinh-cu-20180507114713399.htm

Reale, A\&Handmer, J. (2011). Land tenure, disasters, and vulnerability. Disasters, 35(1), $160-82$

Rubin, H\& Rubin, I (2012). Qualitative interviewing:the art of hearing data (3rd Ed.). Thousand Oaks, Calif.: SAGE. 
Sabatier, P. (1986). Top-Down and Bottom-Up Approaches to Implementation Research: A Critical Analysis and Suggested Synthesis. Journal of Public Policy, 6(1), 2148.

Sandfort, J and Moulton, S. (2015). Effective implementation in practice: integrating public policy and management. San Francisco: Jossey-Bass.

Salamon, L., \& Elliott, Odus V. (2002). The tools of government: A guide to the new governance. Oxford; New York: Oxford University Press.

Salamon, L (1981). Rethinking public management: third-party government and the changing forms of government action. Public Policy: 29(3): 255-275

Salamon, L., \& Lund, Michael S. (1989). “The tools approach: basic analytics”. In Beyond privatization: The tools of government action. Washington, D.C: Lanham, MD: Urban Institute Press; Distributed in the United States and Canada by University Press of America.

Scott, W. Richard (2014). Institutions and Organizations: Ideas, Interests, and Identities. ( $4^{\text {th }}$ Ed.). Los Angeles: SAGE

Singleton, A.R and Straits, C.B (2010). Approaches to social research (5 ${ }^{\text {th }} \mathrm{ed}$.). New York and Oxford: Oxford University Press.

Simons, C.S (2008). The political economy of land conflict in the Eastern Brazilian Amazon. Annals of the Association of American Geographers, Vol. 94, No. 1: 183-206.

Simon, H. (1955) “A Behavioral Model of Rational Choice”. The Quarterly Journal of Economics: 69 (1): 99-118. 
Schneider, A., \& Ingram, H. (1990). Behavioral Assumptions of Policy Tools. The Journal of Politics, 52(2), 510-529.

Schneider, A., \& Ingram, Helen M. (1997). Policy design for democracy (Studies in government and public policy). Lawrence: University Press of Kansas.

Shafritz, J., Russell, E. W., \&Borick, Christopher P. (2007). Introducing public administration (8th ed.). New York: Pearson Longman.

Suu, N.V (2004). The Politics of Land: Inequality in Land Access and Local Conflicts in the Red River Delta since De-collectivization. In Taylor, P., \& Institute of Southeast Asian Studies. (Ed.). Social inequality in Vietnam and the challenges to reform (Vietnam update series). Singapore: Institute of Southeast Asian Studies.

Suu, N.V. (2009). Agricultural land conversion and its effects on farmers in contemporary Vietnam. European Journal of Anthropology, 54: 106-113.

Stake, R. (1995). The art of case study research. Thousand Oaks: Sage Publications.

Stone, D. (2012). Policy Paradox: The art of political decision making ( $3^{\text {rd }}$ Ed.). New York: W.W. Norton \& Company.

T\&C Consulting (2014). Public Land Disputes in Vietnam: a multi-Actor Analysis of Five Case Studies with an East Asian Comparative. Research Report. Retrieved from https://asiafoundation.org/publication/public-land-disputes-in-vietnam-a$\underline{\text { multi-actor-analysis-of-five-case-studies-with-an-east-asian-comparative-2/ }}$

TN News (2012, June 21). Official land prices far below real values, gov't says. Thanhniennews. Retrieved fromhttp://www.thanhniennews.com/business/officialland-prices-far-below-real-values-govt-says-6775.html 
The Economist (2017, June 15). No man’s land. The Economist. Retrieved fromhttps://www.economist.com/news/asia/21723423-communist-party-does-notknow-how-handle-them-property-disputes-are-vietnams-biggest.

Thanh Nhan (2018, July 16). Thu Thiem: nhieu ho dan da chuyen den noi o moi. Laodong.vn. Retrieved from https://laodong.vn/xa-hoi/sau-gan-1-thang-lanh-daotphcm-tiep-xuc-nguoi-dan-thu-thiem-nhieu-ho-dan-da-chuyen-den-noi-o-moi$\underline{618760.1 d o}$

Thien Ngon (2018, December 10). Ong Nguyen Thien Nhan: Gio la luc thuan loin hat giai quyet van de Thu Thiem. Viettimes.vn. Retrieved from https://viettimes.vn/ong-nguyen-thien-nhan-gio-la-luc-thuan-loi-nhat-giai-quyetvan-de-thu-thiem-310633.html

Thu Ha (2019, May 17). Bat cap thu hoi dat: bang gia dat thap hon thi truong. Vietnambiz.vn. Retrieved from https://vietnambiz.vn/bat-cap-thu-hoi-dat-banggia-dat-thap-hon-gia-thi-truong-20190517163718079rf54870.htm

Toan, L and Quang, N (2014). An historical overview of Vietnamese land law and dispute resolution. inFu, H., \& Gillespie, J. Resolving land disputes in East Asia: exploring the limits of law. Cambridge: Cambridge University Press

Tuyen, N.Q (2010): Land Law Reforms in Vietnam. Working Paper Series No. 015. Asian Law Institute. Retrieved from http://law.nus.edu.sg/asli/pdf/WPS015.pdf

Tuyen, Q.N; An, H.N; Huong, T.N; Binh, N.H; Thinh, T.N; Dung, T.B; Thuong, T.T; and Duong, T.P (2013). Conciliation of land disputes in Vietnam: a critical analysis of current law and practice with recommendations for reform. Research Report. Institute for Research on Policy, Law, and Development. Retrieved from 
$\underline{\text { https://asiafoundation.org/resources/pdfs/ConciliationofLandDisputesinVietnamPLD.pdf }}$

TriaKerkvliet, B. (2006). Agricultural Land in Vietnam: Markets Tempered by Family, Community and Socialist Practices. Journal of Agrarian Change, 6(3), 285-305.

Truong Minh (2019a, January, 2). Mot tuong lai cua hai the he bi bo lo. Viettimes.vn. Retrieved from https://viettimes.vn/thu-thiem-mot-tuong-lai-cua-hai-the-he-bi-bolo-312404.html.

Truong Minh (2019b, January 9). Vi dau nen noi doan truong Thu Thiem? Viettimes.vn. Retrieved from https://viettimes.vn/vi-dau-nen-noi-doan-truong-thu-thiem312908.html

Truong Minh (2019c, April 10). Ai da pha vo quy hoach khu do thi moi Thu Thiem? Viettimes.vn. Retrieved from https://viettimes.vn/ai-da-pha-vo-quy-hoach-khudo-thi-moi-thu-thiem-350228.html

Truong Minh (2019, April, 11). Nhung phan doi luu lac o Thu Thiem. Viettimes.vn. Retrieved from https://viettimes.vn/ky-cuoi-nhung-phan-doi-luu-lac-o-thu-thiem350229.html

TSG - Tu Son district government (2017). Annual report of land-taking policy implementation.

TSG - Tu Son People’s Committee website. Retrieved from http://tuson.bacninh.gov.vn/ieu-kien-tu-nhien-xa-hoi

Tyler, T. (2006). Psychological perspectives on legitimacy and legitimation. Annual Review of Psychology, 57, 375-400. 
Thy Hue (2018, May 2). Ban do quy hoach Thu Thiem that lac 20 nam van chua tim thay. Vtc.vn. Retrieved from https://vtc.vn/ban-do-goc-quy-hoach-khu-do-thimoi-thu-thiem-that-lac-hon-20-nam-van-chua-tim-thay-d396392.html

United Nations in Vietnam (2012). Revising the 2003 law on land in Vietnam: Creating equitable treatment for rural land use right holders. Policy Brief. Retrieved from: http://www.un.org/en/land-natural-resources conflict/pdfs/GN_Land\%20and\%20Conflict.pdf

UNDP in Vietnam (2014). Land-taking disputes in East Asia: acomparative analysis and implications for Vietnam. Research Report. Retrieved from:

http://www.vn.undp.org/content/vietnam/en/home/library/democratic_governance/land_t aking_disputes_in_east_asia.html

Van Meter, S.D. and Van Horn, E.C (1975). The policy implementation process: a theoretical framework. Administration \& Society. Vol. 6, Issue 4: 445-488.

Van, T.T (2006). Urban expansion and loss of agricultural land in the North of Ho Chi Minh city: a GIS and remote sensing approach. Ho Chi Minh city: Vietnam National University.

Viettel (2019). https://vietteltelecom.vn/

Vietnamnet (2018, May 4). Chinh quyen noi that lac, dan buc xuc cong bo ban do goc Thu Thiem. Retrieved fromhttps://vietnamnet.vn/vn/thoi-su/chinh-quyen-noi-thatlac-dan-buc-xuc-cong-bo-ban-do-goc-thu-thiem-449157.html\#inner-article

Vietnamnet (2019, May 8). Thieu minh bach la ke ho lon de quan an dat. Vietnamnet.vn. Retrieved from https://vietnamnet.vn/vn/goc-nhin-thang/xu-ly-quan-chuc-thamnhung-tu-dat-dai-529540.html 
Vnexpress (2018, May 3). Ban do quy hoach Thu Thiem that lac da duoc thay the moi. Vnexpress.net. Retrieved from https://vietnamnet.vn/vn/thoi-su/chinh-tri/ban-doquy-hoach-thu-thiem-that-lac-da-duoc-thay-the-moi-446976.html\#inner-article Vtc (2018, June 5). Nguyen chu tich TP. HCM: khong co ban do 1/5.000 Thu Thiem. Vtc.vn. Retrieved from https://vtc.vn/nguyen-chu-tich-tphcm-khong-co-ban-do-15000-thu-thiem-d397227.html

Vo, D. H (2011, September 30). Story of land price in Vietnam. English Vietnamnet.vn. Retrieved fromhttp://english.vietnamnet.vn/en/special-report/13610/story-of-landprice-in-vietnam.html

Vo Hai (2019, April 25). Thanh tra chinh phu: ket luan cua Hanoi ve dat dai o Dong Tam la chinh xac. Retrieved from https://vnexpress.net/thoi-su/thanh-tra-chinh-phuket-luan-cua-ha-noi-ve-dat-dai-o-dong-tam-la-chinh-xac-3914633.html

Vaismoradi, M., Turunen, H., \&Bondas, T. (2013). Content analysis and thematic analysis: implications for conducting a qualitative descriptive study. Nursing \& Health Sciences, 15(3), 398-405.

Weaver, K. (1989). Setting and Firing Policy Triggers. Journal of Public Policy, 9(3), 307-336.

Wehrmann, B (2008). Land conflict: a practical guide to dealing with land disputes. Eschborn, Germany: Deutsche Gesellschaff fur TechnischeZusammenarbeit (GTZ) GmbH.

Wells-Dang, A (2013). Promoting land rights in Vietnam: amulti-sector advocacy coalition approach. Paper presented at the "Annual World Bank Conference on land and Poverty. Washington DC. 
Retrieved fromhttps://landportal.info/library/resources/promoting-land-rightsvietnam-multi-sector-advocacy-coalition-approach

Weiss, J.A (2002). “Public information”. In Salamon, L., \& Elliott, Odus V. (2002). The tools of government: A guide to the new governance. Oxford; New York: Oxford University Press.

Wiegersma, N. (1988). Vietnam-peasant land, peasant revolution: Patriarchy and collectivity in the rural economy. New York: St. Martin's Press.

Winter, Soren C., \& May, Peter J. (2001). Motivation for compliance with environmental regulations. Journal of Policy Analysis \& Management, 20(4), 675-698.

Williamson, O. (1979). Transaction-Cost Economics: The Governance of Contractual Relations. The Journal of Law and Economics, 22(2), 233-261.

World Bank (2006). Urban development strategy: meeting the challenges of rapid urbanization and the transition to a market-oriented economy. Hanoi: World Bank in Vietnam.

World Bank (2009). Improving Land Acquisition and Voluntary Land Conversion in Vietnam.Policy Note. Retrieved from https://openknowledge.worldbank.org/handle/10986/18611

World Bank (2011a). Compulsory land acquisition and voluntary land conversion in Viet Nam: the conceptual approach, land valuation and grievance redress mechanisms. Policy Note. Retrieved from https://openknowledge.worldbank.org/handle/10986/26886

World Bank (2011b). Improving land governance: the land governance assessment frameworks. Research Report. 
Retrieved fromhttps://openknowledge.worldbank.org/handle/10986/2376

World Bank (2012). Revising the land law to enable sustainable development in

Vietnam: summary of priority policy recommendations drawn from World Bank studies. Policy Note.

Retrieved fromhttps://openknowledge.worldbank.org/handle/10986/26777

World Bank and GIV (2012). Corruption from perspectives of citizens, firms, and public officials. Hanoi: National Publishing House.

World Bank(2014). Land transparency study:synthesis report. Hanoi: Hong Duc

Publishing House. Retrieved

fromhttps://openknowledge.worldbank.org/handle/10986/20714

World Bank and the Ministry of Planning and Investment of Vietnam (2016). Vietnam 2035:toward prosperity, creativity, equity, and democracy. Research

Report.Retrieved fromhttps://openknowledge.worldbank.org/handle/10986/23724

Yin, R. (2014). Case study research: design and methods (5th ed.). Los Angeles: SAGE.

Zing (2018a, May 6). Dong tien lam bien dang quy hoach Thu Thiem. Zing.vn. Retrieved from https://news.zing.vn/nguyen-chu-tich-tp-hcm-dong-tien-lam-bien-dang-quyhoach-thu-thiem-post840318.html

Zing (2018b, May 9). Nuoc mat Thu Thiem. Zing.vn. Retrieved from https://news.zing.vn/nuoc-mat-thu-thiem-sau-20-nam-quy-hoach-do-thi-moipost841311.html

Zing (2018c, September 21). UBND thanh pho xin loi nhan dan vi sai pham o Thu Thiem. Zing.vn. Retrieved from https://news.zing.vn/ubnd-tp-hcm-xin-loi-nhandan-vi-sai-pham-o-thu-thiem-post878524.html 


\section{Appendix A: Interview Guides}

\section{Part I: Introduction}

- Researcher’s name, background, and research purposes.

- Explain the informed consent to the participants, ask them to sign the form, and ask for a permission to record an interview.

\section{Part II: Background of Informant}

- Name, Position, and Working Experience

Part III: Land-Taking Policy Implementation

- Please tell me an overview of land-taking policy implementation in your district in recent years? Can you describe typical procedures and process to implement a land-taking project?

- Is district government flexible in implementing land-taking programs or must follow fixed procedures and rules issued by central and provincial governments?

- Please share with me the role of government agencies involving in land-taking implementation? How do they collaborate with non-state actors to carry out landtaking programs?

- What are roles of non-state actors (investors) and target group (land -users) in the policy implementation process?

- Can you tell me in detail the structure and operation of district BCGC? How it works? What are strengths? Weaknesses? 
- How does district government communicate with stakeholders during land-taking implementation process? Can you tell me ways of communicating with landholders? How effective? Which one is more effective?

- By what ways do land users voice their demands? How does district government respond to land users' demands? Do land users' voice play a role in district government's final decisions on land-takings?

- How does the government conduct land price calculations and compensation for appropriated land?

- What kind of economic incentives offered by district government to encourage land users' compliance with government's land-taking decisions? How effective?

- In your opinion, what are problems of current land-taking policy implementation? Considering Vietnam's context, how can we improve those procedures for more effective policy implementation?

- Why affected land users disagree with local governments' land-taking decisions? Is it simply because of economic losses? Or what else explains land-users' noncompliance with local governments’ decisions? 


\section{Appendix B: Questions guiding}

\section{Analysis of Documents and Transcripts, Coding, and Theme Development}

-What are mechanisms and tools available for land-taking policy implementers?

Direct or indirect mechanisms?

- Implementers' tool preferences: direct or indirect government, economic incentives, coercive authority, or persuasion and capacity building? Variations?

-What political, economic, institutional, and socio-cultural factors affect policy implementers' tool choice and use?

- Do non-state actors such as investors and land users play any role when government officials select implementation tools? If not, why?

- In response to land users' noncompliance, do implementers change their choice and use of tools? How do they make changes? Similarities and variations?

- How effective are those tool changes? If they do not change tool choice and use, why? Similarities and variations across three incidents?

- Factors affecting tool-based responses? Similarities and Variations?

- Patterns of tool-based responses to noncompliance? Similarities and variations?

-Linkages between tools and policy compliance? How? 


\section{Appendix C: 2013 Law on Land - Selected Articles}

\section{Article 61: Land acquisition for security and defense purposes}

The State has authority to acquire land for security and defense purposes in following situations:

1. To construct military stations and office buildings

2. To construct military bases

3. To construct special units for national security and defense

4. To construct military ports and transportation stations

5. To construct industrial bases, science-technology-recreation units serving defense purposes.

6. To construct logistics units for defense

7. To construct shooting practice and weapon testing fields

8. To construct training units, hospitals, and health recovery units

9. To construct public accommodations for defense force

10. To construct correctional centers and jails/prisons managed by Ministry of Defense and Ministry of Police.

\section{Article 62: Land acquisition for economic development and public purposes}

The State has authority to acquire land for economic development and public purposes in following situations:

1. To implement important projects approved by the National Congress

2. To implement development projects approved by the premier, including:

a. Industrial zones, manufacturing and exporting zones, high-tech parks, economic zones, new urban areas, investment projects funded by ODA sources. 
b. State's office buildings, foreign organizations' office buildings, historical and cultural sites, public parks and squares, monuments, memorial sites.

c. Infrastructures at national level such as road, bridges, fuel transportation system, national reservation sites, and public constructions at national level.

3. Development projects approved by provincial people’s councils, including:

a. State's office buildings, historical and cultural sites, public parks and squares, monuments, memorial sites.

b. Public infrastructures at provincial level such as road, bridges, historical and cultural sites, memorial sites, monuments.

c. Public accommodations, new resettlement areas, sport and recreational sites, religion units, markets...

d. New urban areas, new resident units in rural areas, industrial units, manufacturing and exporting units, forest development projects.

e. Natural resource exploiting projects such as coal, sand...

\section{Article 66: Authority to acquire land}

1. Provincial people's committees have authority to acquire land in following situations:

a. Acquire land used by public organizations, religion organizations, Vietnamese people living oversea, foreign organizations with diplomatic functions, business organizations invested by foreign sources.

b. Agricultural land managed by ward/communes’ public land funds.

2. District people's committees have authority to acquire land in following situations

a. Acquire land used by households, individuals, and community units 
b. Acquire land used by Vietnamese people living oversea

3. If the acquired land area includes both users as stated in (1) and (2), provincial people’s committees can acquire land or authorize district people’s committees to acquire land.

\section{Article 67: Land acquisition announcement and compliance with land acquisition plan}

1. Public authorities have to inform affected landholders 90 days before acquiring agricultural land and 180 days before acquiring non-agricultural land.

2. If landholders agree to give up their land earlier than the required time, people's committees can acquire land earlier than deadlines as stated above.

3. Affected landholders have responsibility to cooperate with agencies responsible for land acquisition to execute land-taking plan.

4. Once land-taking decisions are effective, compensation and resettlement proposals are approved by State's agencies, affected landholders are required to comply with land-taking plans.

\section{Article 71. Compulsory land acquisition by force (selected important rules)}

1. Compulsory land acquisition by force is implemented in accordance with Article 70 of this Law.

2. Compulsory land acquisition by force is implemented in following situations:

a. Despite propaganda and communication efforts, affected landholders do not comply with land-taking executive orders.

b. Executive orders approving land acquisition by force are publicly displayed at communes’ offices and public places in residential units. 
c. Executive orders approving land acquisition by force are effective.

d. Affected landholders are received executive orders approving land acquisition by force.

If affected landholders do not accept executive orders approving land acquisition by force, commune/ward people's committees document their noncompliance.

3. Mayor of district people's committees issue executive orders approving coercive land acquisition and enforce land-takings by force.

4. Procedures and steps to acquire land by force:

a. Mayor of district people's committees establish Unit of coercive land acquisition before enforcing land-takings by force.

b. Unit of coercive land acquisition communicates with landholders to convince them giving up their land. If landholders accept land-taking plan and compensation, unit of coercive land acquisition documents landholders' compliance. Landholders have 30 days to return their land to government.

If landholders do not accept executive orders of coercive land acquisition, the unit of coercive land acquisition enforces executive orders by force.

c. Units of coercive land acquisition have authority to forcefully remove people and assets out of the acquired land areas. If affected landholders do not receive their assets, units of coercive land acquisition document and protect their assets as required by law. 